\title{
Efficacy of manual therapy and physiotherapy for back and neck complaints
}

Citation for published version (APA):

Koes, B. W. (1992). Efficacy of manual therapy and physiotherapy for back and neck complaints.

[Doctoral Thesis, Maastricht University]. Rijksuniversiteit Limburg.

https://doi.org/10.26481/dis.19920327bk

Document status and date:

Published: 01/01/1992

DOI:

10.26481/dis.19920327bk

Document Version:

Publisher's PDF, also known as Version of record

\section{Please check the document version of this publication:}

- A submitted manuscript is the version of the article upon submission and before peer-review. There can be important differences between the submitted version and the official published version of record.

People interested in the research are advised to contact the author for the final version of the publication, or visit the DOI to the publisher's website.

- The final author version and the galley proof are versions of the publication after peer review.

- The final published version features the final layout of the paper including the volume, issue and page numbers.

Link to publication

\footnotetext{
General rights rights.

- You may freely distribute the URL identifying the publication in the public portal. please follow below link for the End User Agreement:

www.umlib.nl/taverne-license

Take down policy

If you believe that this document breaches copyright please contact us at:

repository@maastrichtuniversity.nl

providing details and we will investigate your claim.
}

Copyright and moral rights for the publications made accessible in the public portal are retained by the authors and/or other copyright owners and it is a condition of accessing publications that users recognise and abide by the legal requirements associated with these

- Users may download and print one copy of any publication from the public portal for the purpose of private study or research.

- You may not further distribute the material or use it for any profit-making activity or commercial gain

If the publication is distributed under the terms of Article $25 \mathrm{fa}$ of the Dutch Copyright Act, indicated by the "Taverne" license above, 


\section{EFFICACY OF MANUAL THERAPY AND PHYSIOTHERAPY FOR BACK AND NECK COMPLAINTS}




\title{
EFFICACY OF MANUAL THERAPY AND PHYSIOTHERAPY FOR BACK AND NECK COMPLAINTS
}

\section{PROEFSCHRIFT}

\author{
ter verkrijging wan de graad van doctor \\ aan de Rijksuniversiteit Limburg te Maastricht, \\ op gezag van de Rector Magnificus, Prof. Mr. M.J. Cohen, \\ volgens het besluit van het College van Decanen, \\ in het openbaar te verdedigen \\ op vrijdag, 27 maant 1992 \\ om 14.00 uur
}

door

\section{Bart Willem Koes}

geboren te 's-Gravenhage in 1962 
$\begin{array}{ll}\text { Co-promotores: } & \text { Dr. L.M. Bouter } \\ & \text { Dr. H. van Mamen }\end{array}$

Beoordelingscommissie:

Prof. Dr. J. Drukker, RL (voorzitter)

Prof. Dr. J.A. Knottnerus, RL

Prof. Dr. J.M.J.P. van der Linden, RL

Dr. J. Lodder, RL

Prof. Dr. R.A.B. Oostendorp, VU Brussel

CIP-GEGEVENS KONINKLUKE BIBLIOTHEEK, DEN HAAG

Koes, Bart Willem

Efficacy of manual therapy and physiotherapy for back and neck complaints / Bart Willem Koes. - Masustrichi :

Rijksuniversiteit Limburg, Vakgroep Epidemiologie en Biostatistiek. III.

Proefschrift Maastricht. - Met lit opg. - Met samenvalting in luet Nederlands.

ISBN 90174130-04-6

NUGT 751

Trefw.: manuele therapie / fysiotherapie.

Lay-out: Thum Aarts, Vakgroep Epidemiologie en Biostatistiek, RL

Omslagontwerp: Hans Rensema, Vakgroep Anatomie en Embryologie, RL Druk: Datawyse Maastricht/Krips Repro Meppel

Het onderzoek dat de gronslag vormt van dit proefschrift, werd verricht met financiële ondersteuning van het Ministerie van Welzijn, Volksgezondheid en Cultuur, en van de Ziekenfondsraad.

De uitgave van dit proefschrift werd mede mogelijk gemaakt door de financiële steun van: De Nederlandse Vereniging voor Manuele Therapie en de Stichting Het Scholten-Cordes Fonds. 
Chapter 2: Spinal manipulation and mobilization for back and neck pain:

a blinded review.

Chapter 3: Physiotherapy exercises and back pain: a blinded review.

Chapter 4: The effectiveness of manual therapy, physiotherapy and continued treatment by the general practitioner for chronic non-specific back and neck complaints: design of a randomized clinical trial.

Chapter 5: The effectiveness of manual therapy, physiotherapy and continued treatment by the general practitioner for chronic non-specific back and neck complaints: a randomized clinical trial.

Chapter 6: A blinded randomized clinical trial of manual therapy and physiotherapy for chronic back and neck complaints: physical outcome measures.

Chapter 7: Randomised clinical trial of manual therapy and physiotherapy for persistent back and neck complaints: results of one year follow-up.

Chapter 8: A randomised clinical trial of manual therapy and physiotherapy for persistent back and neck complaints: subgroup analysis and relationship between outcome measures.

Chapter 9: General discussion.

Summary

Samenvatting

Dankwoord 


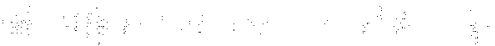

4 
efficacy of manipulation and mobilization. However, the inefficacy of manipulation and mobilization has not been demonstrated either and some studies have already shown promising results.

Physiotherapy is widely used in the treatment of back and neck pain. ${ }^{21-23}$ The treatment often includes exercises, massage, heat and other therapeutic modalities, given alone or in combination with each other. In chapter 3 we summarize and critically assess the available randomized clinical trials of physiotherapy exercises for back pain. We were also interested in the efficacy of physiotherapy exercises for neck pain, but we could find only one relevant trial which met our inclusion criteria. Presently, there are at least 16 randomized trials on physiotherapy exercises for back pain. Most trials appear to be of poor methodological quality. As yet, no conclusion can be drawn whether exercise therapy is better than other conservative treatments.

Because the scientific evidence for treatment with manual therapy and physiotherapy for back and neck complaints turned out to be inconclusive and incomplete, we decided to conduct a new randomized clinical trial in the Netherlands. The trial has been designed in cooperation with the Royal Dutch Society for Physiotherapy and the Dutch Society for Manual Therapy. The research project was funded by the Dutch Ministry of Welfare, Health and Cultural Affairs and the Dutch National Health Insurance Council. The research question has primarily been focused on the efficacy of manual therapy and physiotherapy for persistent back and neck pain in the Netherlands. The complaints were considered to be persistent if the duration of the current episode was 6 weeks or longer.

In chapter 4 the design of this trial is described in detail. A total of 256 patients with back and neck complaints entered the trial and were randomly assigned to (1) manual therapy, (2) physiotherapy, (3) treatment by the general practitioner, and (4) placebo therapy (i.e. detuned shortwave diathermy and detuned ultrasound). The outcome measures are in order of importance: the severity of the complaints, global perceived effect, pain, and functional status, physical functioning and spinal range of motion. The outcome measures were placed in this hierarchical order before the results were available. Measurements are taken at baseline and after 3, 6, and 12 weeks, and 6 and 12 months after randomization.

Chapter 5 describes and discusses the prognostic comparability of the 4 study groups at baseline and the results of main outcome measures after 3,6 , and 12 weeks follow-up. The main outcome measures are operationalized as follows. (1) Severity of the complaint was rated by a blinded research assistant on a 10-point scale. Patients presented at baseline their most important complaint. The rating of the severity of this complaint is based on history taking and physical examination. (2) Global perceived effect was rated on a 6-point scale. (3) Severity of the pain was rated on a 7-point scale (measured with the sub-scale 'pain severity' of the West Haven Yale Multidimensional Pain Inventory). (4) Functional status was rated on a 100-point scale (measured with the Sickness Impact Profile). The latter three outcome measures were rated by the
patients themselves. 


\section{Chapter 1}

\section{INTRODUCTION}

The central topic of this dissertation is the efficacy of manual therapy and physiotherapy for back and neck pain. Back and neck pain occur frequently.

Epidemiological studies indicate that about $80 \%$ of the population experience back pain during their active lives. ${ }^{12}$ Back and neck complaints account for using a large amount of health care resources, major losses due to sick leave, and reduced work

productivity. ${ }^{3-6}$ In the Netherlands, exact figures for the costs of backache are unknown. The total annual costs of backache in the United Kingdom is nearly 1 billion pounds. ${ }^{7}$ In the United States of America low back pain costs at least 16 billion dollars each year. ${ }^{8}$ There are also no exact figures on the total amount of money spent on physiotherapy and manual therapy for the treatment of back and neck complaints in the Netherlands. In 1989, howewer, the total costs for physiotherapy were about 1 billion guilders, while about $50 \%$ of the patients at issue were suffering from back or neck complaints. ${ }^{9}$ In most cases the complaints are self-limiting and in about $90 \%$ of the patients the complaints disappear within 6 weeks. ${ }^{2381112}$ After an episode of low back pain, $60 \%$ of the patients experience recurrent symptoms within a year, indicating a relatively high recurrence rate. ${ }^{8}$ In most cases no underlying pathology can be established and thus the causes of the complaints remain unknown. These complaints are usually labelled as non-specific. ${ }^{813}$ Possibly as a consequence of this situation, there are many therapeutic interventions available for patients with back and neck complaints, but none seems to be clearly superior to the others. ${ }^{38}$ Most patients with acute conditions stay untreated or are treated by means of a few days of (bed)rest, analgesics, or home exercises as long as the duration of the complaints is less than 6 weeks. ${ }^{2} 814$

In about $10 \%$ of the patients the complaints still persist after 6 weeks. The Dutch general practitioner often refers these patients for physiotherapy or, less frequently, for manual therapy ${ }^{15}$ The effectiveness of these referrals has not been sufficiently investigated. ${ }^{3} 1116$ In the Netherlands physiotherapy consists of exercises, massage and physical therapy modalities (e.g. electro therapy, shortwave diathermy, ultrasound therapy) given as a single treatment or in combination with each other. Manual therapy may be defined as the application of passive movements to the joints in order to restore the function of the spine. ${ }^{7}$ In the Netherlands manual therapy is applied by physiotherapists who have received further education consisting of a course (duration of 3 or 4 years) in manual therapy.

Within the field of manual therapy there appear to be many different manipulative techniques which can be applied to the spine. ${ }^{18-20}$ The similarities and differences among the available techniques are far from clear.

In chapter 2 we summarize and critically assess the available randomized clinical trials of manipulation and mobilization for back and neck pain. Manipulation involves a high velocity thrust to a joint beyond its restricted range of movement. Mobilization involves low velocity passive movements within or at the limit of joint range. ${ }^{19}$ Presently, there are at least 35 randomized trials on this topic. Unfortunately, many studies show serious methodological flaws which makes it difficult to draw a final conclusion about the 
Chapter 2

SPINAL MANIPULATION AND MOBILIZATION FOR BACK AND NECK PAIN

a blinded review*

BW Koes, WJJ Assendelft, GJMG van der Heijden, LM Bouter, PG Knipschild 
Chapter 6 deals with the results of the physical outcome measures (physical functioning and spinal mobility) after 3, 6, and 12 weeks follow-up. Spinal mobility is generally considered to be an objective outcome measure for evaluating progress in patients with back pain. ${ }^{24-26}$ Physical functioning, which we define as the ability to perform active and passive movements, has also been measured as a relatively objective outcone parameter. Both have been measured in our trial by the same blinded research assistant.

In chapter 7 we present the results after 6 and 12 months follow-up in our trial. The short term results (up to 12 weeks follow-up) presented in chapter 5 and 6 are of importance in order to detect the short term recovery rates in each groups. However, we are also interested in the results after a longer follow-up period. The reviews of the literature (chapter 2 and 3) show that long term effects (12 months follow-up) have been measured in only 7 trials of manipulation and in only 2 trials of physiotherapy exercises. Long term positive effects of manipulation were reported in only one of these 7 studies. ${ }^{27}$ Long term positive effects of physiotherapy exercises were reported in only one study. 28

Chapter 8 presents the results of the explorative subgroup analysis. With the use of the inclusion and exclusion criteria for patients to participate in this trial, we have tried to select a relatively homogeneous study population. However, within this study population the effects in certain subgroups have been studied separately. The purpose of this analysis is to formulate hypotheses of treatment effects in certain subgroups which should be further investigated in future trials. In this chapter we also present the strengths of the associations between the outcome measures severity of the main complaint, global perceived effect, and physical functioning.

Chapter 9 consists of a general discussion of the research described in this dissertation This chapter starts by drawing attention to the interpretation of the results of the reviews. Furthermore, certain issues of the design and results of our trial are discussed. Special attention will be paid to the study population, the interventions, the effect measurement, and data analysis. We present some practical problems that arose when conducting the trial. Finally, the possibilities for generalization of our findings and implications for the treatment of patients with back and neck complaints are considered.

Due to the fact that this dissertation consists of seven articles, the content of some chapters will also be (partly) described in other chapters. This is mainly the case in the chapters dealing with the results of the trial in which the design of the trial is repeated every time. An advantage of this approach is that the individual chapters can be read separately. 


\section{References}

1. Keisy IL, White AA. Epidemiology and impact of low back pain. Spine 1980; 5: 133-142.

2. Waddel $\mathrm{C}$. A new clinical model for the treatment of low-back pain. Spine 1987; 12: 632-644.

3. Spitzer WO, Leblanc IE, Dupuis M. (EDS) Scientific approach to the assessment and management of activity-related spinal disorders. Spine 1987; 7 (suppl): $1-59$.

4. Irymoyer $\mathrm{JW}$, Pope MH, Clements JH, Wilder DO, Macpherson B, Ashikaga $T$. Risk factors in low-back pain. I Bone Joint Surg 1983; 65-a: 213-218.

5. Deyo RA, Tsur WU YJ. Descriptive epidemology of low-back pain and its related medical care in the Unites States: Spine 1987, 12: 264.268.

6. Wood PHN, Badley EM. Epidemiology of back pain. in: Jayson MIV (ed). The lumbar spine and back pain. Tunbridge Well, Kent, 1980.

7. Waddell G. An approach to backache. Br J Hosp Med 1982; sept: 187-219.

8. Frymoyer JW. Back pain and sciatica. $N$ Engl $J$ Med 1988; 318: 291-300.

9. Ministerie van Welzifn, Volksgezondheld en Culltuur. Financieel Overzicht Zorg 1991. Tweede Kamer, vergaderjarar 1990-1991, 21812, nrs 1-2. "s Gravenhage: SDU uitgeverij, 1991.

10. Kerssens JJ, Curfs ECHR, Groenewegen PP. Fysiotherapie in de Nederlandse gezondheidszorg: kachten van patienten, indicatiestelling van (huis)artsen en tysiotherapeutische behandelingen. Utrecht: Nivel, 1987.

11. Deyo RA. Conservative care for $l$ low back pain. JAMA 1983; 250: 1057-62.

12. White AA, Gordon SL. Synopsis: workshop on idiopathic low-back pain. Spine 1982; 7: 141-149.

13. Nachemson A. Towards a better understanding of low back pain. Rheum Reh 1975; 14: 129-143.

14. Hoekstra GR. Patienten met lage rugklachten in een huisartspraktijk, Stafleu, Alphen aan den Rijn, 1983.

15. Grundrieijer HGLM, Brouwer HJ. De betekenis wan fysiotherapie bij aandoeningen van het bewegingsapparaat. Huisarts Wet 1988; 31 (suppl 12): 44-59.

16. Di Fabio RP. Clinical assessment of manipulation and mobilization of the lumbar spine: a critical review of the literature. Phys Ther 1986; 66: $51-54$.

17. Haldenan S. Spinal manipulative therapy in sports medicine. Clinics in Sports Medicine 1986; 5: $277-293$.

18. Grayson MF. Manipulation in back disorders. Br Med J 1986; 293; 1481-1482.

19. Ottenbacher K, Di Fabio RP. Efficacy of spinal manipulation/mobilization therapy: a meta-analysis. Spine 1985; 10:833-837.

20. Greenland $S$, Reisbord $L S$, Haldeman $S$, Buerger $A A$. Controlled clinical trials of manipulation: a review and a proposal. J Occup Med 1980; 22: 670-676.

21. Lidström A, Zachrisson M. Physical therapy on low back pain and sciatica. Scand J Rehab Med 1970; 2: $37-42$.

22. Zylbergold RS, Piper MC. Lumbar dise disease: comparative analysis of physical therapy treatments. Arch Phys Med Rehab 1981; 62: 176 m179.

23. Martin PIR, Rose MJ, Nichols PJR, Russell PL., Hughes JG. Physiolherapy exercises for low back pain: process and clinical outcome. Int Rehabil Med $1980 ; 8 ; 34-38$.

24. Bergquist-Lliman $M$, Latsson $U$. Acute low back pain in industry: controlled prospective study with special reference to therapy and confounding factors. Acta Orthop Scand 1977; 170 (suppl): 11 . 117.

25. Postachini $F$, Facchini $M$, Palieri P. Efficacy of warious forms of conserwative treatment in low back pain: a comparative study. Neuro-Orthopedies 1988; 6:28-35.

26. Wagen CN, Haldeman S, Cook G, Lopez D, DeBoer KF. Shott term trial of chiropractic adjustments for the relief of chronic low back pain. Manual Med 1986; 2:63-67.

27. Meade "TW, Dyer S, Browne W, Townsend J, Frank AO. Low back pain of mechanical origin: randonised comparison of chiropractic and hospital outpatient treatment. $\mathrm{Br} \mathrm{Med} J \mathrm{~J}$ 199; 300 : 1431.1437 .

28. Stankovic $R$, Johnell $O$. Conservative treatment of acute low back pain: a prospective randomized trial. Spine 1990; 15: 120-123. 


\section{Abstract}

Objective - to assess the efficacy of spinal manipulation and/or mobilization for patients with back pain or neck pain.

Design - Computer aided search for published papers and blinded assessment of the methods of the studies.

Subjects - 35 randomized clinical trials comparing spinal manipulation with other treatments:

Main outcome measures- Score for quality of methods (based on four main categories; study population, interventions, measurement of effect, and data presentation and analysis) and main conclusion of author(s) with regard to spinal manipulation. Results - Not a single trial scored 60 or more points (maximum score was set at 100 points) indicating that most were of poor quality. Eighteen studies (51\%) showed favorable results for manipulation. In addition, 5 studies $(14 \%)$ reported positive results in one or more subgroups only. Among the 4 studies with 50-60 points, 1 was positive, 1 was negative, and 2 were positive only in a subgroup of the study population. Eight trials attempted to compare manipulation with some placebo therapy, with inconsistent results.

Conclusions - Although some results are promising, so far the efficacy of manipulation has not been convincingly demonstrated. Further trials are needed, but much more attention should be paid to the methods of study. 


\section{Introduction}

The frequent occurrence of back pain is well known. About $80 \%$ of the people in western countries will experience back pain at some time during their lives.

Fortunately, the disease is usually self-limiting. The majority of patients $(90 \%)$ recover from an attack of back pain within 6 weeks, irrespective of the type of treatment given, although the recurrence rate is high. ${ }^{23}$ Despite its frequent occurrence; the management of back pain remains controversial. There is a wide variety of therapeutic possibilities but no single treatment modality seems to be superior to others. ${ }^{4}$ Spinal manipulation or mobilization are widely used for the treatment of back pain and its efficacy has frequently been studied in randomized clinical trials (RCTs). ${ }^{5}$ The similarities and differences between the several manipulative techniques available are not always clear. However, there seems to be agreement that manipulation involves a high velocity thrust to a joint beyond its restricted range of movement. Mobilization involves low velocity passive movements within or at the limit of joint range. ${ }^{6}$ Throughout this article we will use the word manipulation to cover both manipulation itself and mobilization.

The rationale given for manipulation in the management of back and neck pain ranges from reduction of a bulging disk, correction of the internal displacement of disc fragments, freeing of adhesions around a prolapsed disk or facet joints, to inhibition of transmission of nociceptive impulses. ${ }^{78}$ Whether the manipulation is effective on a clinical level can only be evaluated in RCTs. However, the outcome of a RCT may be biased by flaws in the methodological quality of the study. In this article we present a critical review of the available RCTs about the efficacy of spinal manipulation for back and neck pain. Strong emphasis will be put on the methodological quality of the studies included.

\section{Methods}

\section{Selection of studies}

A MEDLINE literature search was carried out for the period 1966-1990 (keywords: backache, musculoskeletal diseases, joint diseases, manipulation, osteopathy, chiropractic, evaluation studies, outcome and process assessment). In addition, the references given in relevant publications were further examined. Albstracts and unpublished studies were not selected. Studies had to meet the following criteria:

1 - The (experimental) treatment regimen included manipulation or mobilization of the spine. Additional interventions were allowed.

2 - The study subjects suffered from back or neck pain.

3 - It concerned a randomised clinical trial.

\section{Assessment of validity}

All trials were scored according to the criteria listed in table 1.

The criteria are based on generally accepted principles of intervention research. 910 The criteria have been developed by Ter Riet et al. ${ }^{11}$ and have been modified for the present purpose. To each criterium a weight is attached. The maximum score was set at 100 points for each study. All publications were blinded for author(s), journal and outcome by one of the reviewers (BK). Subsequently the methodological quality of the studies was assessed by two blinded reviewers (WA, GH) independently. In a 
subsequent meeting they (still blinded) tried to reach consensus on each criterium they disagreed about.

Table 1. Criteria list for the methodological assessment of randomized clinical trials of manipulation for back and neck pain (for details, see appendix).

Study population (30):

$\begin{array}{lr}\text { A Homogeneity } & 2 \\ \text { B Comparability of relevant baseline characteristics } & 5 \\ \text { C Rardomization procedure adequate } & 4 \\ \text { D Drop-outs described for each study group separately } & 3 \\ \text { E }<20 \% \text { loss to follow-up } & 2 \\ <10 \% \text { loss to lollow-up } & 2 \\ \text { F }>50 \text { subjects in the smallest group } & 6 \\ >100 \text { subjects in the smallest group } & 6\end{array}$

Interventions (30):

$\mathrm{G}$ Interventions included in protocol and described 10

H Pragmatic study 5

I Co-interventions avoided 5

I Placebo controlled 5

K Mentioning good qualification of manipulative therapist 5

Effect (30):

L. Patients blinded 5

M Outcome measures relevant 10

N Elinded outcome assessments 10

O Follow-up period adequate

Data presentation and analysis (10):

$P$ Intention-to-treat analysis 5

Q Firequencies of most important outcomes presented for each treatment group 5

a Further details given in Appendix

Where disagreement persisted, a third blinded reviewer (LB) made the decision. The assessments resulted in a hierarchical list in which higher scores indicate studies with a better methodology. The outcome of the studies will be discussed in relation to their methodological scores.

\section{Outcome of the studies}

A study was determined positive if the authors concluded (in their abstract and/or conclusions) that manipulation was more effective than the reference treatment. Sometimes the authors reported favorable outcomes for manipulation only in a subgroup of the study population. In a negative study the authors reported no differences between the study treatments, or even better results in favor of the reference treatment. Short term outcome refers to effect measurements during or just 
after the intervention period. Long term outcome refers to outcome measurements at least three months after randomization.

\section{Results}

A total of 38 trials met the inclusion criteria. However, three of thein turned out to be double publications of which the ones with the lowest methodological score were excluded. $^{71213}$ The remaining 35 trials are presented in table 2 in a hierarchical order according to their methodological score. In 30 trials back pain patients were included, while 5 trials included neck pain patients. Initially the two blinded reviewers did not agree on $276(20 \%)$ of the 1400 times a criterion had to be applied. Usually this appeared to be due to errors in reading. After their consensus meeting this number was reduced to 4 , for which the third blinded reviewer made the final decision.

Tabie 2. Randomised trials on the efficacy of mampulation for back pain and neck pain in order af methods soore.

Soores for methods criterita ${ }^{\text {a }}$

Back pain trilis ly

\begin{tabular}{|c|c|c|c|c|c|c|c|c|c|c|c|c|c|c|c|c|c|c|}
\hline $\begin{array}{l}\text { MacDonald, } \\
\text { Bell: }\end{array}$ & 1 & 4 & - & 3 & 4 & $\propto$ & 10 & 5 & 5 & - & 5 & - & 6 & & 3 & 5 & 5 & 56 \\
\hline Hadler et al ${ }^{15}$ & 1 & 3 & - & 。 & 4 & - & 10 & 5 & 5 & - & 5 & 3 & 4 & 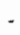 & 3 & 5 & $\$$ & 53 \\
\hline Ongley et $x^{16}$ & 2 & 4 & 2 & - & 4 & $\approx$ & 5 & 5 & - & . & - & 5 & 4 & 4 & 5 & 5 & 5 & 50 \\
\hline $\begin{array}{l}\text { Bergquist, } \\
\text { Lasson }^{17}\end{array}$ & 2 & 1 & 2 & - & 4 & 6 & 10 & 5 & - & $\$$ & 5 & 2 & 2 & - & 5 & 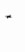 & 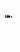 & 49 \\
\hline
\end{tabular}

Meade et al ${ }^{15} \quad-44-212-5-5-5-6-5=548$

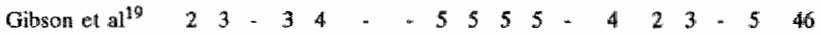
Sims-Williarns $12-.4-555 \times 5=625.545$ $\mathrm{ell} \mathrm{al}^{20}$

Helliwell,

Cunliffe ${ }^{21}$

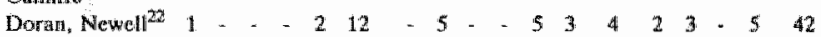

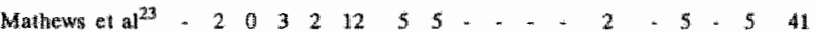

Evans et al ${ }^{24}-\quad-2 \cdot 2-555-5-6-63-540$

Glower $\mathrm{et} \mathrm{al}{ }^{25}-3434-5-55 *-2 \times 3+5.39$

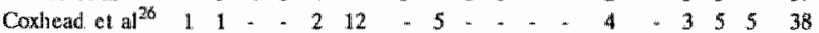

Waagen el al $12 \ldots-\ldots 55.554237$

Hohter et al ${ }^{28}-1-4-4-5-34-35535$

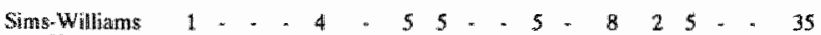

el $\mathrm{at}^{29}$

Zylbergold,

Piper ${ }^{30}$

Postachini.

et $\mathrm{al}^{31}$

${\text { Rasmusse }{ }^{32}}^{32}$

Farrell,

Twomey ${ }^{33}$

Nwuga acate and elturonic

low back pain

acute low back pain

chronic low back pain

acule low back pain

acute and chronic low back panits

(sub)acate low back pain negatiwe

acule and chronic negative low barkilk pailn

acule low back pain

acente and chironio

low back pain

acdite low back pain

cllromic low begk partin acute low benck patin sciatic symploms chromíc low back pain acule and chroni:us low back pain acute arid chronic low back pain

nol methtioned

thete and chronic low bacli pain acule low back pain actuke low back pain

6ucute low back pain (prolapposed disco) pexiline

(sabgroup onty)

positive (subgroup onily $)^{\text {n }}$

positive

positive compared will placebo negative compared with back school posilive

negigthe

negintwe

postltise (sullagrotap only)

postlitive

negative

posiliwe

poritliwe

posiliwe

porsiline

negative

positive (suberoup anty)

positives

positive

posilinie 


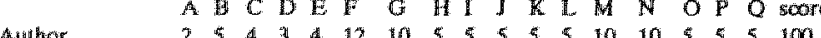

\begin{tabular}{|c|c|c|c|c|c|c|c|c|c|c|c|c|c|c|c|c|c|c|c|c|}
\hline $\begin{array}{l}\text { Whaterworth, } \\
\text { Hunter }\end{array}$ & 2 & 3 & - & 3 & 4 & ; & 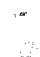 & 9 & 5 & - & - & - & 6 & - & 3 & “ & - & 31 & acette low back pain & negatrue \\
\hline Arlatebidewskij & - & 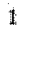 & 2 & $\therefore$ & 4 & -. & $\because$ & 5 & - & $=$ & $\therefore$ & - & 4 & - & 5 & 5 & 5 & 31 & $\begin{array}{l}\text { aculte and chronic } \\
\text { low back pain }\end{array}$ & positive \\
\hline Bsulerger & 1 & . & 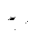 & $\approx$ & 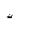 & - & 10 & 5 & 5 & - & 5 & - & 2 & + & 3 & - & - & 31 & not mentioned & positive \\
\hline Tobols, Noenler ${ }^{38}$ & $:$ & $\approx$ & - & . & $\therefore$ & - & 5 & 5 & 5 & 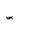 & 5 & 3 & 4 & - & 3 & - & . & 30 & not mine ntifoned & positivita \\
\hline Bronlort ${ }^{30}$ & 1 & 2 & - & * & 2 & 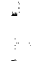 & - & 5 & - & - & 5 & 3 & 2 & - & 5 & * & 5 & 30 & $\begin{array}{l}\text { acule and chronic } \\
\text { low back pain }\end{array}$ & no conclusiton ${ }^{\text {hi }}$ \\
\hline Kinatiket ent al & $\therefore$ & $\therefore$ & - & $\because$ & 4 & 6 & - & " & 5 & - & - & - & 4 & - & - & $*$ & 5 & 24 & not meritioned & positive \\
\hline Godfrey et all & 1 & $i$ & " & $\therefore$ & 2 & - & $\therefore$ & 5 & - & 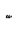 & - & - & $\mathrm{g}$ & 2 & 3 & - & - & 22 & acune low back puin & negallive \\
\hline Sienll of $a l^{42}$ & 1 & 1 & - & 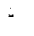 & - & 。 & + & 5 & 5 & - & 5 & $\because$ & - & $=$ & 5 & - & - & 22 & not mentioned & possillive \\
\hline Rupert at allig & 1 & 1 & * & . & - & - & - & - & - & 5 & 5 & 3 & 2 & - & 3 & - & - & 20 & $\begin{array}{l}\text { aculte and chronic } \\
\text { low back pain }\end{array}$ & pasilive \\
\hline \multicolumn{21}{|l|}{ Neck paing thals } \\
\hline Slooper al al & 2 & 1 & 2 & 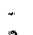 & 4 & - & $\$$ & - & $"$ & 5 & 5 & 5 & 4 & 4 & 3 & 5 & 5 & 50 & chtoronic neck pain & neggat ine \\
\hline $\begin{array}{l}\text { Nordlemar. } \\
\text { Thorner }\end{array}$ & 1 & 3 & - & 3 & 4 & + & 5 & 5 & 5 & $\cdots$ & - & - & 4 & - & 3 & 5 & 5 & 43 & acate neck pain & megative \\
\hline Brodlint & “ & 1 & 4 & $=$ & 2 & - & 5 & 5 & 5 & - & 5 & - & 4 & : & 3 & $\cdot$ & 5 & 39 & $\begin{array}{l}\text { aceice and chromic } \\
\text { teck paun }\end{array}$ & positive \\
\hline Howe of all & * & 3 & 2 & “ & $=$ & - & 5 & 5 & - & $\cdot$ & - & 。 & 4 & 2 & 3 & - & 5 & 29 & $\begin{array}{l}\text { dister and chronic } \\
\text { neck pair }\end{array}$ & positive \\
\hline Moaly ot $\mathrm{nt}^{48}$ & 1 & 2 & 4 & - & 2 & - & - & 5 & - & - & - & $\cdot$ & 4 & $\cdot$ & 3 &. & 5 & 26 & $\begin{array}{l}\text { acute mieck pain } \\
\text { (whiplasin) }\end{array}$ & positave \\
\hline
\end{tabular}

\footnotetext{
- See apperadix for details of criteria

The labels acute and chronic are according to the authors of study. Chassification might hherefore wary between the studies

- Conclusion of the author(s) of the study. Positice conclusion manipulation better than the control treatment; negative conclusion - manipulation worse than or equally effective as control tretiment.

- Posilive only in subgroup duration 2-4 weeks, not in subgroup $<2$ weeks, and subgroup $>4$ weeks.

- Positive only in subgroup duration $2-4$ weeks, not in subgroup $<2$ weeks.

f Positive only in subgroup with limited straight leg raising (SLR), not in subgroup with no limited SL.R.

g. Posilive only in subgroupss with acute low back pain, not in subgroups with chronic low back pain.

thi Auhor refrained from drawing a conclusion.

1 Positive only in subgroup with no neive root compression, not in subgroup with nerve root compression.
}

No single trial scored 60 or more points, whereas only 4 studies ( 3 back pain, 1 neck pain) had a methodological score of more than 50 points, indicating the general poor quality. Reading table 2 in the vertical direction shows that the most prevalent methodological problems concern (D) the proper description of drop-outs, (F) the small size of the study population, $(J)$ the lack of a placebo group, $(L)$ the blinding of patients, and $(N)$ the blinded effect measurements. There are 18 trials $(51 \%)$ in which the authors report better results for manipulation compared to the reference treatment (e.g. short wave diathermy, massage, exercises, analgesics, or a placebo treatment). In addition, $S$ other trials report better results in a subgroup of the study population only. In 11 studies manipulation seemed to be no more effective than the reference treatment.

Considering the 4 trials with methodological scores of $50-60$ points, there is one positive and one negative study, while two studies report better results in a subgroup of the study population only.

Considering the 9 trials with methodology scores of $40-50$ points there are 2 positive studies, 6 negative studies, and 1 study reports better results in a subgroup only. There were only 14 studies which included a(n) (long term) effect measurement of at least 3 
months. In only 4 of these do the authors report long term positive effects of manipulation.

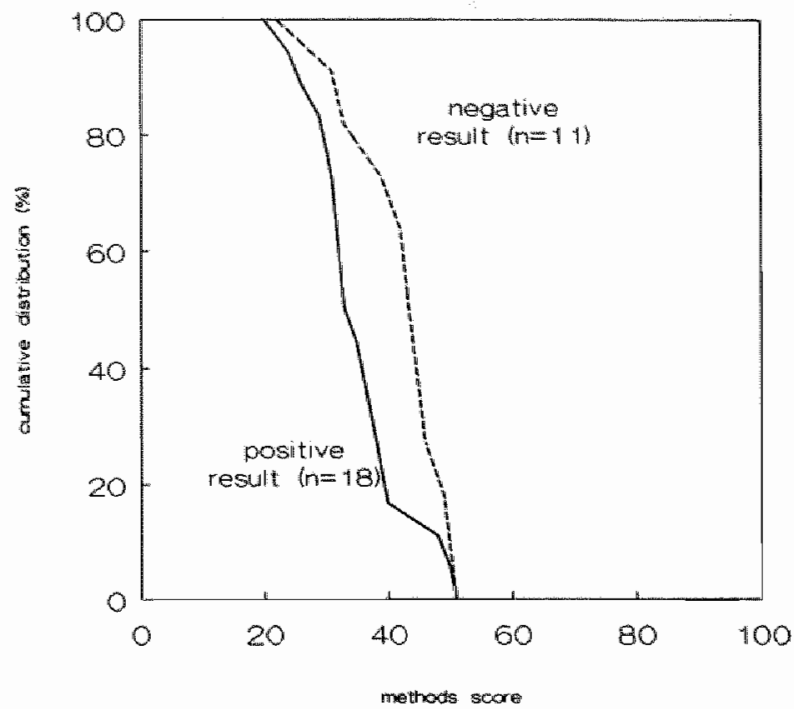

Figure 1. Relation between methods score of trials and their results.

Figure 1 presents the relation between the methodological score and the outcome of the study. Included are the 18 positive studies and the 11 negative studies. The 5 trials reporting positive results of manipulation only in a subgroup of the study population were omitted, because labeling as positive or negative would be ambiguous for these. The one study in which the author refrained from drawing a conclusion was also omitted. Only 3 of the 18 positive studies $(17 \%)$ scored 40 points or more. In contrast, 7 of the 11 negative studies (64\%) scored 40 points or more. In generall the negative studies appear to have higher methodological scores.

Table 3. Details of trials contuparing manipulation with other conservative treat nnents.

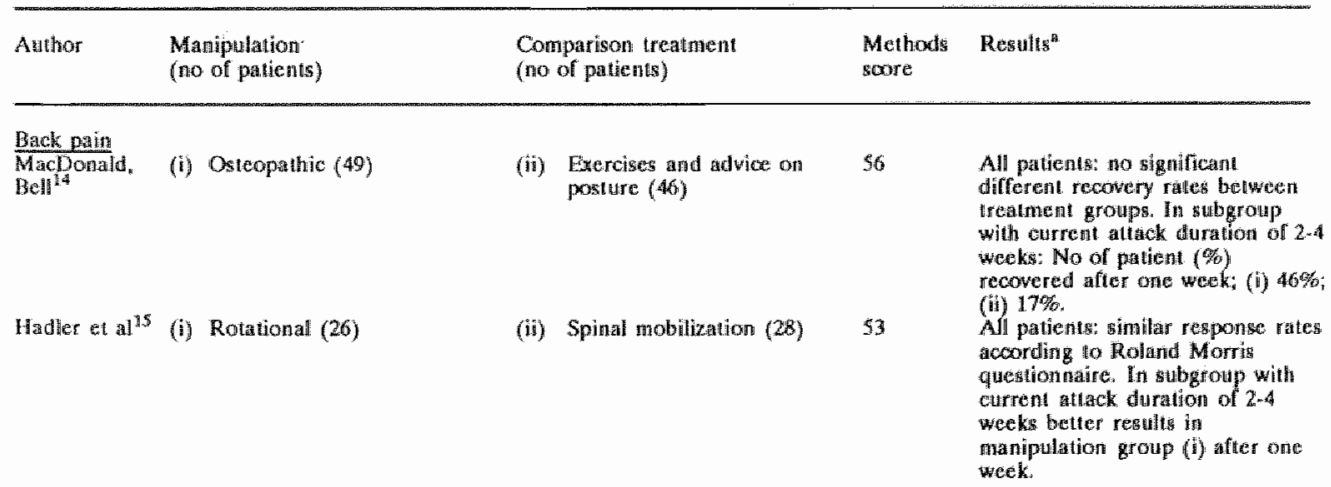


Heging

larescour

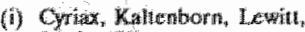
Janda (72)

Meded et all ${ }^{18}$

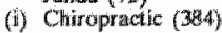

(ii) Back school (70)

49

(if) hysiotherapy $(357)$

48

Giborn et al (i) Oetcopathic (41)

Hellwet

Conntirfe $^{22}$

(i) Cyniax (6)

Doran

Newetell ${ }^{22}$

(i) At discretion manipulator (116)

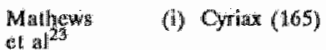

Duans et at ${ }^{24}$

(i) Motational (15)

Comenetud

et al ${ }^{2}$

(i) Matthind (155)

Wragen et at (i) Chiropractic $(9)$

Hoehter et al ${ }^{\text {8s }}$ (i) Rolational (56)

46

(iii) Analgesics (it3) manipulation (10)

(ii) Massage (39) (ii) Shortawiane diathermy (34)

(iii) Heal and exercises (10)

$2 y$ limergotd

(i) Rotational (8)

piper

Pontacohini (a) $\left[\mathrm{i}^{3}\right)^{3}$

(i) Chiropracte $(87)$ (ii) Analges (8)

(ii) Physiotherapy (114),

(iv) Consel (109)

(ii) Inffirared heat (126)

(ii) Analgesics (17)

40

(ii) Exercises, or corsen, or traction $(137)$

(ii) Massinge and sham (ii) Physiotherapy (78)

(iii) Drugbtherapy (81)

(iv) Bedtrest (29)

(v) Backischool ( 50 ) (ii) Shortwave diathermy (12)
Mear no of dave that recovery: (i) 158, (ii) 14.8 .

Difference in change in Oswestry questionnaire (nean score group (ii) minus mean score group (i) after 6 weeks, 6 monthis, 1 year, and 2 years: $1.69,3.31,2.09,7.16$ Manipillation significantly better after 6 months and 2 years.

No of patients ( $\%$ ) tree of pain after 4 and 12 weeles: (i) $28 \%$ $42 \%$ (ii) $28 \%, 37 \%$.

Combined sympton soore (SD) (maximal severity $=28$ ) after 1 and 4 weeks: (1) $2.6(2.6), 3.8(3.3)$; (ii) $6.1(7.2), 2,2(25) . \mathrm{NiO}$ significant differences.

No of patients $(\%)$ better affer 6 and 12 weeks: (ii) $65 \%, 74 \%$; (ii) $67 \%, 65 \%$ (iiil) $58 \%, 76 \%$ (iv) $77 \%, 83 \%$

No of patients $(90)$ recowered after 2 weeks: In subgroup (in $=58$ ) whthout limitation in shraight leg raising (i) $62 \%$; (ii) $70 \%$ In subgroup $(n=233)$ with limitation in straight leg raising (i) $80 \%$; (ii) 67\%. Manipulation sugniticant benefictal effect in subygroup with linsited stitraight le räging. No of patients assessing treatment as effective after 3 weeks: (i) 9 ; (ii) 3. Significant:

No of patients reporting to feel better compared lo basilline after 4. weeks and 4 nonths: (i) 127 , 100 , (ii) 100,81 . No significant difference.

Improwement on vistal analogue scale ( $10 \mathrm{~cm}$ ) after 2 weeks: (i) 2.3 ; (ii) 0.6 . Martipalation significantly better.

No of patients reporting moderate to severe pain at discharge (variable) and 3 weeks gifter discharge: (i) 17,21 ; (ii) 29,48 .

Manipulation significantly better after first treatment. No differences al discharge and 3 weoks later.

Improwement (SD) on 5-point pain scalle: (i) 1 s. (0.1): (ii) - 1.0(0.85). No significant ditierences but resulls indicate silight advardage for manipulation. Mean improvement on combined pain, disabilliry, and spinal mobility socore (5-32) after 3 weeks, 2 and 6 months: lin subgroup with aculte pain (i) $7.5,9.7,123_{\text {; }}$ (ii) $5.0,8.4$ 10.2; (iii) $3.0,107,14.0$; (iv) 5.4 , $7,5,7$, Manipulation sigmilicatul ly beter (short term) only in subgroup with aculte pain on ly after 3 weelss. In subgrotip with chronic pain; (i) $2.2,26,4.3$; (iii) $3.9,4.2,6.0$, (iii) $2.6,2.2,4.0$; (v) $0.5,4.6,89$. Manipulation not better in subgroup with chtrontic pain

No of patients $(\%)$ total restored after 14 days: (i) 11 (92\%); (ii) 3 (25\%). Mamipulation significantly 5tperior. 


$\begin{array}{ll}\text { Farre:t, } & \text { (i) Stoddardi, Maithand (24) } \\ \text { Thiomey } & \\ \text { Nwriga }^{34} & \text { (i) Rotational (26) }\end{array}$

Nunga $^{34}$ (i) Rotational (26)

Waterworth, (i) At discretion physiotherapist Hunter ${ }^{3}$

Arkuszewsiki $i^{30}$ (ii) Lewit $(50)$

Buerger $r^{37}$

(i) Rotational (w)

Tobis

Howler

(i) Rotational (-)

(ii) Massige (-)

30

Brontont $^{39}$

(i) Chiropractic (10)

Xinalshi et a A $^{40}$ (i) Janda, Lewitt (61)

(ii) Physiolherapy $(50)$

Godfrey et al ${ }^{41}$ (i) Rotational manipulation (44)

(ii) Massenge and electrical stirmulation (37)

Siehl $\mathrm{et} \mathrm{al}^{42} \quad$ (i) Osteopathic $(21)$

Rupert el a $\|^{43}$ (i) Chiropractic ( $(4)$

(ii) Drugs and bedrest (-)

(iii) Honte care instrictions ()

(ii) Conservative treatment (7)

(iii) Surgery (19)

22

Rert er al

32

32

H:

4

2

.

0

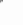

Neck pain

Sloop a a

(i) Cyrinx, Maigne, Mailland (21) (ii) Dirzepan (18)

50

Nordentuar, (i) mobilization the rapy (10)
Thoraters:

(ii) Transentaneous nerve stimulation (10)

(iii) Neck collar (10)

Mrodint $\quad$ (i) Stoddard (23) (ii) Analgesios (23)

(iii) Analgesics and mock mannal therapy (17)
Manipulation goroup were symproni free im sinenificantly leses days: (dwa in yranhs).

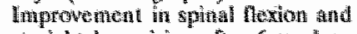
straight beg raisine aftor 6 week (i) $34^{*}, 39^{\circ}$, (ii) $13^{\circ}, 4^{\circ}$. Nanupulation significantly better than oxnparsons treatment.

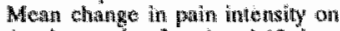
4 points seale alter and 12 dass: (i) $-1,1,4.7 \%$ (ii) $-0.9,-1.6$ (iii) $-0,9$, - 1.7. No significant differences in pain and nuobility. Paún severity (SD) on t4 poinat scale (0-3) wfter ireatment and 6 nonthis (i) 0.60 .0 .5$), 0.7(0.6)$ (ii) 1. (0.4), 1 (20.5). Improvement was significantly greater in manipuletion group.

No of patienus (\%) who foel betler after last treatment, and 5 days later: (i) $83 \%, 52 \%$ (ii) $670 \%$ $66 \%$. Mamipulation significanty superior only irmmedianely afor last treatnuent.

Matripulation signiflearuly beter resull in pain relief immediately afle treatment. After 5 day no signiflicant differences any more (data ito graphs).

No of palients (\%) improved after $1_{1} 3$, and 6 monithe (i) $70 \%{ }^{2} 70 \%$ $80 \%$, (ii) 55\%, 66\%, 66\%. Author gives no conclusion because of snatl sample size.

No of patients with good resuli (low pain grade) after treatment:

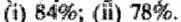

No of pattients (\%) with moderate/marked improventenl on general symptomathology on a 5 point scalle alter 2 weeks: (i) $77 \%$ (ii) $70 \%$. Five other indexes also showed tho significant differences. No of patients showing electromyographic and clinaical improwement after 6 and 12 months: (i) 14\%; (ii) 0\%: (iii) 4.790.

Inprow med on pethl wisual ansiogute sonte during lowetment: group (i) more pali feduchion thas group (ii) and (iii). Data î graphis.

No of pasticnts (\%) veporting that the trealment helped after 3 wewles: (i) $57 \%$ : (ii) $28 \%$. No significani difference. Merist (SD) on pain visual anclogue scale afluer 1 and 6 werks: (i) $18(25), 0$; (ii) $17(19), 0$; (iii) $35(45)$, a. No significant differentice.

No of patictuts (\%) reporting no paila cone week afluer final tireatment: (i) $48 \%$; (ii) $22 \%$; (iii) 120\%. Manipulation signilicantly better. 


\begin{tabular}{|c|c|c|c|c|c|}
\hline Anithor & $\begin{array}{l}\text { Mariputhathon } \\
\text { no of patherte) }\end{array}$ & $\begin{array}{l}\text { Con } \\
(\pi 00\end{array}$ & $\begin{array}{l}\text { jperison treatiment } \\
\text { of patients) }\end{array}$ & $\begin{array}{l}\text { Mathoxs } \\
\text { goore }\end{array}$ & Rerulus \\
\hline 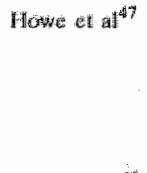 & $\begin{array}{l}\text { (1) Boiradilon }(26) \\
\therefore \quad \therefore\end{array}$ & (iin) & Angligestos $(20)$ & 29 & 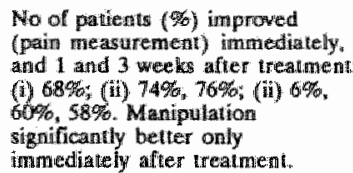 \\
\hline Medly at a & (1) Watland (31) & (ii) & Rest and cervical collar ( 30 ) & 26 & 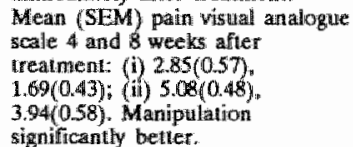 \\
\hline
\end{tabular}

a Pesillig of the mosit inportant butcone neasure acoording to the athor(s) of the study, When not explicilly siated presentation of pain or a global measure of intprowement. Sigaificanl meana $\mathbf{P}<0.05$.

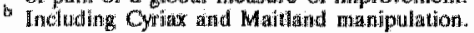

Table 3 presents the comparison of manipulation with other conservative treatment modalities. The main characteristics of the forms of manipulation included in the trials are presented here. Manipulation is given alone or in combination with other therapeutic modalities. The reference treatments are mainly physiotherapeutic interventions (e.g. shortwave diathermy (SWD), massage, exercises) and drug therapy (analgesics). There are 31 trials in which a comparison is made between manipulation and other conservative treatment modalities. Of these, there are $15(48 \%)$ positive studies, including patients with both acute and chronic back and neck pain.

Considering the 3 studies with methodological scores of 50-60 points there is 1 negative study, and 2 studies reporting a favorable outcome of manipulation only in a subgroup of the study population. Among the 8 studies with methodological scores of $40-50$ points there are 5 negative studies, 2 positive studies, and 1 study reporting favorable outcome of manipulation only in a subgroup of the study population.

Table 4. Details of trals comparing manipulation with plawebo therapy.

$\begin{array}{lll}\text { Author } & \text { Manipulation } & \text { Mlacebo the rapy } \\ \text { (no of pathents) } & \text { (not patients) } & \begin{array}{l}\text { Methods Results } \\ \text { score }\end{array}\end{array}$

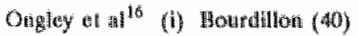

Mergatuis,

Uhissong

(i) Cyrix, Katienborm, Lewif, Jandili $(72)$

Gibson of all ${ }^{10}$ (i) Ostoopathic (all)

Sins Willingus (i) Maitland (48) at $\left.\right|^{20}$

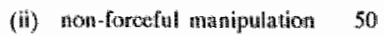
(41)

(ii) Shortwave dimithermy at 49 lowest intensity (75)

(ii) Dettined Shortwaye diathermy (34)

(ii) Microwawe at lowest setting 45 (46)
Mean (SEM) pain orn visual andogue scalo after 1,3 , and 6 nuonth:s: (i) $2.1(0.2), 1.8(0.2)$, $1.5(0.2) ;(i i) 3.1(0.3), 2.900 .3)$, 3.1.(0.3). All differences significant. Mean no of days until recowery: (i) 15.8. (ii) 28.7 . Diffierence signifficant.

Ne of patients (\%) free of paith after and 12 weeks: (i) $28 \%$, $42 \% ;$ (ii) $27 \%, 44 \%$.

No of patients improwed after 4 and 12 weeks: (i) 29,28 ; (ii) 25 , 27. Not significantly different. Also no evidence that manipulation produced any long term (one year) benefit. 


\begin{tabular}{|c|c|c|c|c|c|}
\hline Author & $\begin{array}{l}\text { Manipuiation } \\
\text { (no of patients) }\end{array}$ & Plece & $\begin{array}{l}\text { obo thempy } \\
\text { of patientis) }\end{array}$ & $\begin{array}{l}\text { Melhodis } \\
\text { soore }\end{array}$ & Resulus \\
\hline Glover et al ${ }^{25}$ & (i) Rotational manipulation (43) & (ii) & $\begin{array}{l}\text { Detuned Shortwaye } \\
\text { diathermy }(41)\end{array}$ & 39 & 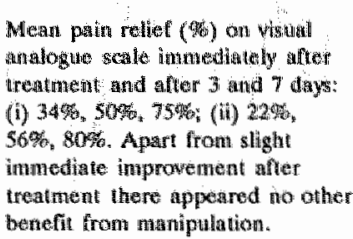 \\
\hline 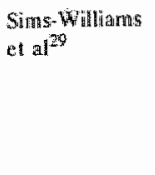 & (i) Maitland (47) & (ii) & $\begin{array}{l}\text { Microwave at lowest setting } \\
\text { (47) }\end{array}$ & 35 & 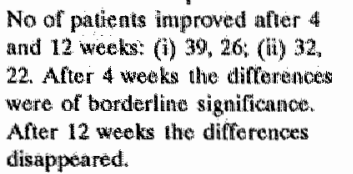 \\
\hline $\begin{array}{l}\text { Postachini } \\
\text { et at } \text { al }^{3 / 1}\end{array}$ & (i) Chiropractic (87) & (iii) & Anti-oedema gel (73) & 33 & 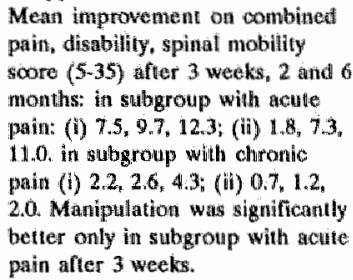 \\
\hline Rupert el all ${ }^{43}$ & (i) Chiropractic $(-)$ & (ii) & $\begin{array}{l}\text { Sham manipulation, massage } \\
(-)\end{array}$ & 20 & $\begin{array}{l}\text { Improvement on patin whatll } \\
\text { analogene scale during treatment: } \\
\text { more pain reduction in group } \\
\text { receiving manipalation (datat in } \\
\text { graphs). }\end{array}$ \\
\hline
\end{tabular}

: Restilts of the most important outcome measure according to the atithor(s) of the study. When not explicitly stated presentation of pairi or a global measure of improvement. Significant means $\mathbf{P}<0.05$.

Table 4 presents the 8 trials comparing manipulation with a placebo therapy. In most studies the placebo therapy consists of detuned shortwave diathermy. There were 4 $(50 \%)$ positive studies, 1 positive only in a subgroup, and 3 negative studies. The study populations included both acute and chronic conditions. What is remarkable are the findings of Sims-Williams et al. 2029 who, in two studies with comparable designs, report positive results of manipulation (compared with microwave at lowest setting) for patients in general practice, but not for hospital patients. Long term effects were only found in Ongley's study. ${ }^{16}$ However, in this study the manipulative treatment was only one part of a treatment regimen which also included injections and exercises. Thus, in this study it was not possible to isolate the effect of manipulation.

\section{Discussion}

The value of a review of the literature depends on the success in obtaining the results of all studies (RCTs) which have been conducted on the subject at issue. The bias that is created when the outcomes of published and unpublished studies differ is called publication bias. There are indications that especially small clinical trials with positive results are more likely to be published. ${ }^{49}$ Thus, although we have put much effort into obtaining all the available published randomised clinical trials, it remains possible that we have missed both published and unpublished trials of which the results might differ from the ones we have presented here. In this area of research there is no agency which 
registers the trials that are or will be carried out. Thus it is unknown whether there are trials that have not been published because of negative results. We did not find any completed unpublished study, although, our search was not primarily focused to trace. them.

Manipulation appears to be frequently studied in randomized clinical trials. However, most studies show major methodological flaws. From table 2 the most common flaws can be read. The methodological criteria which we used are based on the requirements for high quality of intervention research in this area. Although the 'gold standard' of 100 points is probably a goal which is difficult to reach in this area of research, it was disappointing to find out that the majority of the trials scored less than 50 points. In the future more attention should be given to the description of drop-outs, the size of the study population, the use of placebo groups, and blinded effect measurements. It seems difficult to develop a placebo manipulation therapy which both has no specific effect and is trustworthy for the patients. Some authors ${ }^{16} 44$ supplied high doses of diazepam to patients, thus making the patients amnesic for the procedure and unaware of the treatment given. Other authors include a 'nontherapeutic' massage ${ }^{43}$, or massage in combination with sham adjustments ${ }^{27}$ in order to simulate the effect of 'laying-on-of hands'. These efforts can be criticised on the grounds of their possibility of having some therapeutic effects. Detuned shortwave diathermy seems to be a placebo therapy which patients can trust and which has no specific effects, but this has little similarity to a manipulation treatment.

There have been other reviews of the efficacy of manipulation which summarized 7 to 17 of the 35 RCTs which we included in our meta-analysis. Of these Greenland et al. ${ }^{50}$, Brunarski $^{51}$ and Di Fabio ${ }^{52}$ stated that adequate randomized clinical trials are still needed for a valid assessment of the efficacy of manipulation. Ottenbacher and Di Fabio $^{6}$ conducted a quantitative meta-analysis in which the results from 9 trials were pooled statistically. They conclude that there is only limited empirical support for the efficacy of manipulation. We chose not to pool statistically the results of the available trials. The main reason for this is that we do not like the idea of pooling together data from studies of high and low methodological quality. This decision was supported by our finding that the trials which reported positive results of manipulation more often had relatively low methodological scores. The reason for not pooling the results of the subgroup of trials with a rellatively high methodological score is that we do not think that the patient characteristics and treatments used in these trials show enough similarity to permit statistical pooling of their data. The weights attached to the methodological criteria are arbitrarily chosen. The methods used in this review are similar with the methods in a review on physiotherapy exercises which has been published recently. 55 The only difference is that in this review on manipulation we gave 5 points if the article indicated that the manipulative treatment had been carried out by a qualified and/or experienced manipulative therapist. These 5 points were withdrawn from the 17 points that could be earned for the size of the study population which thus left 12 points for this criterion. The weights attached to the methodological criteria remain arbitrarily chosen. For example, the description of an adequate randomisation procedure was given low weight ( 4 points) because all the studies included were randomised clinical trials and thus satisfied our demand of random allocation of the participants. Studies could, however, earn points with a proper description of an adequate randomisation procedure. Readers may wish to assign their own weights or 
assess the quality of the trials by themselves. It appeared that assessing the trials by blinded reviewers was not difficult, and after a consensus meeting the interobserver agreement was almost perfect.

Most trials report short term effects only. Long tern effects (more than 3 months after randomization) are seldomly provided. The studies which do include a long term followup mostly show no positive results. Many studies, especially the ones with relatively higher methodology scores ( $\geq 40$ points), report negative results, even when compared with a placebo therapy. The negative results might be caused partly by relatively small study populations, thus making it difficult to detect existing treatment differences between manipulation and reference treatments. ${ }^{53}$ Therefore, the information from figure 1 must also be interpreted with some caution. The labelling of studies as negative might be influenced by the lower power of small trials. However, the results of the trials presented indicate that manipulation is not consistently better than other therapeutic approaches. Possibly manipulation is effective only in certain subgroups of patients with back and neck pain. The findings of Sims-Williams et al. ${ }^{20} 29$ seem to support this suggestion. Furthermore, there are 5 trials reporting better results for manipulation in subgroups only. However, it is still unclear which subgroup(s) benefit most from manipulation. For example, there are positive as well as negative studies for patients with both acute and chronic back and neck pain. In two studies with relatively high methodological scores favorable results of manipulation were found for a subgroup of low back pain patients with a duration of $2-4$ weeks. ${ }^{14} 15$ Although the findings from subgroup analyses should be interpreted cautiously ${ }^{54}$, this seems to be an interesting finding for further research.

In the meantime we conclude that, although there are some promising results, so far the efficacy of manipulation has not been convincingly demonstrated. Any further research should pay more attention to the methodological quality of the study design. 


\section{References}

1. Kelsey III. White AA. Epidemiology and impact of low-back pain. Spine 1980; 5: 133-142.

2. Waddell G. A new clintical model for the treatment of low-back pain. Spine 1987; 12: 632-644.

3. Frymoyer JW. Back pain and sciatica. N Engl M Med 1988; $318: 291-300$.

4. Deyo RA Conservative therapy for low back pain. IAMA 1983; 250: 1057-1062.

5. Spitzer WO, Leblane TE, Dupuis M. (EDS) Scientific approach to the assessment and management of activity-related spinal disorders. Spine 1987; 7 (suppl): 1-59.

6. Ottenbacher K, Di Fabio RP. Efficacy of spinal manipulation/mobilization therapy: a meta-analysis. Spine $1985,10.833,837$.

7. Jayson MTV, Sims Willams H, Yowng S, Baddeley H, Collins E. Mobilization and manipulation for low-back pain. Spine $1981 ; 6: 409416$.

8. Catterman Mil. Chiropractic management of spine related disorders. Baltimore: Willians \& Wilkins, $1990,37-54$

9. Meinen CL. Clinicall trials design, conduct and analysis. New York: Oxford University Press; 1986.

10. Feinstein AR. Clinical epidemiology: the architecture of clinical research. Philladelphia: W.B. Saunders; 1985.

11. Ter Riet G, Kleijnen J, Knipschild P. Acupuncture and chronic pain: a criteria-based meta-analysis. JClin Epidemiol 1990:43: 1191-1199.

12. Mathews $W_{*}$ Morkel $M$, Mathews $\mathbb{J}$. Manipulation and traction for lumbago and sciatica: physiotherapewtic techniques used in two controlled trials. Phyciotherapy Practice 1988; 4: 201-206.

13. Brodin H. Cervical pain and nobillization. Int J Rehab Res 1984; 7: 190-191.

14. MacDonald RS, Bell CMI. An open controlled assessment of osteopathic manipulation in nonspecific low-back pain. Spine 1990; 15:3644370.

15. Hadler NM, Curlis $\mathrm{P}$, Gillings $\mathrm{DB}$. Stinnett $\mathrm{S}$. A benefit of spinal manipulation as adjunctive therapy for acute low back pain: a stratified controlled trial Spine 1987; 12: 703-705.

16. Ongley $\mathrm{MJ}_{\mathrm{s}}$ Klein RG, Dorman TA, Eek BC, Hubert LJ. A new approach to the treatment of chronic low back pain. Lancet 1987: 143-146.

17. Bergquist Ullman $M$, Larsson U. Acute low back pain in industry: a controlled prospective study with special reference to therapy and confounding factors. Acta Orthop Scand 1977; 170 (suppl): 11117.

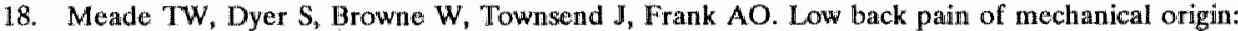
randomised conparison of chiropractic and hospital outpatient treatment. Br Med J 1990; 300: 1431.1437.

19. Gibson T, Grahame R, Harkness $\mathfrak{J}$, Woo P, Blagrave P, Hills R. Controlled comparison of shortwave diathermy treatment with osteopathic treatment in non-specific low back pain. Lancet 1985: $1258-1261$.

20. Sims-Willitums $\mathrm{H}$, Jayson MIV, Young SMS, Baddeley H, Collins E. Controlled triall of mobilisation and manipulation for low back pain: hospital patients, Br Med J 1979; 2: 1318-1320.

21. Helliwell PS, Cunliffe G. Manipulation in low back pain. The Physician 1987; April: 187-188.

22. Doran DML, Nowell DJ. Manipulation in treatment of low back pain: a multicentre study. Br Med I $1975 ; 2$ : $161-164$.

23. Mathows JA, Mills SB, Jenkins VM, et al.. Back pain and sciatica: controlled trials of manipulation, traction, sclerosant and epidural injections. Br J Rheumatol 1987; 26:416-423.

24. Evans DP, Burke MS, Lloyd KN, Roberts EE, Roberts GM. Lumbar spinal manipulation on trial. Pturt 1: Clinical assessment. Rheumatol and Rehab 1978; 17: $46-53$.

25. Glover JR, Morris $\mathrm{JG}_{3}$ Khoslø $\mathrm{T}$. Back pain: a randonized clinical trial of rotational manipulation of the trumk. Br I lnd Med 1974; 31: 59-64.

26. Coxhead CE, Inskip H, Meade TW, North WRS, Troup DDG. Multicentre trial of physiotherapy in the management of sciatic symptoms. Lancet $1981 ; 1$ : 1065-1068.

27. Waagen GN, Haldeman S, Cook G, Lopez D, DeBoer KF. Short term trial of chiropractic adjustments for the relief of chronic low back pain. Manual Med 1986; 2: 63-67.

28. Hoehler GK, Tobis JS, Buerger AA. Spinal manipulation for low back pain. JAMA 1981; 245: 1835 1838.

29. Sims-Williams $\mathbf{H}$, Jayson MV, Young SMS, Baddeley $\mathbf{H}$, Collins E. Controlled trial of mobilisation and manipulation for patients with low back pain in general practice $\mathrm{Br}$ Med J 1978; 2: 1338-1340. 
30. Zylbergold RS, Piper MC. Lumbar disc disease: comparative analysis of physical therapy treatiments. Arch Phys Med Rehabil 1981: 62: 176-179.

31. Postachini $F$, Facchin M, Palieri P. Efficacy of various forms of conservative treatment in low back pain: a comparative study. Neuro-Orthopedics $1988 ; 6: 28-35$.

32. Rasmussen GG. Manipulation in treatment of low back pain a randomized clinicical trial Manual Med 1979; 1: 8-10.

33. Farrell JP, Twomey LT. Acute low back pain: comparison of two conservative trealtment approaches. Med J Aust 1982; 1: 160-164.

34. Nwuga VCB. Relative therapeutic efficacy of vertebral manipulation and conventional treatment in back pain management. Am J Physical Med 1982; 1: 1.60-164.

35. Waterworth RF, Hunter IA. An open study of diflunisal, conservative and manipulative therapy in the management of acute mechanical low back pain. NZ Med J 1985: 372-375.

36. Arkuszewski $Z$. The efficacy of manual treatment in low back pain a clinical trial. Manual Med 1986: 2: 68-71.

37. Buerger AA. A controlled trial of rotational manipulation in low back pain. Manual Med 1980; 2 : $17-26$.

38. Tobis JS, Hoehler FK. Musculoskeletal manipulation in the treatment of low back pain. Bull NY Acad Med 1983; 7: 660-668.

39. Brontfort GDC. Chiropractic versus general medical treatment of low back pain: a small scale controlled clinical trial. Am J Chiropractic Med 1989; 2*145*150.

40. Kinalski R, Kuwik W, Pietrzak D. The comparison of the results of mamual therapy versus physiotherapy methods used in treatment of patients with low back pain syndromes. Manual Med $1989 ; 4: 44-46$.

41. Godfrey CM, Morgan PP, Schatzker J. A randomized trial of manipulation for low-back pain in a medical setting. Spine 1984; 9: 301-304.

42. Sieh1 D, Olson DR, Ross HE, Rockwood EE. Manipulation of the lumbar spine with the patient under general anaesthesia: Evaluation by electromyography an clinical-neurologic examination of its use for lumbar nerve root compression syndrome. J An Osteopath Assoc 1971; 70:433-450.

43. Rupert RL, Wagnon R, Thompson P, Ezzeldin MT. Chiropractic adjustments: Results of a controlled clinical trial in Egypt. ICA Int Review of Chiropractic 1985 (winter); 58-60.

44. Sloop PR, Smith DS, Goldenberg E, Doré C. Manipulation for chronic neck pain: a double-blind controlled study. Spine 1982; 7: 532-535.

45. Nordemar $\mathrm{R}$, Thörner $\mathrm{C}$. Treatment of acute cervical pain: a comparative group study. Pain 1980; 10: 93-101.

46. Brodin H. Cervical pain and mobilization. Med Phys $1983 ; 6: 67-72$.

47. Howe $\mathbb{D H}$, Newcombe R. Manipulation of the cervical spine: $\mathbb{I}$ Coll Gen Pract 1983; 33: 574-579.

48. Mealy $\mathbb{K}$, Brennan H, Fenelon GCC. Early mobilisation of acute whiplash injuries. Br Med J 1986; 292: $656-657$.

49. Dickersin $\mathrm{K}$. The existence of publication bias and risk factors for its occurrence. JAMA 1990; 263; $1385-1389$.

50. Greenland $S$, Reisbord LS, Haldeman $S$, Buerger AA. Controlled clinical trials of manipulation: a rewiew and a proposal. J Occup Med 1980; 22:670-676.

51. Brunarski DJ. Clinical trials of spinal mamipulation: a critical appraisal and review of the literature. J Manipulative Physiol Ther 1984; 7: 243-249.

52. Di Fabio RP. Clinical assessment of manipulation and mobilization of the lumbar spine: a critical rewiew of the literature. Phys Ther 1986; 66:51-54.

53. Freiman JA, Chalmers TC, Smith H, Kuebler RR. The importance of beta, the type II error and sample size in the design and interpretation of the randomized controlled trial. N Engl J Med 1978; 299: 690-694.

54. Pocock SI, Hughes MD, Lee RJ. Statistical problems in the reporting of clinical trials N Engl J Med 1987; 317: 426-432.

55. Koes $\mathbb{B W}$, Bouter LM, Heijden GMMG van der, Knipschild PG. Physiotherapy exersises and back pain: a blinded review. Br Med J1991; 302: 1572-1576. 


\section{Apperidix}

Operationalization of the criteria from table 1. Each criterion must be applied independently of the other criteriat.

A Description of inclusion and exclistion criteria ( 1 point). Restriction to a homogeneous study population (1 point).

1 Comparability for duration of complaints, value of outcome measures, age, recurrence status and radiating complaints (1 point exach).

C Randomization procedure described (2 points). Randomization procedure which excludes bias (e.g. sealed envelopesi) ( 2 points).

$\mathrm{D}$ Informatton from which group and with reason for withdrawal.

E Loss to follow up: all randomized patients minus the number of patients at mañn moment of effect measurement for the mait outcome measure, divided by all ramdomized patients times 100 .

f Smallest group immediately after randomization.

Q Manipulative treatment explicitly described (5 points).

All reference treatments explicitly described ( 5 points).

H Comparison with an existing treatment modality.

1 Other physical therapy modalities or medical interventions are avoided in the design of the study (except analgesics, advice on posture or use at home of heat, rest, or a routine exercise scheme).

$₫$ Comparison with a placebo therapy.

K. Mentioning of qualified education and/or experience of the manipulative therapist(s).

L. Placebo controlled: attempt for blinding ( 3 points), blinding evaluated and fully successful ( 2 points).

Pragmatie study: patients fully naive ( 3 points), or time restriction (no manipulative treatment for at least one yeat) ( 2 points), naiveness evaluated and fully successful: 2 points.

M Use (measured and reported) of: pain, global measure of improvennent, functional status (activities of daily living), spinal mobility, medical consumption ( 2 points each).

$\mathrm{N}$ Each blinded measurement mentioned under point $M$ earns 2 points.

O Moment of measurement during or just after treatment ( 3 points). Moment of measurement 6 months or longer ( 2 points).

$\mathrm{P}$ When loss to follow-up is less than 10\%: All randomized patients for most important outcome measures, and on the most important moments of effect measurement minus missing values, irrespective of non-compliance and co-interventions.

When loss to follow-up $>10 \%$ : Intention-to-treat as well as an alternative analysis which accounts for missing values.

Q For most important outcome measures, and on the most important moments of effect measurement. In the case of (semi)continuous variables: presentation of the mean or median with standard error or percentiles. 
Chapter 3

\section{PHYSIOTHERAPY EXERCISES AND BACK PAN}

a blinded review*

BW Koes, LM Bouter, H Beckerman, GJMG van der Heijden, PG Knipschild 
Objective - To determine the quality of randomised controlled trials of exercise therapy for back pain.

Design - Computer aided search of published papers and blinded assessment of the methods of studies.

Subjects - 23 randomised controlled trials, of which 16 studied exercise therapy given by physiotherapists to individual patients with back pain. Other conservative treatments could be included.

Main outcome measures - Score for quality of methods (based on four main categories; study population, interventions, measurements of effect, and data presentation and analysis) and main conclusion of author(s) with regard to exercise therapy.

Results - Only four studies scored more than 50 points (maximum 100), indicating that most were of poor quality. Six studies found that exercise was better than reference treatments, 10 reporting it to be no better or worse than the reference treatment. Those reporting positive results tended to have higher methods scores (4/6 positive $\mathrm{v} 4 / 10$ negative scores $\geq 42$ ).

Conclusions - No conclusion can be drawn about whether exercise therapy is better than other conservative treatments for back pain or whether a specific type of exercise is more effective. Further trials are needed in which greater attention is paid to methods of study. 


\section{Intraduction}

Epidemiological studies indicate that about $80 \%$ of the population will suffer from back pain during their active lives. ${ }^{12}$ Fortunately the complaints are usually self limiting and in about $90 \%$ of the patients the complaints disappear within a few months, often with the help of some rest, analgesics and home exercises. ${ }^{2} 3$ For patients with chronic back pain there are many therapeutic interventions available, but none seems to be clearly better than the others. ${ }^{23}$

Although exact figures are lacking, physiotherapy is probably the treatment most widely used for back complaints. ${ }^{4-6}$ Physiotherapists usually give exercise therapy, alone or in combination with other treatments (for example, massage, heat, traction, ultrasound or short wave diathermy). Despite their widespread use the efficacy of these treatments still remains questionable. ${ }^{2} 78$ Rationales for exercise therapy in the management of back pain include relieving compression of the nerve in the intervertebral foramen, shifting nuclear material away from the bulging annulus (in the case of a protruded disc), increasing endorphin concentrations, strengthening weak muscles, decreasing. mechanical stress, stabilizing hypermobile segments, and improving posture and mobility. ${ }^{910}$ Whether the presumed rationale is valid can only be evaluated in randomized clinical trials. The methods used in such trials of physiotherapy have been shown to vary substantially. ${ }^{8}$ Studies with serious flaws in their methods tend to report biased outcomes. We present a review of randomised controlled trials assessing the efficacy of exercises for back pain.

\section{Methods}

We conducted a MEDLINE search of papers published during 1966-90 (keywords: backache, musculoskeletal diseases, joint diseases, spinal diseases, physical therapy, evaluation studies, outcome, and process assessment). In addition, a number of relevant journals that are not covered by MEDLINE were screened. Abstracts and unpublished studies were not included. To be included in this review studies had to meet three conditions. Firstly the physiotherapy regimen should include exercise therapy provided by physiotherapists. Additional physical treatment modalities (for example, ultrasound or short wave diathermy) were allowed. Studies in which the exercise therapy was given in groups (for example, fitmess training, back school programs) were excluded. Secondly, the subjects in the study must have suffered from back pain at the moment of inclusion. Initially we were also interested in the efficacy of physiotherapy exercises for neck pain, but only one study was found. ${ }^{11}$ Thirdly, the study must be a randomised clinical trial. This design is generally considered to be the paradigm for intervention studies because its potential to provide a valid assessment of the efficacy of an intervention. ${ }^{12} 13$ Table 1 shows the criteria used for assessing the methodological quality of the trials. This list was adapted from Ter Riet et al. ${ }^{14}$ and the criteria are based on generally accepted principles of intervention research. ${ }^{12} 13$ Studies could earn points in four categories dealing with the study population, interventions, measurement of effect, and data presentation and analysis. The maximum score was 100 points. The papers to be reviewed were first blinded for author(s), journal, and outcome by one of the authors (BK).

Thereafter the quality of the studies' methods was assessed by two blinded reviewers $(\mathrm{HB}, \mathrm{GH})$ independently. In a subsequent meeting the rewiewers tried to reach 
consensus on each criterion they disagreed about. Where disagreement persisted, a third blinded reviewer (LB) made the final decision. The assessments resulted in a hierarchical list in which higher scores indicate studies that used better methods.

Table 1. Criteria list for a methodological assessment of randomized dinical trials of physiotherapy excrcises lor back complaints (for detals see appendix).

Study population (35):

$\begin{array}{lr}\text { A Homogeneity } & 2 \\ \text { B Comparabiliby of relevant baseline characteristics } & 5 \\ \text { C Adequate randomisation procedure } & 4 \\ \text { D Drop outs described for each study group separately } & 3 \\ \text { E }<20 \% \text { loss to follow-up } & 2 \\ <<10 \% \text { loss to follow-up } & 2 \\ \text { F }>50 \text { subjects in the smallest group } & 8 \\ & >100 \text { subjects in the smallest group }\end{array}$

Interventions $(25)$ :

$\mathrm{O}$ Interventions included in protocol and described 10

H Praginatic study

1 Co interventions awoided 5

J Placebo controlled

Measurement of effect $(30)$ :

K Patients blinded 5

L. Relevant outcome measures

M Blinded assessments of outcome

N Adequate follow-up period 5

Data presentation and analysis (10):

$O$ Intention to treat analysis 5

P Frequencies of mosi important outcomes presented for each treatment group 5

"a Further details given in appendix..

A study was labelled "positive" if its author(s) concluded that in one of the exercise therapy modalities was more effective than the reference treatment. Generally, this meant that the differences were significant. A study was considered "negative" when the author(s) reported no difference between the study treatments or showed better results with the reference treatment.

\section{Results}

A total of 23 studies were considered for inclusion, seven of which were rejected. In three of these all study groups received the same exercises thus making it impossible to assess the effects of the exercise regimen separately, ${ }^{15-17}$ two publications described different aspects of the same trial in which the exercises were given in groups, ${ }^{18} 19$ and in one trial only a few patients in both study groups performed exercises. ${ }^{20}$ Two 
publications turned out to deal with the same study. After assessing both publications the one with the lowest score was rejected. ${ }^{21}$ Sixteen randomised clinical trials met the conditions for inclusion. Table 2 presents all trials in a hierarchical order according to their methods score.

Table 2. Hicrarchical list of randomized trials on the effeacy of exercise therapy for back pain.

Soores for methods criteriat

Asthor

A B C D E F G H I J K L M N O P score

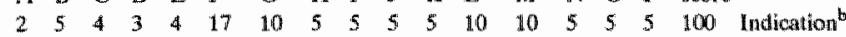

Conchusion"

\begin{tabular}{|c|c|c|c|c|c|c|c|c|c|c|c|c|c|c|c|c|c|c|c|}
\hline Deyo et $\mathrm{al}^{22}$ & 1 & 3 & 4 & 3 & 2 & 8 & 10 & 5 & $m$ & $*$ & - & 10 & 2 & 3 & 5 & 5 & 61 & Chronic low lack paiti & Posilfine \\
\hline Manniche et a $\mathrm{a}^{23}$ & 2 & 1 & 4 & 3 & 2 & . & 10 & 5 & $=$ & - & - & 10 & 2 & 5 & 5 & 5 & $\$ 4$ & Chronic low back pain & Positive \\
\hline Exans et al $^{24}$ & 2 & 5 & $=$ & . & $=$ & 8 & 10 & 5 & - & - & - & 10 & 2 & 5 & 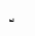 & 5 & 50 & Acute low back pain & Negatitive \\
\hline Coxhead et al ${ }^{25}$ & 1 & 2 & - & - & 4 & 17 & - & 5 & - & . & - & 6 & 。 & 5 & 5 & 5 & 50 & Seitatio symptoms & Megativa \\
\hline $\begin{array}{l}\text { Lidströmm, } \\
\text { Zachrisson } \\
\text { Zatbergold, }\end{array}$ & 1 & 2 & $s$ & 3 & 4 & 。 & 10 & 5 & - & - & - & 6 & 2 & 3 & $\dot{s}$ & $s$ & 46 & $\begin{array}{l}\text { Chronic low back pain } \\
\text { and sciatica }\end{array}$ & Positikes \\
\hline $\begin{array}{l}\text { Piper } \\
\text { Waterworth, }\end{array}$ & 1 & 2 & - & 3 & 4 & - & 10 & 5 & - & - & - & 6 & - & 3 & 5 & 5 & 44 & Munbrat disc disease & Negative \\
\hline $\begin{array}{l}\text { Hunter } \\
\text { Stankovic, }\end{array}$ & 2 & 5 & - & 3 & 4 & - & 5 & 5 & 5 & - & - & 6 & - & 3 & 5 & - & 43 & Acutte low back puin & Negalliwe \\
\hline Johnet. $1^{27}$ & 1 & 3 & 4 & 3 & 4 & - & 10 & 5 & - & - & - & 2 & - & 5 & $\$$ & - & 42 & Acule low back pain & Positive \\
\hline Nwwigat 28 & 2 & 4 & 2 & - & - & - & 10 & 5 & . & $\times$ & 3 & 2 & 2 & 3 & • & 5 & 38 & Prolapsed dise & Negative \\
\hline $\begin{array}{l}\text { Fartell, } \\
\text { Twomey }\end{array}$ & 2 & 5 & - & - & 2 & $=$ & 10 & 5 & $=$ & - & * & 8 & 2 & 3 & . & $=$ & 37 & Acute low back pain & Nega tîke \\
\hline $\begin{array}{l}\text { Kendali } \\
\text { Jenkins }\end{array}$ & 1 & - & 2 & - & 2 & - & 10 & 5 & $=$ & $\approx$ & * & 6 & 2 & 3 & * & 5 & 36 & Chronic low back pain & Possiltive \\
\hline Martin et al ${ }^{\sigma_{1}}$ & 2 & n. & 2 & - & - & * & 10 & 5 & - & 5 & - & 6 & 2 & 3 & . & . & 35 & Chronic low back pain & Negag tiwe \\
\hline Davies et a ${ }^{31}$ & 2 & 3 & . & - & 4 & - & - & $\$$ & - & - & 3 & 6 & 2 & 3 & - & 5 & 33 & Sub(ncute) low back pain & Negrawe \\
\hline $\begin{array}{l}\text { Buswell } \\
\text { Nwolgat }\end{array}$ & - & 1 & . & - & - & - & 10 & 5 & - & - & . & 4 & - & 5 & 5 & 。 & 30 & Chronic low back pain & Nedatime \\
\hline Noniga $a^{32}$ & 2 & 2 & 2 & - & * & - & - & 5 & - & - & 3 & 4 & 2 & 3 & * & 5 & 28 & Prolapsed disc & Posilive \\
\hline White & 1 & - & . & - & - & 8 & - & 5 & $\$$ & - & - & 2 & - & 3 & - & - & 24 & Chronic low back pain & Negativo \\
\hline
\end{tabular}

a See appendix for details of criteria

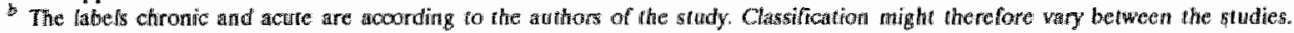

- Conclusion of the authors(s) of the study. Positive condusion-cxercise better thath control treatment; negalive condusionsexercise worse than or equally effectwe as control treatment.

Only four trials scored 50 or more points, indicating that the methods of most studies were poor. The main shortcomings were: lack of description of drop outs, considerable loss to follow-up, small samples sizes, use of cointerventions with exercise therapy, no placebo control group, lack of blinding of patients, and no intention to treat analysis.

Figure 1 presents the relation between the methods score and the overall conclusion (positive or negative) of the studies. Included are 6 positive studies and 10 negative studies. Only $4(40 \%)$ of the 10 negative studies scored 43 points or more, while 4 $(67 \%)$ of the 6 positive studies scored 42 points or more. In general the positive studies seemed to have higher methods scores.

It is difficult to draw conclusions about the efficacy of exercise therapy because some studies compare exercise therapy, with another conservative treatment or with a placebo therapy, or both, whereas other studies compare different types of exercise, tables 3-5 give more specific information on the interventions and the study results. 


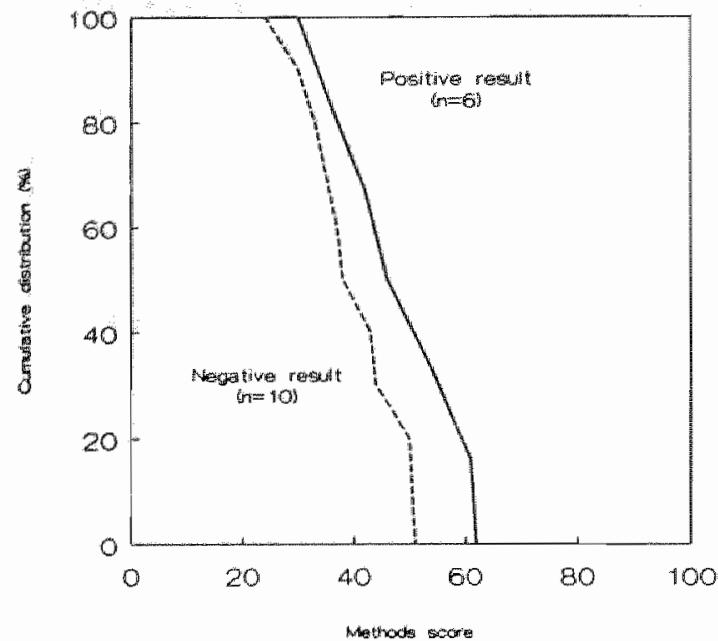

Higure 1. Relation between methods score of trials and and their results. (Positive resull shows exercise is better than reference treatment, negative result shows exercise to no betler or worse than reference tratment?.

Table 3. Comparison of exercise the rapy with other conservalive treantonen modalities.

\begin{tabular}{|c|c|c|c|}
\hline Aulthor & $\begin{array}{l}\text { Dxercise regimen } \\
\text { (no of pathents) }\end{array}$ & $\begin{array}{l}\text { Heference treatment } \\
\text { (no of patientis) }\end{array}$ & $\begin{array}{l}\text { Methodis } \\
\text { score }\end{array}$ \\
\hline
\end{tabular}

\begin{tabular}{|c|c|c|c|c|c|c|}
\hline $\begin{array}{l}\text { Lidstrón, } \\
\text { Zachurissont" }\end{array}$ & (i) & $\begin{array}{l}\text { Isometrib strengthening and } \\
\text { pelvic traction (20) } \\
\text { Motbilinging/strengthening } \\
\text { hot packs and massage (21) }\end{array}$ & (bii) & Hot packs and rest (21) & 46 & 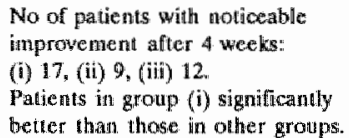 \\
\hline $\begin{array}{l}\text { Zylbergoldin } \\
\text { Pipers }\end{array}$ & $\begin{array}{l}\text { (i) } \\
\text { (ii) }\end{array}$ & $\begin{array}{l}\text { Flexion and heat }(10) \\
\text { Hotate cate instractions }(10)\end{array}$ & (ilii) & Manual therepy and heat $(8)$ & 4.4 & $\begin{array}{l}\text { Mean (SD) change in pain } \\
\text { intersity on } 5 \text { points scale after } 1 \\
\text { month: (i) }-1.0(0.85) \text {, (ii) }-1.5 \\
(0.10) \text {, (iii) - } 0.6(0.82) \text {. }\end{array}$ \\
\hline $\begin{array}{l}\text { Waterworth, } \\
\text { Huntertio }\end{array}$ & (i) & 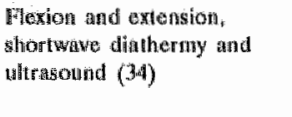 & (ii) & $\begin{array}{l}\text { Mon-usoroidal arti-inflam- } \\
\text { matowy druge }(36) \\
\text { Manpulatian }(38)\end{array}$ & 43 & $\begin{array}{l}\text { Matu change in pain intentity } \\
\text { on } 4 \text { points scale after } 4 \text { and } 12 \\
\text { days: (i) } 0.9,-1.6 \text { (ii) }-0.9,-1.7 \\
\text { (iti) }-1.1,-1.7 \text {. }\end{array}$ \\
\hline $\begin{array}{l}\text { Stankiowho, } \\
\text { Johmellit" }\end{array}$ & (1) & Mokenzilo (extension) (50) & (ii) & Mini back sachool (50) & 42 & $\begin{array}{l}\text { Significantly less pain in exercise } \\
\text { group with reference at } 3 \text { weeks } \\
\text { and a year (no data). }\end{array}$ \\
\hline $\mathrm{Nuwh}^{2 \mathrm{~g}}$ & (i) & 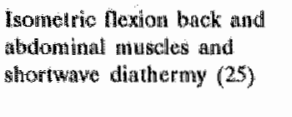 & (iii) & Manipulation (26) & 38 & $\begin{array}{l}\text { Improwement in spinal nexion and } \\
\text { straight leg ratsing: (i) } 39^{\circ}, 4^{\circ} \text {; } \\
\text { (ii) } 34^{\circ}, 39^{\circ} \text {, Manpulation } \\
\text { significantly better than exercise. }\end{array}$ \\
\hline $\begin{array}{l}\text { Torrell" } \\
\text { "Twoniey }\end{array}$ & (i) & $\begin{array}{l}\text { Isometric tlexion abdominal } \\
\text { muscles and microwave } \\
\text { distherny }(24)\end{array}$ & (ii) & $\begin{array}{l}\text { Mantipulation and } \\
\text { mobilisation }(24)\end{array}$ & 37 & $\begin{array}{l}\text { Manipulation group were } \\
\text { symptom free ins significantly less } \\
\text { days (data in graphs). }\end{array}$ \\
\hline Davies at al ${ }^{31}$ & (ii) & $\begin{array}{l}\text { Extension and shortwave } \\
\text { diantherny (1.4) } \\
\text { isontetric flexion and } \\
\text { ghor wave diathermy (14) }\end{array}$ & (iii) & Shorrwate diathermy (15) & 33 & $\begin{array}{l}\text { No of patients showing intprove- } \\
\text { ment after } 2 \text { and } 4 \text { weeks: } \\
\text { (i) } 11,13 ; \text { (ii) } 7,12 ; \text { (iii) } 8,10 \text {. } \\
\text { No significant difference. }\end{array}$ \\
\hline
\end{tabular}

A Results of the ntost important outcome measture acoonding to the athor(s) of the study at igsue. When not explicitely stated presentation of pain or a global measure of improvenen. 
Table 3 shows the 7 trials that contrasted exercise therapy with other conservative treatments. Two studies found that exercise therapy was better than hot packs and rest, or minil back school (that is - one session of 45 minutes with instructions and education). ${ }^{27}$ In the last study the difference between the two groups was stilli present one year after randomisation. The five other studies indicated that exercise therapy was not better than manual therapy or home care instructions, non-steroidal antiinflammatory drugs, ${ }^{26}$ manipulation, ${ }^{28}$ manipuiation and mobilization ${ }^{29}$ or short wave diathermy. ${ }^{31}$ These studies included patients with either acute or chronic back pain. However, three "negative" studies had a low methods score (< 40 points).

Table 4 gives details on 4 trials that contrasted exercise therapy with no exercise therapy or placebo therapy. The studies that compared with no exercise therapy used factorial designs; 22425 the other comparisons included in the factorial designs will not be discussed. The study with the highest methodological score ${ }^{22}$ showed that exercise therapy was better than no exercise therapy for chronic low back pain. After three months follow-up the benefit had disappeared. Two other studies with high methods scores found no positive effect for patients with acute low back pain ${ }^{24}$ and patients with sciatic symptoms. 25 The only study comparing exercise therapy with placebo therapy (detuned ultrasound and detuned short wave diathermy) indicated no differences in effect. 5

Table 4. Comparison of exercise therapy to no exercise therapy (in factorial designs) or with placebo therapy.

$\begin{array}{llll}\text { Author } & \text { Exercise regimen } & \text { Refere atce treatment } & \text { Methods Results } \\ & \text { (no of patients) } & \text { (no of paticnts) } & \text { soore }\end{array}$

\begin{tabular}{|c|c|c|c|c|c|c|}
\hline Deyo et $\mathrm{al}^{22}$ & (ii) & $\begin{array}{l}\text { Stretching exercises and } \\
\text { transcutaneous electrial } \\
\text { nerve stimulation ( } 34) \\
\text { Stretching exercises and sham } \\
\text { transcutaneous electrial } \\
\text { nerve stimulation (29) }\end{array}$ & (iv) & $\begin{array}{l}\text { Transcutaneous electrial } \\
\text { nerve stimulation (31) } \\
\text { Sham Iranscutaneious } \\
\text { eflectrial merve stimulation } \\
\text { (31) }\end{array}$ & 61 & $\begin{array}{l}\text { Mean improvement on visual } \\
\text { analogue seale for pain and } \\
\text { activity (0-100\%) after } 4 \text { and } 12 \\
\text { weeks: (exercises: i and ii) } 52 \%, \\
48 \% \text {; (reference fil and iv) } 37 \% \\
41 \% \text {. Exercise giknifficantly better. }\end{array}$ \\
\hline Evans et a ${ }^{24}$ & (ii) & $\begin{array}{l}\text { Isometric flexion, education } \\
\text { and bedrest }(65) \\
\text { Isometric fexion and } \\
\text { educathon }(62)\end{array}$ & $\begin{array}{l}\text { (iii) } \\
\text { (ivi) }\end{array}$ & $\begin{array}{l}\text { Bedrest }(60) \\
\text { No intervention }(65)\end{array}$ & 50 & 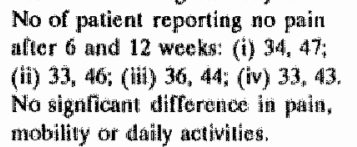 \\
\hline Cothead el a ${ }^{25}$ & (i) & $\begin{array}{l}\text { Exercises using all ranges } \\
\text { of motion and nuscle groups } \\
\text { given alone or witl tration, } \\
\text { manipulation, or corset ( } 150 \text { ) }\end{array}$ & (ii) & $\begin{array}{l}\text { No intervention, tractionil, } \\
\text { manipulation, or corsel } \\
\text { (142) }\end{array}$ & 50 & 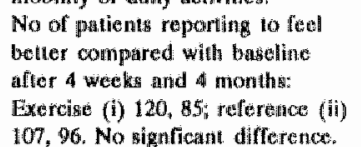 \\
\hline Martin et al ${ }^{6}$ & (i) & $\begin{array}{l}\text { Mobilising abdominal and } \\
\text { back nuscles (12) } \\
\text { Isomatric abdominal and } \\
\text { pelvic floor muscles (12) }\end{array}$ & (iii) & $\begin{array}{l}\text { Detuned uturasound and } \\
\text { and detumed shortwave } \\
\text { diathermy }(12)\end{array}$ & 35 & 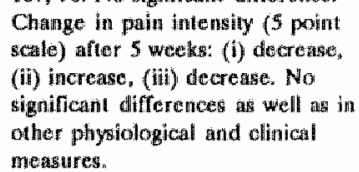 \\
\hline
\end{tabular}

2 Results of the most important outcome measuire according to the author(s) of the study. When not explicitely staled presemiation of pain or a global measure of improwement.

Table 5 shows the 8 trials which compared different types of exercise therapy. The comparisons were mainly between isometric flexion exercises and extension exercises. Four studies reported no differences between the exercise regimens, but these had 
major flaws in the design ( $\leq 35$ points). 313234 In 4 other studies the results favoured one type of exercise therapy over other types. ${ }^{43} 3033$ In the study with the highest score ${ }^{23}$ the results favoured an exercise scheme of three months intensive dynamic back extensor exercises over a similar treatment at one fifth of the exercise intensity and mild isometric training, massage, and heat for patients with chronic low back pain. One other study found on an extension programme to be better than a flexion programme, ${ }^{33}$ but two studies suggested that a flexion programme was better. Lidstrom and Zachrisson reported that isometric flexion exercises in combination with pelvic traction were more effective than mobilising and isotonic strengthening exercises in combination with massage and heat, ${ }^{4}$ and Kendall and Jenkins showed that flexion was more effective than both mobilising exercises and extension exercises. ${ }^{30}$

Table 5. Cumparison of different exencive regimens.

Author Exarcise regintens

(No of patients)
Methods Riesulutsis

score
Mamniche ef al ${ }^{23}$ (i) Intengive back extenser (27)

(ii) Mild esometric and mascage and hot compress (32)

(iii) mild back extensor (31)

\begin{tabular}{|c|c|c|}
\hline Lidstrôn. & (i) & Isometric flexion and petvic iraction (20) \\
\hline Zanchrisson" & (ii) & $\begin{array}{l}\text { Mobilising } / \text { streng ghening, hot packs and } \\
\text { massage (21) }\end{array}$ \\
\hline Kandall, & (i) & Isometric Mexion (14) \\
\hline \multirow[t]{2}{*}{ Jenkirus ${ }^{391}$} & (ii) & Mobilising (14) \\
\hline & (iii) & Extension (14) \\
\hline \multirow[t]{2}{*}{ Marlin el xil ${ }^{6}$} & (i) & $\begin{array}{l}\text { Isometric abdiominal and pelvic floor } \\
\text { nuscles (12) }\end{array}$ \\
\hline & (ii) & Mobilizing abdominal and back muscles (12) \\
\hline \multirow[t]{2}{*}{ Davies ict al $\mathrm{a}^{31}$} & (i) & $\begin{array}{l}\text { Isometric fiexion and shortwave diatherny } \\
\text { (14) }\end{array}$ \\
\hline & (ii) & Extienision and ghortwave diathermy (14) \\
\hline \multirow[t]{2}{*}{ Duswe:12 ${ }^{32}$} & (i) & Mlexion prograninc $(25)$ \\
\hline & (iii) & Dxtension progranme (25) \\
\hline \multirow[t]{2}{*}{ Nwiga, Nwuga ${ }^{33}$} & (i) & Makenzino (extension) (31) \\
\hline & (ii) & Willinms (t)exion) (31) \\
\hline \multirow[t]{2}{*}{ Wituite } & (i) & $\begin{array}{l}\text { Mild static trunk and shoriwawe } \\
\text { dilint inermy }(76)\end{array}$ \\
\hline & (ii) & Vigorous nexion an axlension (72) \\
\hline
\end{tabular}

Improwement (median and 10th90th centile) in combined pain, dissabillity, physical impairment index (0-100 points) after 3 and 9 months: (i) 147 $(-3.2 / 29.4), 150(-8.4 / 31.4)$; (ii) $2.0(-11.7 / 19.5), 5.5$ $(-12.8 / 19.5)$; (iii) $5.7(-4.4 / 23.7), 7.0(-11.0 / 21.5)$. Intensive back extensor exercises (i) significantly better.

46 No of patients with noticeable improvement after 4 week: (i) 17 ; (iii) 9 . Isometric flexion (i) significantly better than (ii), but not significant. 36 No of patients symptoms free or improved after 1 and 3 months: (i) 13,11 : (ii) 11,8 ; (iii) 7,6 . Isometric flexion significantly better. Change in pain rating ( 5 points scale) after 5 weeks: (no exact figures given) (i) deterioration (ii) improvenuent. No significant differences: in physiological and clinical measures.

No of patients improved after 2 and 4 weeks: (i) 7,12 ; (ii) 11, 13. No signifucant difference.

Similar umprovement in pain and function after treatiment for both groups (duration and cxact (igures not given) Change in 10 points pain rating after 6 weeks: (i) -5.3 (ii) -2.7 . Mckenzie cextension significantly better.

Proportion of paltien ts showing inprowement after treatment (maximal 7 weeks): (i) $38 \%$ :(ii) $35 \%$. No siggificant difference.

a Results of the most important outcone measure according to the athith(s) of thie study. When not explicitely stated pressentation of pain or a global meas une of improventeat.

\section{Discussion}

The 16 trials included in our review can be considered to be the best studies evaluating the efficacy of physiotherapy exercises for back pain. Because of their use of control treatments and random allocation of the patients their potential to supply valid answers on this topic is much larger than that of uncontrolled or non-randomised studies. 
Nevertheless, we have found that most randomised clinical trials investigating the efficacy of physiotherapy exercises for back pain have major flaws in their methods. Our screening suggests that in the future more attention should be given to the size of the study populations, prevention of loss to follow-up (including an adequate description of the patients lost to follow-up), comparison with placebo therapy (to control for placebo effects and to avoid bias of effect measurements), and adequate data presentation and statistical analysis.

The reviewers who assessed the quality of the trials were blind to the outcome of the studies to prevent reviewer bias. This method has been described by Chalmers et al. and used to assess the quality of trials on other topics. ${ }^{35} 36$ The criteria chosen for assessing the methods of the studies were not intended to be exhaustive. By using these criteria, however, we believed (before as well as after assessment of the trials) that we could distinguish good studies from bad ones. We chose not to pool the results of the available trials, mainly because we dislike pooling data from studies of high and low methodological quality. The trials that reported negative results of exercises more often had relatively low methods scores. We did not pool the results of the trials with higher methods score because we thought that the patient characteristics and treatments used in these trials were not similar enough to permit pooling.

The weights that are given to the criteria listed in table 1 have been chosen arbitrarily. For example, we gave sample size a larger weight (17 points). The first argument for this was our concern for prognostic comparability at baseline. Because there is only limited knowledge of the aetiology in most cases of back pain and neck pain a major problem is to obtain a homogeneous study population. With increasing numbers of participants one can be more confident that the randomisation procedure will succeed in dividing the known and unknown prognostic factors equally over the study groups. We also thought that publication bias would be less likely with large sample sizes. The effort and costs entailed increase the probability that the trial will be submitted and accepted for publication. ${ }^{37}$ The description of an adequate randomisation procedure was given low weight ( 4 points) as all the studies included were randomised clinical trials and thus satisfied our demand of random allocation of the participants. Studies could, however, earn points with a proper description of an adequate randomisation procedure. Generally the weights were based on our assessment of the relative importance of each criterion. Readers may wish to choose different weights for specific criterion and calculate their own scores.

We conclude that the quality of intervention research on physiotherapy exercises is disappointingly low. Despite its frequent application, exercise therapy has not been shown to be more efficacious than other conservative treatment modalities, nor has it been shown to be ineffective. There is little evidence in favour of a specific exercise regimen. Further trials are clearly needed in which much more attention is given to the methods of the studies. 
1. Kelsey IL, White AA Epidemiology and impack of low-back pain. Spine 1980; 5: 133-142.

2. Irymoyer JW. Back pain and sciatica, $N$ Engl J Med 1988; 318: $291-300$.

3. Spitzer WO, Leblane FE, Dupuis M.(eds). Scientific approach to the assessment and management of activily-related spinal disorders. Spine $1987: 12$ (suppl 7): $1-59$.

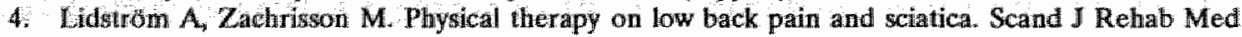
$1970 ; 2: 3742$.

5. Zylbergold RS, Piper MC. Lumbar disc disease: comparative analysis of physical therapy treatments. Arch Phys Med Rehab 1981; 62: 176-179.

6. Martin PR, Rose MJ, Nichois PJR, Russell PL, Hughes JG. Physiotherapy exercises for low back pain: process and clinical outcome, In Rehabil Med $1980 ; 8 ; 34-38$.

7. Nachemson A. A critical look at the treatment for low back pain. Scand J Rehabil Med 1979; 11: $143-147$.

8. Deyo RA. Conservative therapy for low back pain. JAMA 1983; 250: 1057-62.

9. Jackson CP. Brown MD. Is there a role for exercise in the treatment of patients with low back pain? Clin Oruhop 1983; 179: 39-45.

10. Jackson CP, Brown MD. Analysis of current approaches and a practical guide to prescription of exercise. Clin Orthop 1983; 179: 46-54.

11. Goldie I, Landquist A. Evaluation of the effects of different forms of physiotherapy in cervical pain. Scand J Rehab Med 1970; 2-3: 117-121.

12. Meinert CL. Clinical trials: design, conduct and analysis. New York: Oxford University Press, 1986.

13. Feinstein AR. Clinical epidemiology: the architecture of clinical research. Philadelphia: W.B. Saunders, 1985.

14. Riet $G$ ter, Kuleijnen $J$, Knipschild $P$. Acupuncture and chronic pain: a criteria-based meta-analysis. $J$ Clin Eppidemiol 1990; 43: 1191-1199.

15. Macdonald RS, Bell CMJ. An open controlled assessment of osteopathic manipulation in nonspecific low back pain. Spine 1990; 15: 364-370.

16. Klaber-Moffett JA, Clase SM, Portek I, Ennis JR. A controlled prospective study to evaluate the effectiveness of a back school in the relief of chronic low back pain. Spine 1986; 11: 120-122.

17. Landen BR. Heat or cold in the relief of low back pain. Phys Ther 1967; 47: 1126-1128.

18. Harkapa $\mathrm{K}$, Jarvikoski A, Mellin $\mathrm{G}$, Hurri $\mathrm{H}$. A controlled study on the outcome of inpatient and outpatient treatment of low back pain. Part 1: pain, disability, compliance, and reported treatment benefit. Scand J Rehab Med 1989; 21: 81-89.

19. Mellin $G$, Hurri H, Harkaapa $K$, Jarvikoski A. A controlled study on the outcome of inpatient and outpatient treatment of low back pain. Part 2: effects on physical measurentents three months after treatment. Scand J Rehab Med 1989; 21: $91-95$.

20. Meade TW, Dyer S, Browne W, Townsend J Frank OA. Low back pain of mechanical origin: randomised comparison of chiropractic and hospital outpatient treatment. Br Med I 1990; 300: $1431-1.436$.

21. Gilbert JR, Taylor DW, Hildebrand A Evans C. Clinical trial of common treatments for low back pain in family practice. Br Med J 1985; 291: 791-794.

22. Deyo RA, Walsh NE, Martin DC, Schoenfeld LS, Ramamurthy S. A controlled trial of transcutaneous electrical nerve stimulation (TENS) and exercise for chronic low back pain. $\mathrm{N}$ Engl Med 1990; 322: 1627-1634.

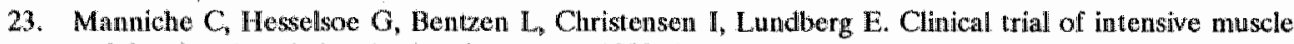
training for chronic low back pain. Lancet 1988; 2: 1473-1476.

24. Evans C, Gibert JR, Taylor DW, Hildebrand A. A randomized controlled trial of flexion exercises, education, and bed rest for patients with acute low back pain. Physiotherapy Canada 1987; 39: 96101.

25. Coxhead CE, Insikip H, Meade TW, North WRS, Troup JDG. Multicentre trial of physiotherapy in the managenent of sciatic symptoms. Lancet 1981; 1: 1065-1068.

26. Waterworth RF, Hunter LA. An open study of diffunisal, conservative and manipulative therapy in the management of acute mechanical low back pain. NZ Med J 1985; 95: 372-375.

27. Stankovic $R$, Johnell $O$. Conservative treatment of acute low back pain: a prospective randomized trial. Spine 1990; 15: 120-123. 
28. Nwuga VCB. Relative therapeutic efficacy of wertebral manipulation and oonventional treatment in back pain management. Am J Phys Med 1982; 61: 273-278.

29. Farrell JP, Twomey LT. Acute low back pain: comparison of two conservative treatment approaches. Med I Aust 1982; 1: 160-164.

30. Kendall PH, Jenkins JM. Exercises for backache: a double-blind controlled trial. Physiotherapy 1968; 54: 154-157.

31. Davies JR, Gibson T, Tester $L$. The value of exercises in the treatment of low back pain. Rheumatol Rehabil 1979; 18: 243-247.

32. Buswell J. Low back pain: a comparison of two treatment programmes. NZ J Physiotherapy 1982 ; 10: 13-17.

33. Nwuga G, Nwuga $V$. Relative therapeutic efficacy of the Williams and MoKenzie protocols in back pain management. Physiotherapy Practice 1985; 1: 99-105.

34. White AWM. Low back pain in men receiving workmen's compensation. Can Med Ass J 1966; 95; $50-56$.

35. Chalmers TC, Smith H, Blackburn B, et all. A method for assessing the quality of a randomized controll trial. Controlled Clinical Trials $1981 ; 2: 31-49$.

36. Tysen $J$, Furzan $J$, Reisch $J$, et al. An evaluation of the quality of therapeutic trials in perinatal medicine. J Pediatr 1983; 102: 10-13.

37. Kleijnen J, Knipschild P, Ter Riet G. Clinical trials of homoeopathy. Br Med J 1991; 302: 316 -323. 


\section{Appenditix}

Scoring for criteria listed in table 1. Each criterion must be applied independently of the other criteria.

A Description of inclusion atd exclusion criteria (1 point). Restriction to a homogemeows study population (1 point).

B) Comparability for duration of complaints, value of outcome measures, age, recurrences and radiating complaints ( 1 point each).

C Randomisation procedure described (2 points). Randomisation procedure which excludes bias $(2$ points).

D Information from which group subjects dropped out from with reason for withdrawal (3 points).

IE Loss to follow-up: all randomised patients minus the number of patients still in study at main point of assessing the main outcome measure (according to the author(s)), divided by all randomised patients multiplied by 100 .

I Size of smallest group immediately after randomisation.

G Physiotherapy treatment explicitly described (5 points). All reference treatments explicitly described (5 points).

H Comparison with other treatment.

I Other medical interventions are avoided in the design of the study (except analgesics, or use at home of heat, rest, or a routine exercise scheme).

I Comparison with placebo therapy.

K Placebo controlled study: attempted blinding ( 3 points), blinding ovaluated and fully successful (2 points).

Pragmatic study: patients fully naive (3 points), or time restriction (no physiotherapy exercises in at least one year) (2 points), naiveness evaluated and fully successful ( 2 points).

L Outcome measures assessed and reported: pain, global measure of improvement, functional status (activities of daily living), spinal mobility, use of medication and medical services ( 2 points each).

$M$ Each blinded measurement mentioned under criterion $L$ earns 2 points,

$\mathrm{N}$ Outcome measuremes assessed during or just after treatment ( 3 poimts). Outcome measures assessed after 6 months or longer ( 2 points).

O Intention to treat analysis. When loss to follow-up is less than $10 \%$ analysis of data on all randomised patients for main outcome measures and at the most important times of measurenent minus missing walues (irrespective of non-compliance and cointerventions). When loss to follow" up $>10 \%$ analysis on intention to treat basis as well as a worst case analysis that accounts for missing values.

P Frequency of main outcome measures at the most important times of measurement.. In the case of (semi) continuous variables presentation of the mean or median with a standard error or per centiles. 
Chapter 4

THE EFFECTIVENESS OF MANUAL THERAPY, PHYSIOTHERAPY AND CONTINUED TREATMENT BY THE GENERAL PRACTITIONER FOR CHRONIC NON-SPECIFIC BACK AND NECK COMPLAINTS

Design of a randomized clinical trial*

BW Koes, LM Bouter, PG Knipschild, H van Mameren, A Essers, JP Houben, GMJR Verstegen, DM Hofhuizen 


\section{Abstract}

There are strong arguments for publishing research protocols before the results are available. Firstly, it permits a critical judgement of the design unbiased by knowledge of the results, and secondly it may prevent publication bias. We present the design of a randomized trial on the effectiveness of manual therapy, physiotherapy, (continued) treatment by the general practitioner and a placebo treatment for patients $(n=300)$ with chronic (more than six weeks) non-specific back and neck complaints. In designing this trial in close cooperation with manual therapists and physiotherapists, special attention has been given to inclusion and exclusion criteria, (blinded) outcome measurements and control (placebo) treatment(s). Outcome measures are severity of complaints rated by a blinded research assistant, global perceived effect assessed by the patient, pain severity, functional status, range of motion (ROM) of the spine and recurrence. Measurements are carried out at baseline and after 3 weeks, 6 weeks, 3 months, 6 months and 1 year. 


\section{Introduction}

There are strong arguments and advantages in publishing the design of a study before the results are available.

Firstly, it may permit critical assessment of the methods independently of the outcome. Secondly, it may prevent publication bias which refers to the situation that only a part of the studies which have been carried out are actually published, while the unpublished studies show different results than the published ones. A third reason for presenting this protocol is our experience that the design of a randomized clinical trial for treatments such as physiotherapy and mamual therapy is more complex and subject to more methodological problems than the classical (drug) clinical trial. Therefore, special attention will be given in this article to the inclusion and exclusion criteria, (blinded) outcome measurements and the choice of control (placebo) treatment(s).

Back and neck complaints occur frequently in western countries. It is estimated that some $80 \%$ of all people experience back problems during their active life. ${ }^{23} \mathrm{Neck}$ problems are less frequently reported, but are a major health problem as well. In most cases no underlying pathology can be established and thus the causes of the complaints remain unknown. ${ }^{4} 5$ The majority of patients with acute low back pain recover within a few weeks, often with the help of (bed)rest, analgesics and advice about posture and exercises. ${ }^{6}$ Within a few months the complaints disappear in about $90 \%$ of the cases. ${ }^{578}$ The course of the back complaints is often recurrent. After an occupationally related episode of low back pain, 60 percent of the patients experience recurrent symptoms within a year. ${ }^{5}$ When the complaints do not disappear, patients will often be referred to a physiotherapist for treatment with massage, exercises and physical therapy modalities (heat, electrotherapy, ultrasound, shortwave diathermy, etc.). Other patients are referred to a manual therapist for manipulative treatment. Despite the widespread use of physiotherapy for back and neck complaints, its effectiveness has been rarely investigated in adequate randomized clinical trials. ${ }^{8}$ There have been a number of trials investigating the effectiveness of manipulation and mobilization of the spine for back and neck complaints. ${ }^{9}$ The interpretation of the results of these studies is often difficult for methodological reasons. Common problems are the small size of the study population, the large variation in criteria for selecting patients, the wide range of manipulative techniques, and the frequent absence of blinded outcome measurements. ${ }^{10} 111213$

In this article we present the design of a study which intends to meet these shortcomings and focuses on the comparison of the effectiveness of manual therapy, physiotherapy and treatment by the general practitioner for patients with chronic nonspecific back and neck complaints. This comparison can be regarded as a 'pragmatic' one, where three relevant treatment regimens are compared. In addition to this, by including a placebo treatment we try to separate the specific and the non-specific effects of a referral to a physiotherapist.

\section{Selection of patients}

Patients $(n=300)$ with pain or self-reported limited range of motion in back or neck are being selected actively by general practitioners $(n=40)$ participating in the study. In addition to this, repeated advertisements in the local press will inform patients about the possibility to participate in the study. Patients do not receive any incentives other 
than the treatment and evaluation of their complaints. Patients showing interest are referred to their general practitioner to check the admission criteria. Subsequently, an appointment is made with the research assistant (one of the authors, A.E.), who also is an experienced physiotherapist and manual therapist. He performs a physical examination and carries out a second check with respect to the selection criteria. The purpose of these criteria is to select a (relatively homogeneous) group of patients suitable for physiotherapy, manual therapy or continued treatment by the genera] practitioner. Patients have to meet the following criteria:

- Complaints are non-specific. This means that no underlying pathology can be been established (e.g. malignity, osteoporosis, herniated disc).

- Duration of the complaints is six weeks or longer.

- No physiotherapy or manual therapy for the back and neck complaints has been received during the previous two years.

- Complaints can be reproduced by active or passive physical examination.

The selection of patients started in march 1988.

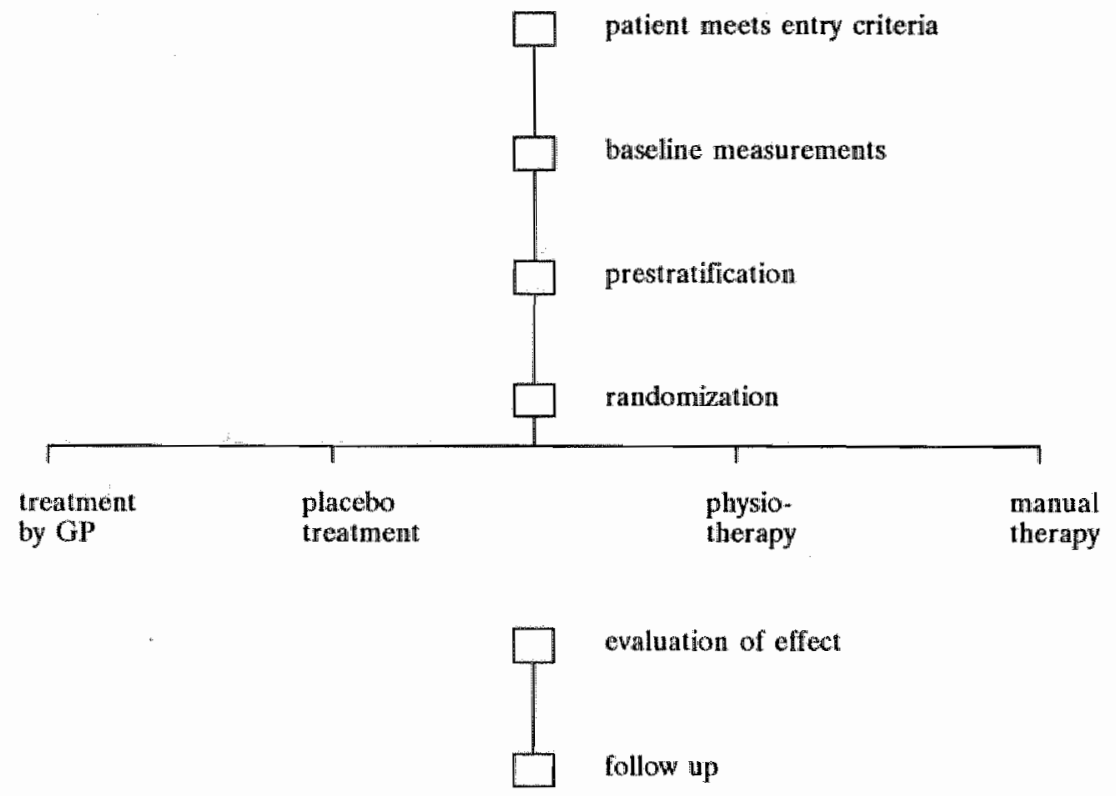

Figure 1. Study design

\section{Study design}

Figure I shows the study design. When a patient meets the selection criteria and is willing to participate, the informed consent procedure will be completed. The patient signs a letter explaining all relevant information about the study including the $25 \%$ chance for receiving placebo treatment. The outcome of the anamnesis and physical examination will be recorded, and the patient fills out certain questionnaires to 
complete the baseline measurements. After that, randomization per stratum takes place using a list of random numbers. Prestratification by age (younger than 40 years, 40 years and older) and localization of the complaints (back, neck) is carried out to prevent unequal distributions by chance for these prognostic factors between the treatment groups. ${ }^{14}$ Thus, prestratification is used as a technique to "help" the randomization procedure in forming comparable groups at baseline. Depending on the outcome of the randomization the patient goes (back) to his general practitioner, to a physiotherapist or to a manual therapist.

\section{Study treatments}

In the study four treatments are included:

1. Manual therapy: manipulative techniques (manipulation and mobilisation) according to the directives of the Dutch Society for Manual Therapy (NVMT).

2. Physiotherapy: exercises, massage and physical therapy modalities (e.g. heat, electrotherapy, ultrasound, shortwave diathermy).

Both the manual therapists and the physiotherapists participating in the study were selected by their professional organizations (NVMT and the Royal Dutch Society for Physiotherapy (KNGF)). In contrast with the manual therapists, the physiotherapists chosen did not had any training in manipulative techniques.

3. Treatment by the general practitioner: medication, advice about posture, exercises, participation in sports, (bed)rest etc.

4. Placebo treatment: physical examination and subsequently detuned shortwave diatluermy ( 10 minutes) and detuned ultrasound (10 minutes) carried out by a physiotherapist. The treatment sessions have a frequency of two times a week for a period of six weeks.

The comparison of the first three treatments refers to the question which of these alternatives treatment regimens for chronic back and neck complaints gives the best results. The physiotherapists, manual therapist and GPs are free to choose from their usual therapeutic domain, within explicitly formulated limits (e.g. no manipulations will be given by physiotherapists). All treatments are given for a maximum of three months. After six weeks the patients return to their general practitioner with a written report from the manual therapist or physiotherapist (physiotherapy and placebo therapy) in order to discuss the results and to decide whether to continue, change or stop the treatment. Patients who are assigned to the GP group, have the same possibility after six weeks. The therapists and GPs register the content, frequency and duration of the therapy that they give to the patients, so that an empirical description of the interventions can be made retrospectively.

\section{Outcome measures}

In our opinion the most important outcome measures are those which have the most relevance for the patient. Besides indices for the global effect of treatment, measures recording severity of complaints, pain and functional status have been selected. ${ }^{15} 16$ In addition, range of motion, physical functioning, satisfaction and recurrence are measured. Figure II shows in the measures of effect in a hierarchical order. This means that severity of complaints, global perceived effect, severity of pain and physical 
dysfunctioning are considered to be the primary outcome measures. Other outcome ineasures (for example ROM) are considered to be secondary outcome measures.

1. sererity of complatints

2. giclotall perceived effect severily of pantin physical dysfunctioning

3. plysical functionimg

4. range of motion assessment by blinded ressearch wssistant assessment by the patient subscale of the West Haven Yalle Multidimensionall Pain Inventory subscale of the Sickness Impact Profile (SIP) standardised physical examination inclinometer (EDI 320 - CYBEX) X-ray cinematography (cervical spine only)

pllysical examination and questionnaire

Figure 2, Outcome measures and ingtruments

Severity of the complaints is measured by the research assistant on a ten-point scale (1. = minimal severity, $10=$ maximal severity). During all follow-up measurements the research assistant will be unaware (blind) of the treatment to which the patients are assigned. At the baseline the patient presents his main complaints which is noted by the research assistant, who also gives a score for the severity of the complaint. This score of the severity is based on an anamnesis and a physical examination which consists of a protocol of active and passive movements. At follow-up the severity of their main complaints will be assessed again. The groups will be compared for their mean improvement in severity score. Reliability of this clinometric index has not been established yet, though by using a single research assistant for all measurements we eliminate inter-observer variation.

Instrument

$\begin{array}{llllll}\text { Base- } & 3 & 6 & 3 & 6 & 1 \\ \text { line } & \text { wks }^{\mathrm{a}} & \text { wks } & \text { miths } & \text { mths } & \mathrm{yr}\end{array}$

Information from $\mathrm{GP}^{\circ}$

Anamnesis

Severity of complaints

Gilobal perceived effect

Range of motion, physical functioning

$X$-rity cinenatograply

Pain (WHYMPI)

Functional status (SIP)

Psychologic status (HSCL)

Compliance, satisfaction

Follow-up

Information from therapist

\begin{tabular}{ll}
$\mathrm{X}$ & \\
$\mathrm{X}$ & \\
$\mathrm{X}$ & $\mathrm{X}$ \\
& $\mathrm{X}$ \\
$\mathrm{X}$ & $\mathrm{X}$ \\
$\mathrm{X}$ & $\mathrm{X}$ \\
$\mathrm{X}$ & $\mathrm{X}$ \\
$\mathrm{X}$ & $\mathrm{X}$ \\
& $\mathrm{X}$ \\
$\mathrm{X}$ & $\mathrm{X}$ \\
\hline
\end{tabular}

a whks $=$ weeks, mths $=$ months, yi $=$ year

b only when treatment has not been terminated after 6 weeks

Figure 3. Schedule of data collection. $\mathrm{x}$

$\begin{array}{llll}\mathrm{X} & \mathrm{X} & \mathrm{X} & \mathrm{X} \\ \mathrm{X} & \mathrm{X} & \mathrm{X} & \mathrm{X} \\ \mathrm{X} & \mathrm{X} & \mathrm{X} & \mathrm{X} \\ & \mathrm{X} & & \\ \mathrm{X} & \mathrm{X} & \mathrm{X} & \mathrm{X} \\ \mathrm{X} & \mathrm{X} & \mathrm{X} & \mathrm{X} \\ & \mathrm{X} & & \\ \mathrm{X} & \mathrm{X} & \mathrm{X} & \mathrm{X} \\ & & \mathrm{X} & \mathrm{X}\end{array}$

$x^{b}$ 
Global perceived effect is measured by self-assessment on a six-point scale $(1=$ no benefit, $6=$ maximal benefit). Pain is measured with the subscalle pain severity of the West Haven-Yale Multidimensional Pain Inventory (WHYMPI) on a six-point scale ( 0 $=$ no severity, $6=$ maximal severity). Reliability of this instrument has previously been reported. ${ }^{16}$ Functional status is measured with the Sickness Impact Profile (SIP), a health status questionnaire which has been validated for the use in back pain trials. ${ }^{17}$ Recurrences are recorded by means of questionnaires to be completed by the patients. $\mathrm{X}$-ray cinematography (cervical spine only) is carried out by (blinded) assistants at the Department of Radiodiagnostics in the university hospital. Patients are blind with respect to the placebo treatment. Figure III shows the schedule of the data collection. The 3 weeks follow-up measurement is included to detect short term effects. The 6 weeks and 3 months follow-up are expected to provide the maximal benefit of the treatments included. The measurements at 6 months and 1 year follow-up are included to detect long term effects and recurrences of the complaints.

\section{Prognostic information}

Information on (other) prognostic variables is collected to assess whether the randomization has been successful and to make subgroup analyses feasible. The latter means that we will also perform an exploratory analysis of the effect of treatment for specific subgroups (e.g. localization and duration of the complaints, gender and age). The following prognostic information will be collected:

- History and current complaints (localization, severity etc.), demographic information, work and sport activities, to be obtained by the research assistant at baseline.

- Range of motion of the spine and measurements of the active and passive movements by physical examination.

- General health status as measured with the Hopkins Symptom Check List (HSCL). ${ }^{18}$

- Compliance and additional treatment measured by a written questionnaire.

- Treatment regimen, duration and frequency to be collected by the therapists and general practitioners.

\section{Data-management and statistical analysis}

A protocol for the data-analysis is written before any results are available. After collection the data are stored on a personal computer (dBase III plus software). Control is carried out for inconsistent combinations of answers and the range of possible values. Subsequently, the data will be further analysed with BMDP statistical software. ${ }^{19}$

Comparability of baseline characteristics between the four study groups will be assessed critically. For the outcome measures severity of the complaints, pain severity, functional status, ROM, and physical functioning, we will calculate the difference between the follow-up score and the baseline score for each individual patient. These scores can thus be regarded as indicators of improvement (or deterioration). Subsequently, the four study groups will be compared for their mean improvement scores. One-way analysis of variance (ANOVA) will be used to test for differences of the means. Group differences and 90 percent confidence intervals will be calculated ${ }^{20}$ Group differences and confidence intervals will also be calculated with the use of a linear regression model. The purpose of this model is to estimate group differences adjusted for (small) 
differences at the baseline for important progmostic factors. The distributions of the outcome measures among the four groups will also be presented graphically by cumulative distributions.

The statistical analysis will be carried out according to the 'intention-to-treat' principle. This means that all patients will remain in the group to which they were assigned by randomization. This includes drop-outs (as far as they participated in the effect measurements) and patients with low compliance. This principle is important to ensure that the comparability of the study groups (obtained by randomization) will remain adequate.

\section{Discussion}

There have been a number of trials on the effectiveness of manipulation and mobilization of the spine for back and neck complaints. However, these studies have been criticized for methodological reasons, as was already mentioned in the introduction. This study intends to meet these shortcomings.

Firstly, the selection criteria thave the purpose of recruiting a relatively homogenous group of patients who are suitable for manual therapy "physiotherapy and (continued) treatment by the general practitioner. Secondly, the manipulative techniques used are performed by qualified manual therapists who were selected by their professional organization. Thirdly, the outcome measures include the assessment by a blinded research assistant. Fourthly, the size of the study population seems to be sufficiently large to detect treatment differences which are clinically important. Furthermore, we believe it is crucial that physiotherapists and manual therapists are involved at all levels in the design and implementation of a trial like this.

After multiple consultations lasting for more than a year, the physiotherapists and manual therapists agreed fully with the research protocol. Especially the choice of an appropriate placebo treatment which should be trustworthy for patients and which should have no specific effects, needed careful consideration. Placebo manipulation, exercises or massage, although desirable, did not appear to be practically feasible. Therefore, our choice became simulated ultra sound and ultra short wave, as the next best solution. Consequently, the study will focus mainly on the pragmatic aspects of the problem at issue i.e. the comparison of physiotherapy, manual therapy and (continued) treatment by the general practitioner for chronic non-specific back and neck complaints. Patients who receive placebo treatment are expected to provide an estimation of the effect of referral to a physiotherapist plus the placebo effects of physiotherapy. 


\section{References}

1. Dickersin $\mathrm{K}$. The existence of publication bias and risk factors for its occurrence. JAMA 1990; 263 : 1385-1389.

2. Nachemson A. The Uumbar spine: An orthopaedic challenge. Spine 1976; 1: 59-71.

3. Kelsey JL, White AA. Epidemiology and impact of low-back pain. Spine 1980; 5: 133-142.

4. Nachemson A. Towards a better understanding of low back pain. Rheumatology and Rehabilitation 1975; 14: 129-143.

5. Frymoyer JW. Back pain and sciatica. N Engl J Med 1988; $318: 291-300$.

6. Nachemson A. A critical look at the treatment for low back pain. Scand J Rehabil Med 1979; 11: 143-147.

7. Deyo RA. Conservative therapy for low back pain. JAMA 1983; 250: 1057-1062.

8. Spitzer WO, Leblanc FE, Dupuis M. Scientific approach to the assessment and managenent of activity-related spinal disorders. Spine 1987; 7 (suppl) 1: 1-59.

9. Koes BW, Assendelft WII, Heijden wan der GJMG, Bouter LM, Knipschild PG. Spinal manipulation and mobilization for back and neck pain: a blinded review. Br Med J 1991; 303: 1298. 1303.

10. Brunarski DJ. Clinical trials of spinal manipulation: a criticall appraisal and review of the literature. J Manipulative Physiol Ther 1984; 7: 243-249.

11. Di Fabio RP. Clinical assessment of manipulation and mobilization of the lumbar spine - a critical review of the literature. Plyysical Therapy $1986 ; 66: 51-54$.

12. Greenland S, Reisbord LS, Haldeman S, Buerger AA. Controlled clinical trials of manipulation: a review and a proposal. J Occup Med 1980; 22: 670-676.

13. Assendelft WJI, Bouter LM, Kessels AGH. Effectiveness of chiropractic and physiotherapy in the treatment of low back pain: a critical discussion of the British randonized clinical trial. J Manipulative Physiol Ther 1991; 14: 281-286.

14. Pocock SJ. Clinical trials: a practical approach. Chicester: Wiley, 1983.

15. Bergner $M_{4}$ Bobbitt RA, Carter WB, Gilsen BS. The Sickness Impact Profile. Medicall Care 1981; 19: 787-805.

16. Kerns RD, Turk DC, Rudy TE. The West Haven-Yale Mulidimensional Pain Inventory (WHYMPI). Pain 1985; 23: 345-356.

17. Follick MJ, Smith TW, Ahern DK. The sickness impact profile: a global measure of disability in chronic low back pain. Pain 1985; 21: 67-76.

18. Derogatis LR, Lipman RS, Rickels K, Uhlenhuth EH, Covi L. 'The Hopkins Symptom Checklist, a self-report symptom inventory. Beh. Science 1974; 19: 1-151.

19. Dixon WJ, Brown MB, Engelman L, Hill MA. BMDP statistical software manual. Berkeley: University of California Press, 1988.

20. Gardner Mr. Allman DG. Statistics with confidence: confidence intervals and statistical guidelines. Belfast: The Universities press, 1990. 

Chapter 5

\section{THE EFFECTIVENESS OF MANUAL THERAPY, PHYSIOTHERAPY AND TREATMENT BY THE GENERAL PRACTITIONER FOR NON- SPECIFIC BACK AND NECK COMPLAINTS}

a randomized clinical trial*

BW Koes, LM Bouter, H van Mameren AHM Essers, GMJR Verstegen, DM Hofhuizen, JP Houben, PG Knipschild 


\section{Abstract}

In a randomized trial we compared the effectiveness of manual therapy, physiotherapy, (continued) treatment by the general practitioner (GP) and a placebo therapy (deturned ultrasound and detuned short wave diathermy) for patients $(n=256)$ with non-specific back and neck complaints (duration longer than six weeks). The principle outcome measures were severity of the main complaint, global perceived effect, pain and functional status. These are presented for 3,6 and 12 weeks follow-up. Both physiotherapy and manual therapy decreased the severity of complaints more and had a higher global perceived effect compared to (continued) treatment by the GP.

Differences in effectiveness between physiotherapy and manual therapy could not be shown. A substantial part of the effect of manual therapy and physiotherapy appeared to be due to non-specific (placebo) effects. 
Back and neck complaints occur frequently in western countries. It is estimated that some $80 \%$ of all people experience back problems during their active life ${ }^{1123} \mathrm{Neck}$ probllems are less frequently reported, but constitute a major health problem as well. In most cases no underlying pathology can be established and the causes of the complaints remain unknown. ${ }^{1122}$ The majority of patients with acute low back pain recover within a few weeks, often with the help of (bed)rest, analgesics and advice about posture and exercises. ${ }^{24}$ Within a few months the complaints disappear in about $90 \%$ of the cases. ${ }^{41} 252627$ When the complaints do not disappear, the general practitioner will often refer these patients to a physiotherapist for treatment with massage, exercises and physical therapy modalities (electrotherapy, ultrasound, short wave diathermy etc.). Other patients are referred to a manual therapist for manipulative treatment. Despite the widespread use of physiotherapy for back and neck complaints, its effectiveness has rarely been investigated in adequate randomized clinical trials. ${ }^{18}$ The effectiveness of manipulation and mobilization of the spine for back and neck complaints has been investigated in a number of trials. ${ }^{19}$ However, these studies often show methodological flaws. Common problems are the small size of the study population, the criteria for selecting patients, the operationalization of the manipulative techniques, and the absence of blinded outcome measurements. ${ }^{2} 61419$ We present a randomized clinical trial which tries to avoid these flaws and which focuses on the relative quantification of the effectiveness of manual therapy and physiotherapy for patients with non-specific back and neck complaints with a duration of at least 6 weeks.

\section{Methods}

\section{Selection of the subjects}

Potential subjects with pain or self-reported limited range of motion in back or neck region were selected by 40 general practitioners (GPs) during a two year period (January 1988 - December 1989). Due to a low admission rate of patients in the early stage of the trial we expanded the recruitment activities by repeated advertisements in the local press informing patients about the possibility of participating in the study. Patients showing interest were asked to contact their GP who checked the admission criteria. Subsequently, an appointment was made with the research assistant, who was also an experienced physiotherapist and manual therapist (one of the authors, A.E.). The research assistant performed a physical examination and did the final check with respect to the admission criteria. The purpose of these criteria was to select a (relatively) homogeneous group of patients suitable for treatment with both physiotherapy and manual therapy and also continued care by the general practitioner. Patients had to have been in pain or to have endured self-reported limited range of motion in back or neck for at least six weeks. Criteria for exclusion were suspicion of underlying pathology (e.g. malignity, osteoporosis, herniated disc). Candidates were also excluded if they had received physiotherapy or manual therapy for their back or neck complaints during the previous two years, were pregnant, were unable to speak and read Dutch, or if their complaints turned out to be not reproducible by active or passive movements during physical examination.

Patients completed the informed consent by signing a letter explaining all relevant information about the study, including the $25 \%$ chance of receiving a 'treatment which 
professionals expected to provide no effect'. The relevant variables in the history and physical examination were recorded, and the patient filled out a number of questioninaires (pain and functional status) to complete the baseline measurements. The study protocol was approved by the ethical committee of the University Hospital.

\section{Treatment assignment}

Randomization per stratum took place using a list of random numbers. Prestratification by localization of the complaints (back, neck), age (younger than 40 years, 40 years and older), and residence (four regions) was carried out to further prevent unequal distributjons between the treatment groups. Within each stratum the random assignment was performed within blocks of eight to ensure approximately equal numbers in the treatment groups. Depending of the outcome of the randomization the patient went (back) to their own general practitioner, to a physiotherapist (for physiotherapy or placebo therapy) or to a manual therapist.

All therapists (except the placebo therapists) were free to choose from their usual therapeutic domain within some explicitly formulated limits (e.g. no manipulative techniques were performed by the physiotherapists). All treatments were given for a maximum duration of three months.

1. Physiotherapy consisted of exercises, massage and physical therapy modalities. The majority of the patients in this group received exercises and massage (exercises and massage only $(10 \%)$, or in combination with heat $(44 \%)$, or in combination with electrotherapy $(12 \%)$, or in combination with heat and electrotherapy $(9 \%)$. A minority of the patients received exercises without massage only $(3 \%)$, or in combination with heat $(9 \%)$, or in combination with electrotherapy (5\%). Finally $5 \%$ of the patients received massage only, and $3 \%$ received massage in combination with heat.

2. Manual therapy consisted of manipulative techniques (manipulation and mobilisation of the spine) according to the directives of the Dutch Society for Manual Therapy (NVMT).

Both the manual therapists $(n=7)$ and the physiotherapists $(n=8)$ participating in the study were selected by their professional organizations (NVMT and the Royal Dutch Society for Physiotherapy (KNGF)).

3. Continued treatment by the general practitioner $(n=40)$ consisted of prescription of medication (analgesics, NSAIDs), advice about posture, home exercises, participation in sports, (bed)rest, etc..

4. Placebo treatment consisted of a physical examination and subsequently detuned short wave diathermy ( 10 minutes) and detuned ultrasound (10 minutes) carried out by a physiotherapist $(\mathrm{n}=8)$. These treatment sessions were scheduled at two times a week for a period of six weeks.

After six weeks the patients returned to their general practitioner with a written report from the manual therapist or physiotherapist in order to discuss the results and to decide whether to continue, change or stop the treatment. The therapists registered the content, frequency and duration of the therapy given to the patients.

Follow-up, outcome measures and blinding

Follow-up measurements (physical examination and questionnaires) were carried out at 3,6 and 12 weeks after randomization. The 3 weeks follow-up measurement was 
included to detect short term effects. The 6 and 12 weeks follow-up were expected to provide the maximal benefit of the treatments included.

The following measures of effect were chosen in sequence of importance:

(a) severity of complaints measured by the blinded research assistant on a 10-point scale $(1=$ minimal severity, $10=$ maximal severity $)$. The score of the severity was based on a anamnesis and a physical examination. This physical examination consisted of a protocol of active and passive movements. During all follow-up measurements the research assistant was unaware of the treatment to which the patients were assigned; (b) global perceived effect measured by self-assessment on a 6-point scale $(1=$ no benefit, $6=$ maximal benefit); (c) pain rating on the subscale pain severity of the West Haven-Yale Multidimensional Pain Inventory (WHYMPI) $(0=$ no severity, $6=$ maximal severity): ${ }^{17}$ (d) functional status measured with the Sickness Impact Profile (SIP). ${ }^{1}$

Spinal mobility and physical functioning were also measured. Furthermore, measurements at 6 months and 1 year follow-up were included to detect long term effects and recurrences of the complaints. These results will be presented separately. ${ }^{21}$

\section{Prognostic information}

Information on prognostic variables was mainly collected to assess whether the randomization has been successful. The following information was obtained: (a) history of current complaints (localization, duration, severity etc.) and demographic information; (b) range of motion of the spine and measurements of active and passive movements by physical examination; (c) general health status as measured with the Hopkins Symptom Check List (HSCL)(3); (d) compliance and additional treatment measured by a written questionnaire; (e) treatment regimen, duration and frequency recorded by the therapists and GPs.

\section{Statistical analysis}

A protocol for the data-analysis was written before the results were available. Comparability of baseline measurements between the four study groups was assessed critically. For severity of the complaint, pain and functional status we calculated the difference between the follow-up score and the baseline score for each individual patient. These scores can thus be regarded as indicators of improvement (or deterioration). The four study groups were compared for their mean improvement scores at 3,6 and 12 weeks of follow-up. Furthermore, cumulative distributions of the improvement scores of severity of the main complaint, and global perceived effect at 6 weeks follow-up were calculated.

One-way analysis of variance (ANOVA) was used for each outcome measure. Group differences and 90 percent confidence intervals were calculated for 6 weeks follow-up. In addition, we calculated group differences and confidence intervals using a linear regression model. The purpose of this model was to estimate group differences adjusted for (small) differences at the baseline for important prognostic indicators. Another reason was to enlarge the precision of the point estimates of the group differences. In this model we entered the following prognostic indicators: localisation and duration of the main complaint, the baseline score of the outcome measure at issue, age and recruitment status (general practitioner or advertisement).

We present one statistical analysis according to the 'intention-to-treat' principle. Thus, all patients remain in the group to which they were assigned by randomization. This 
includes drop-outs (as far as they participated in the effect measurements); patients witly low compliance, and patients who changed from the assigned therapy.

In addition to the intention-to-treat analysis we present an alternative analysis with the purpose of adjusting for missing values and patients who changed from the assigned therapy. In this analysis we substitute the outcomes at follow-up of patients who changed from the assigned therapy, with the score of the last measurement before changing. Similarly we substitute the last measurement for patients with missing values. The analyses were carried out with BMDP version 1988.

\section{Results}

\section{Study sample}

There were more than 1500 responses to the recruitment activities. Most people responded to the publicity in the local newspapers. The majority was not eligible for reasons such as not fulfilling the admission criteria, no persisting interest in participating, or the fact that their general practitioner did not participate in the study. In total 424 people were invited for an appointment with the research assistant to check their eligibility of which 168 people were excluded. The commonest reasons for exclusion were suspicion of prolapse of the disc $(n=43)$, complaints turning out to be not reproducible during physical examination $(\mathrm{n}=39)$, prior treatment (for present complaint) with physiotherapy or manual therapy within the previous two years $(n=24)$, and complaints being of less than 6 weeks duration $(n=19)$. Finally, 256 patients were enroled and randomly assigned to the study treatments: 65 to manual therapy, 66 to physiotherapy, 64 to the placebo therapy and 61 to the general practitioner.

Table 1. Cumulative number of drop-outs (and total number of missing values of the measurement by the blinded research assistant) at follow-up after 3,6 and 12 weeks.

\begin{tabular}{llll}
\hline Treatment & 3 wks & 6 wks & 12 wks \\
\hline Manual therapy & $1(4)$ & $1(11)$ & $3(8)$ \\
Physiotherapy & $2(10)$ & $4(11)$ & $5(12)$ \\
Placebo therapy & $5(14)$ & $6(13)$ & $8(16)$ \\
General practitioner & $4(14)$ & $6(17)$ & $7(20)$
\end{tabular}

After 12 weeks follow-up 23 patients $(9 \%)$ had dropped out. Table 1 shows the cumulative drop out rate for each group at the 3,6 and 12 weeks follow-up. The reasons given for dropping out were inconvenience and lack of time $(n=10)$, problems with the questionnaires $(n=3)$, complaints having disappeared $(n=2$; one in physiotherapy group, one in general practitioner group), no benefit of treatment $(n=2$; in general practitioner group), pregnancy $(n=1)$, and personal reasons or no reason given $(n=5)$. In addition, a number of people failed to attend the physical measurement by the research assistant (mainly because of lack of time). However, they usually did fill out the written questionnaires and could therefore be included in those analyses for outcome measures for which their data were not missing. 
Prognostic comparability

Table 2 shows the demographic and clinical characteristics of the patients who were included in the study. Comparability for the main prognostic variables such as duration, severity, localisation of the complaints and age, seems to be satisfactory.

Table 2. Baseline characteristics of the participants.

\begin{tabular}{|c|c|c|c|c|c|}
\hline Characteristic & $\begin{array}{l}\text { Manual } \\
\text { therapy }\end{array}$ & $\begin{array}{l}\text { Physio- } \\
\text { therapy }\end{array}$ & $\begin{array}{l}\text { Pacebo } \\
\text { therapy }\end{array}$ & $\begin{array}{l}\text { General } \\
\text { piractitioner }\end{array}$ & $\begin{array}{l}\text { All } \\
\text { sulpjocts }\end{array}$ \\
\hline No. of subjects & 65 & 66 & 64 & 61 & 256 \\
\hline \multicolumn{6}{|l|}{ Selected through } \\
\hline advertisement (\%) & 75 & 64 & 60 & 62 & 68 \\
\hline Mearn age (yrs) & 43 & 42 & 43 & 43 & 43 \\
\hline Gender(\% female) & 54 & 48 & 52 & 38 & 52 \\
\hline \multicolumn{6}{|l|}{$\begin{array}{l}\text { Localisation of } \\
\text { complaints }(\%) \text { : }\end{array}$} \\
\hline Back & 55 & 54 & 62 & 53 & 56 \\
\hline Neck & 20 & 32 & 22 & 26 & 25 \\
\hline Back and Neck & 25 & 14 & 16 & 21 & 19 \\
\hline $\begin{array}{l}\text { Median duration of present } \\
\text { episode of complaints (wks): }\end{array}$ & & & & & \\
\hline $\begin{array}{l}\text { complaints }(\mathrm{N}=208) \\
\text { patients with back and neck } \\
\text { complaints }(\mathrm{N}=48) \text { : }\end{array}$ & 52 & 52 & 52 & 45 & 52 \\
\hline back & 78 & 26 & 92 & 78 & 79 \\
\hline neck & 91 & 26 & 65 & 52 & 52 \\
\hline \multicolumn{6}{|l|}{ Mean severity: } \\
\hline main complaint & 7.0 & 7.0 & 6.8 & 6.8 & 6.9 \\
\hline \multicolumn{6}{|l|}{ Previous treatment (\%): } \\
\hline playsiotherapy & 58 & 45 & 58 & 48 & 52 \\
\hline manual therapy & 12 & 18 & 5 & 10 & 11 \\
\hline alternative medicine & 14 & 18 & 9 & 20 & 15 \\
\hline specialist & 17 & 18 & 22 & 18 & 19 \\
\hline \multicolumn{6}{|l|}{ Mean ordinal pain score: } \\
\hline \multicolumn{6}{|l|}{ Mean initial STP score: } \\
\hline Owerall & 5.3 & 5.8 & 5.6 & 4.8 & $\$ .4$ \\
\hline physical-dimension & 3.2 & 3.3 & 4.2 & 2.4 & 3.3 \\
\hline psychosocial-dimension & 4.9 & 5.7 & 5.3 & 5.0 & 5.2 \\
\hline \multicolumn{6}{|l|}{ Mean HSCL score: } \\
\hline psycho-dimension & 7.3 & 6.3 & 6.2 & 7.0 & 6.7 \\
\hline somatic-dimension & 5.6 & 5.2 & 5.8 & 5.3 & 5.5 \\
\hline total & 28.1 & 25.0 & 25.6 & 25.5 & 26.1 \\
\hline
\end{tabular}

For patients with back or neck complaints the median duration of the present episode was 1 year. (For the 48 patients with back and neck complaints the median duration of the back complaints was 1.5 years and 1 year for the neck complaints). Fifty-two percent of all patients had at some time received physiotherapy for their current complaint and 11 percent had received manual therapy (but not in the previous two years). 
Blinding and compliance with treatment

Patients could of course not be blinded for referral to the physiotherapist, manual therapist or GP. However they were blinded for the placebo therapy. Patients were asked whether they thought they received "the treatment which professionals would expect to provide no effect". At 6 weeks half of the patients $(n=32)$ in the GP group answered affirmatively, against 22 in the placebo group, 15 in the manual therapy group, and 9 in the physiotherapy group. The variation across the study groups seems to suggests that the placebo therapy was not systematically unmasked by the patients who were actually treated in that group.

Besides drop-outs (table 1) and patients who changed from the assigned therapy (switch-overs) (table 3), all patients in the physiotherapy group, manual therapy group and placebo group received the assigned therapy. Apart from the drop-outs (table 1) and switch-overs (table 3 ) four patients in the GP group did not wisit the GP. Table 4 shows the number of treatments, session time and duration of treatment for the four study groups. As was expected, the manual therapy group received considerably fewer treatments than the physiotherapy group. Patients in the GP group mostly paid only a single visit to their GP.

Table 3. Cumulative number of deviations from the allocated therapy at followwup.

\begin{tabular}{|c|c|c|c|}
\hline Treatment & 3 wks & 6.wks & 12 wks \\
\hline Manual therapy & 1 inj & $1 \mathrm{inj}$ & $\begin{array}{l}1 \text { inj (painkiller) } \\
2 \text { physiotherapy } \\
1 \text { reforral to specialist }\end{array}$ \\
\hline Physiotherapy & & & 1 manual therapy \\
\hline Placebo therapy & 7 physiotherapy & 9 physiotherapy & $\begin{array}{l}15 \text { physiotherapy } \\
2 \text { manual therapy } \\
2 \text { referral to specialist }\end{array}$ \\
\hline General practitioner & $\begin{array}{l}3 \text { physiotherapy } \\
1 \text { manual therapy }\end{array}$ & $\begin{array}{l}\text { 4. physiotherapy } \\
1 \text { manual therapy } \\
1 \text { sport massage } \\
2 \text { spec }\end{array}$ & $\begin{array}{l}7 \text { physiotherapy } \\
4 \text { manual therapy } \\
2 \text { cesar/mensendieck } \\
1 \text { HNP operation } \\
1 \text { hospitalisation } \\
1 \text { referral to specialist } \\
2 \text { alt med } \\
1 \text { sport massage }\end{array}$ \\
\hline
\end{tabular}

inj $=$ injection by general practitioner

alt med $=$ treatment with alternative medicine

\section{Contamination bias}

Table 3 presents the cumulative frequency of the deviations of the allocated therapy. It appears that contamination mainly occurred in the placebo group and in the general practitioner group. Seven patients in the placebo group received physiotherapy before 3 weeks follow-up (one due to an administrative error, one due to unmasking of the placebo by the patient, five because the therapist unfortunately decided that giving a 
placebo was not appropriate for the patient in question). Four patients in the general practitioner group received physiotherapy or manual therapy before 3 weeks follow-up (one because the patient did not want treatment by the GP, one because the GP carried out manual therapy himself, and two because the GP thought that a referral was more appropriate). At 6 weeks follow-up these figures appear to be slightly higher.

Table 4. Mean number of treatments, session time and duration until twelwe weeks lollow-up. The medians are given in parentheses.

\begin{tabular}{llll}
\hline & $\begin{array}{l}\text { Number of } \\
\text { treatments }\end{array}$ & $\begin{array}{l}\text { Session } \\
\text { time (nin) }\end{array}$ & $\begin{array}{l}\text { Duration } \\
\text { (w/ks) }\end{array}$ \\
\hline $\begin{array}{l}\text { Manual therapy } \\
\text { Physiotherapy }\end{array}$ & $5.4(6)$ & $41(40)$ & $8.9(9)$ \\
Placebo therapy & $14.7(14)$ & $35(30)$ & $7.8(8)$ \\
General practitioner & $11.1(12)$ & $29(30)$ & $5.8(6)$ \\
\hline
\end{tabular}

a (continued) treatment by the GP consisted usually of a single visit by the patient at the general practice.

Between the 6 and 12 weeks follow-up a considerable number of patients in the placebo and GP group changed from the assigned therapy. Although not desirable, according to the study protocol (for ethical reasons) patients could change therapy at 6 weeks after randomization. In the physiotherapy group (one patient received manual therapy) and manual therapy group (two patients received physiotherapy and one was referred to a specialist) these changes occurred considerably less often.

\section{Primary outcomes}

Table 5 lists the results of the primary outcome measures. The trend is that all four study groups show an increasing improvement at 3 follow-up measurements. The improvement of the main complaint (rated by the blinded research assistant) for both the manual therapy group and physiotherapy group is larger than in the general practitioner group at 3 and 6 weeks follow-up. The placebo group also shows a larger improvement than the GP group, but smaller than the manual therapy and the physiotherapy group. At 12 weeks follow-up all four study groups show the largest improvement, but the differences between the study groups have almost entirely disappeared.

The assessment by the patient of global perceived effect $(1=$ no benefit, $6=$ maximal benefit) shows similar results. All study groups show an increasing effect. Both the manual therapy and physiotherapy group show the highest mean scores at 3 and 6 weeks. There are no differences between these two study groups. At 3 and 6 weeks the placebo group has a mean score just below the manual therapy group and the physiotherapy group, but at 12 weeks the mean scores are about equal. The GP group shows the lowest mean scores at all follow-up measurements.

All four study groups show an increasing mean improvement for pain severity (subscale WHYMPI, range $0-6$ ) at the follow-up measurements. However, the improvements are 
small and there appears to be no statistically significant difference between the four study groups ( $P>0.7$ at all follow-up measurements according to one-way ANOVA).

Table 5. Improwement on main complain, global perceived effect, pain and functional status at 3,6 and 12 weeks follow-up in the intention-to-treat analysis.

\begin{tabular}{|c|c|c|c|}
\hline Outcome measure & 3 whs & 6 wks & 12 wks \\
\hline \multicolumn{4}{|c|}{ Mean (SD) inprovement on main complaint (10-point scale) } \\
\hline manual therapy & $2.3(2.1)$ & $3.4(2.1)$ & $4.0(2.6)$ \\
\hline physiotherapy & $2.0(2.3)$ & $3.4(2.4)$ & $3.8(2.3)$ \\
\hline placebo therapy & $1.7(2.6)$ & $2.7(2.4)$ & $3.8(2.6)$ \\
\hline general practitioner & $1.3(2.3)$ & $2.0(3.1)$ & $3.9(2.6)$ \\
\hline \multicolumn{4}{|c|}{ Meran (SD) global perceived effect (6-point scate) } \\
\hline manual therapy & $2.5(1.5)$ & $3.4(1.7)$ & $3.4(2.0)$ \\
\hline pliysiotherapy & $2.6(1.6)$ & $3.3(1.6)$ & $3.7(1.7)$ \\
\hline placebo therapy & $2.1(1.4)$ & $2.8(1.6)$ & $3.3(1.9)$ \\
\hline general practitioner & $1.6(1.0)$ & $1.9(1.3)$ & $2.2(1.7)$ \\
\hline \multicolumn{4}{|c|}{ Mean (SD) improvement on severity of pain (7-point scale) } \\
\hline manual therapy & $0.4(1.3)$ & $0.6(1.5)$ & $0.8(1.7)$ \\
\hline physiotherapy & $0.4(1.3)$ & $0.6(1.4)$ & $0.9(1.5)$ \\
\hline placebo therapy & $0.3(1.3)$ & $0.6(1.7)$ & $1.1(1.7)$ \\
\hline general practinioner & $0.2(1.0)$ & $0.4(1.4)$ & $0.9(1.6)$ \\
\hline \multicolumn{4}{|c|}{ Mean (SD) improvement on functional status (100-point scale) } \\
\hline mamual therapy & $0.9(3.1)$ & $1.8(3.0)$ & $1.6(2.9)$ \\
\hline plnysiotherapy & $1.2(3.3)$ & $1.3(3.8)$ & $1.9(3.8)$ \\
\hline placebo therapy & $1.1(4.4)$ & $1.3(3.6)$ & $2.2(5.1)$ \\
\hline general practitioner & $1.1(2.7)$ & $0.7(2.9)$ & $0.8(4.7)$ \\
\hline
\end{tabular}

The magnitude of the improvement on daily functioning measured by the SIP (physical dimension) is very small for all four study groups. On a scale from $0-100$ the improvement appears to be one point at 3 weeks follow-up, and about two points at 12 weeks follow-up. There are no statistically significant differences between the four study treatments ( $P>0.3$ at all follow-up measurements according to one-way ANOVA).

Figures 1 and 2 are graphical presentations of the cumulative distributions of the improvement scores of the four study groups at 6 weeks follow-up. On the abscissa one can choose the preferred cut-off point of the score and read the proportion of patients of the four study treatments with at least that score, on the ordinate. For example, figure 1 shows that, respectively, $32 \%$ in the GP group, $47 \%$ in the placebo group, and over $60 \%$ in both manual therapy and physiotherapy groups have an improvement score of 3 points or more $(4,5,6$, etc. $)$. In general, bigher curves indicate a more favourable outcone. In all four study groups most patients improve between 0 and 6 points (on a 10-point scale). A small percentage (10-15\%) in each study group shows an improvement of 6 points or more. The manual therapy and physiotherapy groups show the best outcome for the patients with improvement scores of less than 6 points. In 
these two study groups the cumulative distribution of the improvenent scores is almost identical: The cumulative distribution of the GP group is the lowest for almost all improvement scores. The placebo group shows results in between.

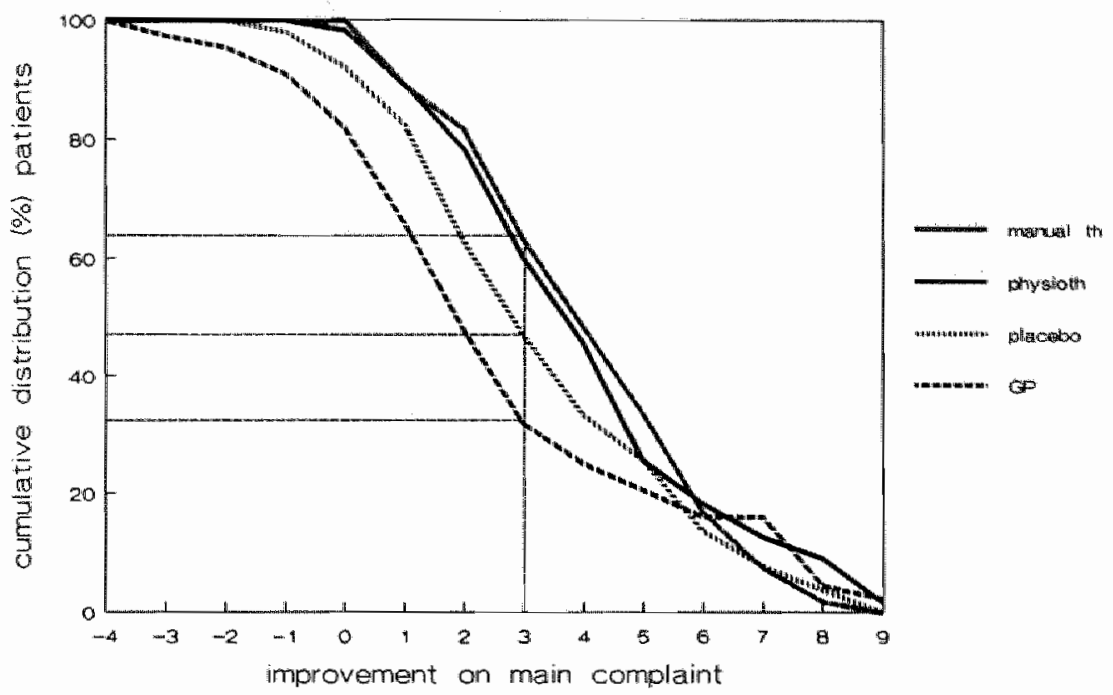

Figure 1 . Improvement on main complaint at six weeks follow-up (intention-to-treat analysis).

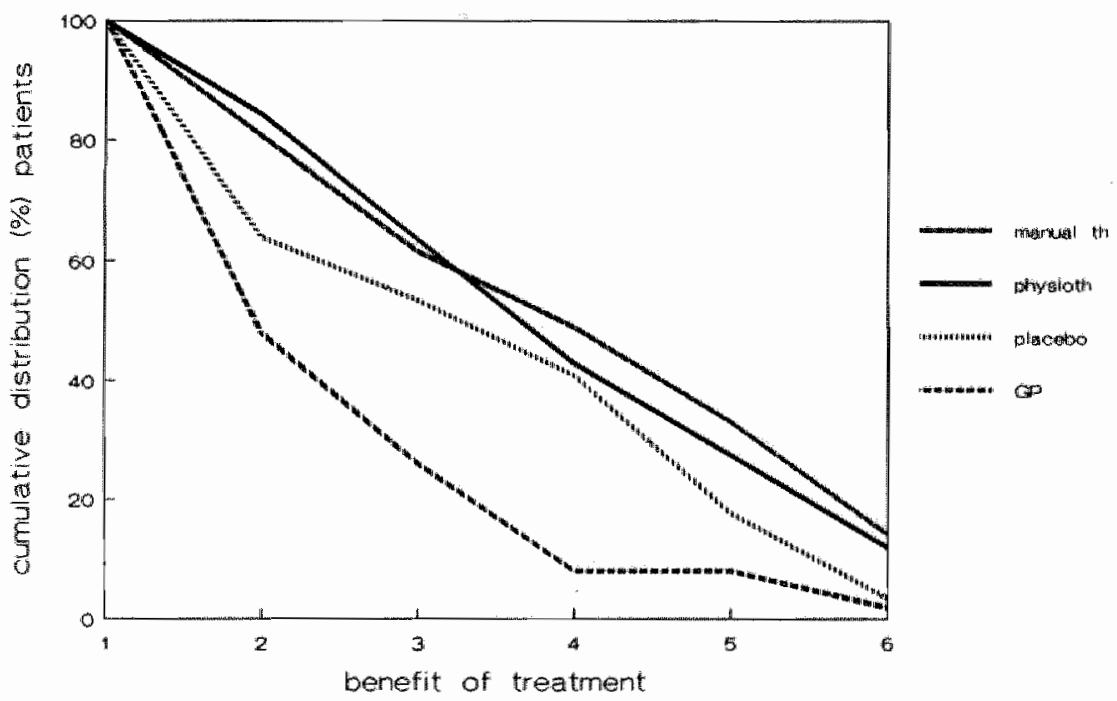

Figure 2. Global perceived effect at six weeks follow-up (intention-to-treat analysis), 
Figure 2 shows the cumulative distribution of the benefit scores at the 6 weeks followup. Again, the distributions of both the manual therapy group and physiotherapy group are almost identical. The GP group shows the lowest outcome at all benefit scores. The placebo group has a score in between, but lies relatively close to the scores of the 'real' treatments.

Table 6. Growp differences (90 percent confidence Jimits) at six weeks: intention-to-treat and alternative andilyisis:

Physiotherapy Placebo therapy General practitioner

Intention-to-treat analysis

Meam improvenuent main complaint

manual therapy

$0.1(-0.6,0.8)$

$0.4(-0.3,1.1)$

$0.4(-0.3,1.2)$

$1.2(0.4,2.1)$

physiotherapy

placebo therapy

Mean global perceived effect

manual therapy

physiotherapy

$0.2(-0.3,0.8)$

$0.7(0.2,1.2)$

$0.5(0.0,1.0)$

$1.2(0.3,2.0)$

$0.8(0.0,1.7)$

placebo therapy

$1.7(1.2,2.2)$

$1.4(0.9,1.9)$

$0.9(0.5,1.4)$

Alterhative analysis

Mean improvement main complaint

manual therapy

physiotherapy

$0.2(-0.4,0.9)$

$1.1(0.5,1.8)$

$1.4(0.7,2.1)$

$1.1(0.4,1.7)$

$1.5(0.5,2.0)$

placebo therapy

Mean global perceived effect

manual therapy

physiotherapy

placebo therapy

$0.4(-0.1,0.9)$

$1.2(0.7,1.6)$

$0.3(-0.4,1.0)$

$0.8(0.3,13)$

$1.9(1.5,2.4)$

$1.5(1.1,2.0)$

$0.8(0.4,1.2)$

Table 6 shows the magnitude of the group differences and the 90 percent confidence intervals at 6 weeks follow-up. When the value 'zero' is not included in the confidence interval, the group difference can be regarded as statistically significant at $5 \%$ level (one-sided test).

The estimates presented were carried out with the use of a linear model. However, these adjusted group differences differed only marginally from the crude estimates with regard to the magnitude of the differences and the precision of the point estimates.

The difference between manual therapy and physiotherapy is small and not statistically significant. The differences between manual therapy and physiotherapy on the one hand and placebo therapy on the other hand are not statistically significant with regard to the improvement of the main complaint. However, there appears to be a trend in favour of manual therapy and physiotherapy. Regarding the global perceived effect the differences are statistically significant. All differences between manual therapy and physiotherapy one the one hand and the GP group on the other hand appear to be highly statistically significant.

Group differences were also calculated at 3 and 12 weeks. Regarding improvement of the main complaint there was only a statistically significant difference between both manual therapy and physiotherapy with the GP group at 3 weeks (difference manual 
therapy and GP group, $0.9(0.3,1.5)$, difference physiotherapy and GP group, $0.7(0.2$, 1.5)). At 12 weeks there were no significant differences any more.

With regard to global perceived effect, all contrasts with the GP group were statistically significant at 3 weeks as well as 12 weeks, while all other contrasts were not statistically significant.

\section{Alternative analysis}

An intention-to-treat comparison is most valid when the drop-out rate (and number of missing values) is low and there is no contamination bias. However, in this study the results in the placebo group and GP group (especially after 12 weeks) of the intentionto-treat analysis may be biased due to drop-outs, missing values and contamination.

Table 7. Improvement on main complaint and global perceived effect at 3,6 and 12 weeks follow-up in the alternative analysis.

\begin{tabular}{llll} 
Outcone measure & 3 wks & 6 wks & 12 wks \\
\hline Mean (SD) improvement on main complaint (10-point scale) & & & \\
$\quad$ manval therapy & $2.1(2.1)$ & $3.0(2.3)$ & $3.8(2.6)$ \\
physiotherapy & $1.7(2.2)$ & $3.0(2.5)$ & $3.4(2.6)$ \\
placebo therapy & $1.1(2.2)$ & $1.8(2.3)$ & $2.3(2.5)$ \\
general practitioner & $1.0(2.1)$ & $1.5(2.7)$ & $2.4(3.0)$ \\
& & & \\
Mean (SD) global effect (6-point scale) & & & \\
manual therapy & $2.4(1.5)$ & $3.4(1.7)$ & $3.4(2.0)$ \\
physiotherapy & $2.4(1.6)$ & $3.1(1.7)$ & $3.5(1.8)$ \\
placebo therapy & $1.8(1.3)$ & $2.3(1.6)$ & $2.5(1.9)$ \\
general practitioner & $1.4(0.8)$ & $1.6(0.9)$ & $1.7(1.3)$
\end{tabular}

Therefore, we also present an analysis in which we assume that patients who droppedout, changed therapy or had a missing value did not improve since the last follow-up measurement. The main underlying assumption for this analysis is that patients probably change therapy because they do not (expect to) benefit (any more) from the assigned therapy. The results of this alternative analysis is presented for improvement on main complaint and global perceived effect in table 7 .

The underlying assumptions for the alternative analysis appear to affect the placebo group and GP group most. The differences between manual therapy and physiotherapy on one side, and placebo therapy and treatment by the GP on the other side appear to be larger at 3 and 6 weeks. This pattern is apparent in the graphical presentations (figure 3 and figure 4). With regard to the improvement of the main complaint the differences between manual therapy and physiotherapy on the one hand, and the placebo therapy on the other hand appear to be statistically significant at 6 weeks (table 6). At 12 weeks these differences still appear to exist. 


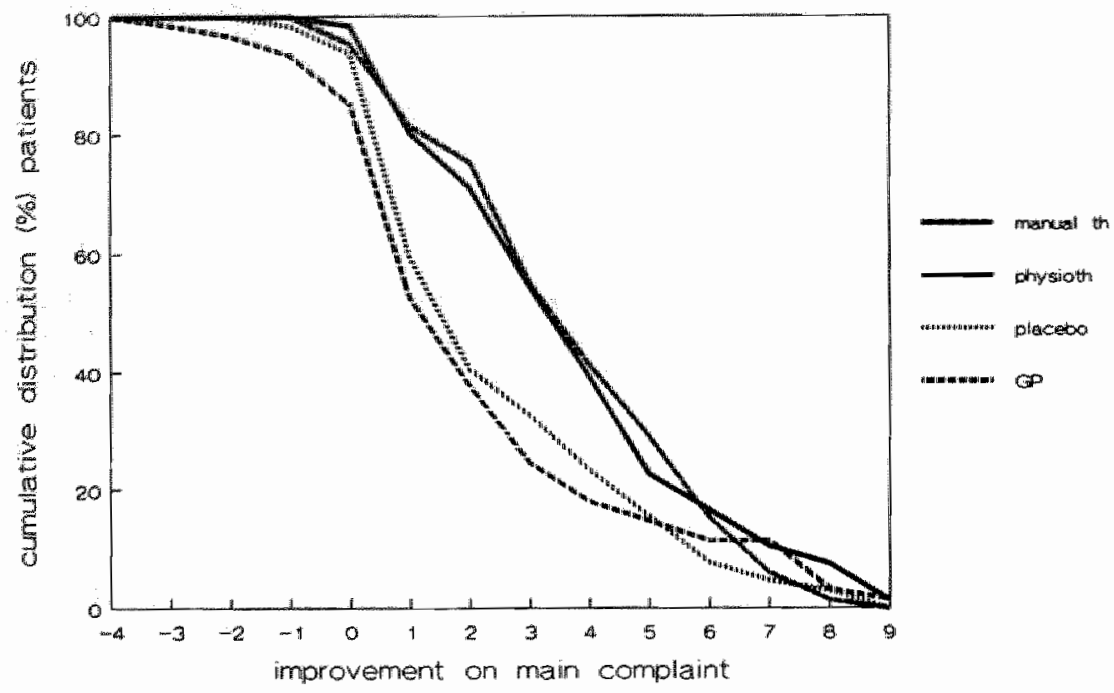

Figure 3. Improvement on main complaint at six weeks follow-up (alternative analysis).

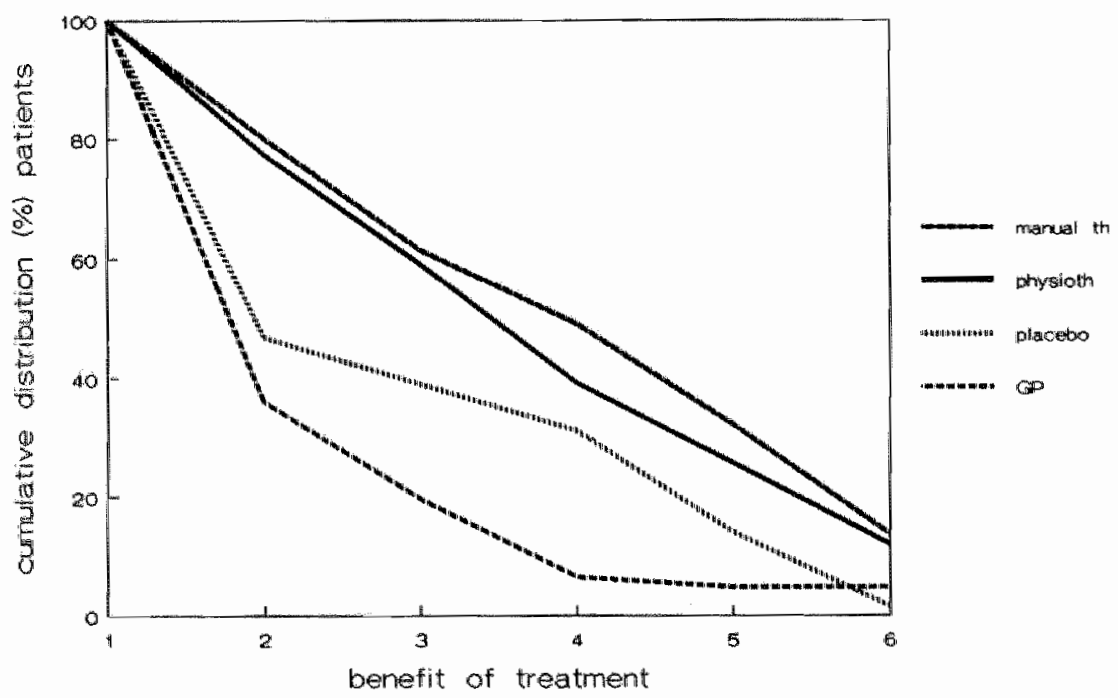

Figure 4. Global perceived effect at six weeks follow-up (alternative analysis). 


\section{Discussion}

The 'pragmatic' comparison that is made in this trial indicates a more favourable outcome for treatment with manual therapy or physiotherapy compared to treatment by the GP. This conclusion is based on the greater improvement of the main complaint assessed by the blinded research assistant at 3 and 6 weeks follow-up, and a larger perceived effect by self-assessment at all follow-up measurements. However, in contrast with the other treatment groups, the patients in the GP group did not receive a 'new' treatment (referral). The patients in the GP group may therefore have thought that they were less well off and therefore could have had a sort of 'negative' placebo effect. This idea is supported by our finding that the placebo therapy (detuned ultrasound and detuned short wave diathermy) showed better results than treatment by the GP.

There was no difference in effectiveness between manual therapy and physiotherapy for all outcome measures at all follow-up measurements. However, the number of treatments (visits) was considerably less for the manual therapy group and this might be regarded as a considerable advantage.

The median duration of the present episode of back and neck pain of 1 year is rather high. However, this figure must be interpreted with some caution. Patients were asked to estimate the duration of the current attack, but the start of this attack is often not clear e.g. when there is a continuous complaint but the intensity varies over time. Thus a reliable estimate of the duration of the current attack seems difficult to obtain. The choice of an appropriate placebo treatment which was trustworthy for the patients and which had no specific effects was difficult. Placebo (sham) manipulation, exercises or massage, although desirable, did not appear to be practically feasible. Therefore, we chose detuned ultra sound and detuned short wave diathermy, as the next best solution. The patients in the placebo group responded remarkably well. Although the improvement of the main complaint (intention-to-treat) in the physiotherapy and manual therapy group was consistently better than in the placebo group at 3 and 6 weeks, the differences were not statistically significant at the conventional 5 percent level. The comparison of placebo therapy versus physiotherapy and manual therapy thus reveals that a substantial part of the effect of referral for physiotherapy or manual therapy may be explained by non-specific effects of the referral (e.g. attention). When designing this trial we had chosen the Sickness Impact Profile (SIP) as an instrument for measuring functional status. ${ }^{20}$ This health status questionnaire has previously been used in back pain trials. ${ }^{510}$ However, in this new trial the scores of the patients at baseline were only slightly higher than in a general population, thus leaving not much room for improvement in daily functioning. The use of this instrument in clinical trials with patients comparable with those in this study might not be very suitable. The same holds for the use of the West Haven Yale Multidimensional Pain Inventory (WHYMPI). Although we only used the subscale pain severity, this instrument (its present name is multi-dimensional pain inventory (MPI)) does not seem to be very responsive to changes in severity of complaints which obviously occurred in the trial and were easily measured by the blinded research assistant.

We presented two analyses of the data. In general we believe that an intention-to-treat analysis is the most walid approach for analyzing results of a clinical trial. In this particular trial, however, the results especially at 12 weeks follow-up might be biased substantially because a number of patients in the placebo group and GP group changed from the assigned therapy to (mainly) physiotherapy and manual therapy. Furthermore, 
the number of drop-outs and missing values were highest in the first two groups. This can be regardied as an outcome measure in itself. The treatments in groups with many patients who change therapy and many drop-outs are probably less effective. We dealt with this contamination bias by substituting the results at follow-up with the last available measurement before changing therapy (to physiotherapy or manual therapy) or before having a missing outcome. Thus, we assumed no further improvement after these moments for the patients involved. This means that for these patients we ignored the general trend of improvement over time, but also ignored the possibility of deterioration among these patients. Reader can choose their own analysis for drawing conclusions. We believe the intention-to-treat analysis overestimates the efficacy of the placebo therapy and treatment by the GP especially at 12 weeks follow-up. On the other hand the alternative analysis might lead to an underestimation of the effect of especially the placebo therapy and treatment by the GP.

Further analysis of the data will be carried out to explore whether there are subgroups of patients (e.g. back patients and neck patients separately) in which different treatment effects occurred.

The results of other randomized trials investigating the effectiveness of manipulative techniques are controversial. ${ }^{19}$ Some investigators did not find a beneficial effect of manipulative techniques over physiotherapy, corset or analgesic tablets, ${ }^{8}$ minimal massage, and low-level electrostimulation, ${ }^{13}$ short wave diathermy (SWD) and detuned SWD. ${ }^{12}$ Other investigators demonstrated better short term results with manipulation over soft tissue massage, ${ }^{16}$ mobilisation, ${ }^{15}$ microwave diathermy and isometric abdominal exercises. ${ }^{9}$ However, these findings usually were found for patients with acute complaints whereas we studied patients with subacute and chronic problems. We conclude that it seems useful to refer patients with non-specific back and neck complaints with a duration of at least 6 weeks for treatment with physiotherapy or manual therapy. Patients responded also remarkably well to the placebo therapy. This, however does not alter this conclusion but suggests the importance of the non-specific effects of a referral. Though this phenomenon needs further study and is not fully understood yet, knowledge that non-specific effects (e.g. extra attention) are that important should preferably be used in a positive sense in the approach and treatment of patients with back and neck complaints. 


\section{References}

1. Bergner $M_{\imath}$ Bobbitt RA, Carter WB, Gilsea BS. The Sickness Impact Profile. Med Care 1981; 19: $787-805$.

2. Brunarski DJ. Clinical trials of spinal manipulation: a critical appraisal and review of the literature. J Manipulative Physiol Ther 1984; 7: 243-249.

3. Derogatis LR, Lipman RS, Rickels K, Uhlenhuth EH, Covi L. The Hopkins Symptom Checklist, a self-report symptom inventory. Bieh Science 1974; 19: 1-151.

4. Deyo RA Conservative therapy for low back pain. JAMA 1983; 250: 1057-1062.

5. Deyo RA. A controlled trial of transcutaneous nerve stimulation (TENS) and exercise for chronic low back pain. N Engl J Med 1990; 322: 1627-1634.

6. Di Fabio RP. Clinical assessment of manipulation and mobilization of the lumbar spine - a critical review of the literature. Physical "Therapy 1986; 66: 51-54.

7. Dixon WJ, Brown MB, Engelman $\mathbb{L}$, Hill MA. BMDP statistical software manual. University of Califormia Press, Berkeley, 1988.

8. Doran DJM, Newell DJ. Manipulation in treatment of low back pain: a multicentre study. Br Med J $1975 ; 2 ; 161-164$.

9. Farrell JP, Twomey LT. Acute low back pain: comparison of two consetvative treatment approaches. Med J Aust 1982; 1: 160-164.

10. Follick MJ, Smith TW, Ahern DK. The sickness impact profile: a global measure of disability in chronic low back pain. Pain 1985; $21: 67-76$.

11. Frymoyer $\mathbb{I W}$. Back pain and sciatica. N Engl J Med 1988; 318: 291-300.

12. Gibson T, Grahame R, Harkness $J_{*}$, Woo P, Blagrave P, Hills R. Controlled comparison of strontwave diathermy treatment with osteopathic treatment in non-specific low back pain. Lancet: 1985; $1258-1261$.

13. Godfrey CM, Morgan PP, Schatzker J. A randomized trial of namipulation for low back paito in a medical setting. Spine 1984; 9: 301-304.

14. Greenland S, Reisbord LS, Halldeman S, Buerger AA. Controlled clinical trials of manipulation: a review and a proposal. J Occup Med 1980; 22: 670-676.

15. Hadler NM, Curtis P, Gillings DB, Stinnett S. A benefit of spinal manipulation as adjunctive therapy for acute low back pain: a stratified controlled trial. Spine 1987; 12: 703-705.

16. Hoehler GK, Tobis JS, Buerger AA. Spinal manipulation for low back pain. JAMA 1981; 245: 18351838.

17. Kerns $R D$, Turk $D C$, Rudy TE. The West Haven-Yale Multidimensional Pain Inventory (WHYMPI) Pain 1985; 23: 345-356.

18. Koes BW, Bouter LM, Beckerman H, Heijden van der GJMG, Knipschild PG. Physiotherapy exercises and back pain: a blinded review. Br Med J 1991; 302; 1572-1576.

19. Koes. BW, Assendelft WJJ, Heijden van der GIMG, Bouter LM, Knipschild PG. Spinal manipulation and mobilization for back and neck pain: a blinded review. Br Med $J 1991 ; 303$; 1298. 1303.

20. Koes BW, Bouter LM, Knipschild PG, Mameren H van, Essers A, Houben PG, Verstegen GMMG, Hofhuizen DM. The effectiveness of manual therapy, phusiotherapy and continued treatment by the general practitioner for chronic non-specific back and theck complaints: design of a randomized. clinical trial. J Manipulative Physiol Ther (In press).

21. Koes BW, Bouter LM, Mameren H van, Essers AMM, Verstegen GJMG, Hofhuizen DM, Houben JP, Knipschild PG. A blinded randomized clinical trial of manual therapy and physiotherapy for chronic back and neck complaints: physical outcome measures. J Manipulative Physiol Ther (in press).

22. Nachemson A. Towards a better understanding of low back pain. Rheum Reh 1975; 14: 129:143.

23. Nachenson A. The lumbar spine: An orthopaedic challenge. Spine 1976; 1: 59-71.

24. Nachemson A. A critical look at the treatment for low back pain. Scand J Rehabil Med 1979; 11: $143-147$.

25. Spizer WO, Leblanc $F E_{n}$ Dupuis M. Scientific approach to the assessment and managentent of activity-related spinal disorders. Spine 1987; 7 (suppl) 1: 1-59.

26. Waddell G. A new clinical model for the treatment of low-back pain. Spine 1987; 12:632-644.

27. White AA, Gordon SL. Synopsis: workshop on idiopathic low-back pain. Spine 1982; 7; 141-149. 

Chapter 6

\section{A BLINDED RANDOMIZED CLINICAL TRIAL OF MANUAL THERAPY AND PHYSIOTHERAPY FOR CHRONIC BACK AND NECK COMPLAINTS}

physical outcome measures*

BW Koes, LM Bouter, H van Mameren, AHM Essers, GMJR Verstegen, DM Hofhuizen, JP Houben, PG Knipschild

* Accepted for publication in $\mathbb{J}$ Manipulative Physiol Ther 
In a blinded randomized clinical trial we compared the effectiveness of manual therapy, physiotherapy, (continued) treatment by the general practitioner (GP), and a placebo therapy (detuned ultrasound and detuned short wave diathermy) for patients $(n=256)$ with chronic non-specific back and neck complaints. The physical outcome measures (spinal mobility and physical functioning) are presented for 3,6 and 12 weeks follow. up. Manual therapy showed a faster and larger improvement in physical functioning compared to the other 3 therapies. The changes in spinal mobility among the 4 study groups appear to be small and show no consistent pattern. 
It is estimated that some $80 \%$ of all people experience back problems during their active life. ${ }^{12}$ Neck problems are less frequently reported, but constitute a major health problem as well. In most cases no underlying pathology can be established and the causes of the complaints remain unknown. ${ }^{13}$ "The majority of patients with acute back pain recover within a few weeks, often with the help of (bed)rest, analgesics and advice about posture and exercises. ${ }^{4}$ Within a few months the complaints disappear in about $90 \%$ of the cases. ${ }^{5-7}$ There is, however, a relatively high recurrences rate.

We know about 35 randomized clinical trials investigating the efficacy of manipulation and mobilization for back and neck complaints. ${ }^{8}$ Unfortunately, the results of these studies are inconsistent and the interpretation is often difficult due to methodological flaws. In most of these studies only a small number of patients were included and the effect measurement involved subjective judgements while not blinded. In this article we present the results of a randomized clinical trial in which we tried to avoid these flaws and in which we compare manual therapy, physiotherapy, treatment by the general practitioner, and a placebo treatment for patients with chronic back and neck complaints. Below we will focus on two physical outcome measures which are assessed by a blinded research assistant: physical functioning and spinal mobility. Physical functioning is operationalized as the ability of patients to perform active lumbar, thoracic, and cervical movements. This was chosen as a relatively objective outcome measure. 10 Spinal mobility is generally considered to be an objective outcome measure for evaluating progress in patients with back pain, ${ }^{10-12}$ and was therefore measured in our study as well. Elsewhere, the results on severity of the complaints, global perceived effect, pain and functional status are reported. ${ }^{13}$

\section{Methods}

\section{Selection of the patients}

Patients were selected by general practitioners (GPs) during a two year period (January 1988 - December 1989). Due to an initially low admission rate we expanded the recruitment activities by repeated advertisements in the local press. Potential subjects were seen by one research assistant, who was an experienced physiotherapist and manual therapist. The research assistant performed a physical examination and did the final check with respect to the admission criteria. Criteria for inclusion were pain or self-reported limited range of motion in back or neck for at least six weeks. Criteria for exclusion were: suspicion of underlying pathology (e.g. malignity, osteoporosis, herniated disc), treatment with physiotherapy or manual therapy for back or neck complaints received during the previous two years, pregnancy, language problems, or inability to reproduce the complaints by active or passive movements during physical examination. Eligible patients completed the informed consent by signing a letter. Subsequently, randomization was carried out by a second research assistant using a list of random numbers.

\section{Treatments}

The following 4 treatments were included: (1) physiotherapy e.g. exercises, massage and physical therapy modalities (heat, electrotherapy, ultrasound, shortwave diathermy); (2) manual therapy, which consisted of manipulative techniques (manipulation and 
mobilisation of the spine) according to the directives of the Dutch Society for Manual Therapy (NVMT); (3) continued treatment by the general practitioner $(\mathrm{n}=40)$, which consisted of prescription of medication (analgesics, NSAIDs), advice about posture, home exercises, participation in sports, (bed)rest, etc; (4) placebo treatment, which consisted of a physical examination and subsequently detuned shortwave diathermy (10 minutes) and detuned ultrasound (10 minutes) carried out by the participating physiotherapists. The sessions of the placebo treatment were scheduled at two times a week for a period of six weeks. Both the manual therapists $(n=7)$ and the physiotherapists $(n-8)$ participating in the study were selected by their professional organizations (NVMT and the Royal Dutch Society for Physiotherapy (KNGF)). All therapists (except for the placebo treatment) were free to choose from their usual therapeutic domain within some explicitly formulated limits (e.g. no manipulative techniques could be performed by the physiotherapists). All treatments were given for a maximum duration of three months. After six weeks the patients had the opportunity to discuss the results of the treatment with their GP and to decide whether to continue, change or stop the treatment.

\section{Follow-up, outcome measures and blinding}

Follow-up measurements were carried out at 3, 6 and 12 weeks after randomization. Primary outcome measures were the severity of the complaint, global perceived effect, pain and functional status. ${ }^{13}{ }^{14}$ In the research protocol physical functioning and spinal mobility were chosen to be the most important secondary outcome measures. ${ }^{14}$ Both were measured by the research assistant who was unaware (blind) of the treatment assignment of the patients at the time of all follow-up measurements. Physical functioning was operationalized as the ability of patients to perform active spinal movements. Patients with neck complaints performed a standardized set of cervical movements (anteflexion, retroflexion, lateroflexion, and rotation). Patients with back complaints performed a similar set of trunk movements. This included forward flexion, backward flexion, lateroflexion, and rotation of the trunk with the patient in sitting and standing position. These movement were followed by trunk forward flexion while the patient was standing on one leg (right and left leg alternately) and the other leg is bend in the hip and knee joint towards the trunk (patient is supported by the research assistant). After these movements patients were asked to stand on one leg (right and left leg alternately). Finally, in a sitting position, they had to put one leg over the other (right and left leg alternately).

At baseline the research assistant noted for each patient the movements (maximally 3 ) for which the patient reported the most severe pain or a limitation of the range of motion (ROM). In addition, the research assistant scored the severity of the pain (or of the limitation of the ROM) for these movements on a ten-points scale $(1=$ minimal severity, $10=$ maximal severity). During the follow-up measurements the movements chosen at baseline were re-assessed by the researeh assistant who again scored the severity of the pain or the limitation of the ROM. The research assistant had no information about previous severity scores. The physical functioning score was calculated by counting the severity scores of all (max. 3 ) the movements at issue divided by the number of movements.

Spinal mobility was measured by the research assistant with the use of an inclinometer (Cybex EDI 320). The reproducibility of spinal measurements with the EDI 320 
appeared to be satisfactory in a previous study. ${ }^{15}$ Table 1 presents the three spinal movements we assessed.

At baseline and the three follow-up measurements the patients performed these movements two times consecutively. The mean of these two measurements was taken as the range of motion (ROM) at the moment at issue. Cervical movements were performed by all patients with neck complaints. Forward spinal flexion was performed by all patients with back pain.

Table 1. Movements between extremes of the path of motion ${ }^{\text {कa }}$ and position of the inclinometer.

Movenent

Position

inclinometer

Position

patient

1 Cervical forward flexion

os nasale

2. Cervical lateral flexion

os temporale

sitting

proc. zygomaticus

3 Spinall forward flexion

T1

sitting

standing

a movement 3: from anatomical to extreme position

\section{Statistical anabsis}

For both outcome measures we calculated the differences between the follow-up scores and the baseline score for the individual patients. The four study groups were compared for their mean improvement in physical functioning and spinal mobility at 3,6 and 12 weeks after randomization. Furthermore, cumulative distributions of the improvement scores for physical functioning were calculated. Group differences and 90 percent confidence intervals were calculated for 6 weeks follow-up using a linear regression model. In this model we entered the following prognostic indicators: localisation and duration of the main complaint, the baseline physical functioning score, age and recruitment status (general practitioner or advertisement). We present firstly a statistical analysis according to the 'intention-to-treat' principle. Thus, all patients remain in the group to which they were assigned by randomization. This includes dropouts (as far as they participated in the effect measurements), patients with low compliance, and patients who changed from the assigned therapy. In addition to this, we present an alternative analysis with the purpose of adjusting for missing values and patients who changed from the assigned therapy. In this analysis we substitute the outcomes at follow-up of patients who changed from the assigned therapy, with the score of the last measurement before changing therapy. Similarly we substitute the last measurement for patients with missing values, with the score of the last measurement available. The analyses were carried out with BMDP version $1988 .{ }^{16}$

\section{Results}

Study sample and prognostic comparability

A total of 256 patients were included and randomly assigned to the study treatments. Table 2 shows the demographic and clinical characteristics of the patients who were 
included in the study. Comparability for the main prognostic variables such as duration, severity, localisation of the complaints and age, seems to be satisfactory.

After 12 weeks follow-up 23 patients (9\%) had dropped out. Table 3 shows the cumulative drop out rate for each group at the 3,6 and 12 weeks follow-up. The reasons given for dropping out were inconvenience and lack of time $(n=10)$, problems with filling in questionnaires $(n=3)$, complaints having disappeared $(n=2$; one in physiotherapy group, one in general practitioner group), no benefit of treatment $(n=2$; in general practitioner group), pregnancy $(n=1)$, and personal reasons or no reason given $(n=5)$. In addition, a number of people did not show up for the physical measurements by the research assistant (mainly because of lack of time).

Table 2. Baseline characteristics of the study population.

\begin{tabular}{|c|c|c|c|c|c|}
\hline Characteristic & $\begin{array}{l}\text { Manual } \\
\text { therapy }\end{array}$ & $\begin{array}{l}\text { Physio- } \\
\text { therapy }\end{array}$ & $\begin{array}{l}\text { Placebo } \\
\text { therapy }\end{array}$ & $\begin{array}{l}\text { General } \\
\text { pract. }\end{array}$ & $\begin{array}{l}\text { All } \\
\text { subjects }\end{array}$ \\
\hline No. of subjects & 65 & 66 & 64 & 61 & 256 \\
\hline \multicolumn{6}{|l|}{ Selected through } \\
\hline advertisement $(\%)$ & 75 & 64 & 60 & 62 & 68 \\
\hline Mean age (yrs) & 43 & 42 & 43 & 43 & 43 \\
\hline Gender(\% fenale) & 54 & 48 & 52 & 38 & 52 \\
\hline \multicolumn{6}{|l|}{ Localisstion of complaints $(\%)$ : } \\
\hline Back & 55 & 54 & 62 & 53 & 56 \\
\hline Neck & 20 & 32 & 22 & 26 & 25 \\
\hline Back and Neck & 25 & 14 & 16 & 21 & 19 \\
\hline \multicolumn{6}{|l|}{$\begin{array}{l}\text { Median duration of present } \\
\text { episode of complaints (wks) }\end{array}$} \\
\hline $\begin{array}{l}\text { complaints }(n=208) \\
\text { patients with back and neck } \\
\text { complaints }(n=48)\end{array}$ & 52 & 52 & 52 & 45 & 52 \\
\hline back & 78 & 26 & 92 & 78 & 79 \\
\hline neck & 91 & 26 & 65 & 52 & 52 \\
\hline $\begin{array}{l}\text { Moan physical functioning } \\
\text { score (10 points scale) }\end{array}$ & 5.9 & 5.8 & 5.7 & 5.7 & 5.8 \\
\hline \multicolumn{6}{|l|}{ Range of motion (degrees) } \\
\hline cervicall antellexion & 113 & 112 & 117 & 116 & 115 \\
\hline cervical laterollexion & 60 & 61 & 64 & 62 & 62 \\
\hline spinall forward flexion (T1) & 133 & 126 & 129 & 127 & 129 \\
\hline
\end{tabular}

Table 3. Cumulative number of drop-outs (and total number of missing values of measurement by blinded research assistant) at follow-up after 3,6 and 12 weeks.

\begin{tabular}{llll} 
Treatment & 3 wks & 6 wks & 12 wks \\
\hline Manual therapy & $1(4)$ & $1(11)$ & $3(8)$ \\
Physiotherapy & $2(10)$ & $4(11)$ & $5(12)$ \\
Placebo therapy & $5(14)$ & $6(13)$ & $8(16)$ \\
General pract. & $4(14)$ & $6(17)$ & $7(20)$
\end{tabular}


Blinding and compliance with treatment

Patients could not be blinded for referral to a physiotherapist, a manual therapist or a GP. However, they were blinded for the placebo therapy. Patients were asiked whether they thought they received "the treatment which professionals would expect to provide no effect' (the phrase used in the informed consent document). At 6 weeks half of the patients $(n=32)$ in the GP group answered affirmatively, against 22 in the placebo group, 15 in the manual therapy group, and 9 in the physiotherapy group. The variation across the study groups seems to suggest that the placebo therapy was not systematically unmasked by the patients who were actually treated in that group.

Table 4 shows the number of treatments, session time and duration of treatment for the four study groups. The manual therapy group received considerably fewer treatments (mean number of treatments is 5.4) than the physiotherapy group (mean number of treatments is 14.7). Patients in the GP group mostly paid only a single visit to their GP.

Table 4. Mean number of treatments, session time and duration until 12 weeks follow-up. The medians are given in parentheses.

\begin{tabular}{|c|c|c|c|}
\hline & $\begin{array}{l}\text { Number of } \\
\text { treatments }\end{array}$ & $\begin{array}{l}\text { Session } \\
\text { time (min) }\end{array}$ & $\begin{array}{l}\text { Duration } \\
\text { (wks) }\end{array}$ \\
\hline Manual therapy & $5.4(6)$ & $41(40)$ & $89(9)$ \\
\hline Physiotherapy & $14.7(14)$ & $35(30)$ & $7.8(8)$ \\
\hline Placebo therapy & $11.1(12)$ & $29(30)$ & $5.8(6)$ \\
\hline General practitioner ${ }^{a}$ & - & $-\quad$ an & $=$ \\
\hline
\end{tabular}

a (continued) treatment by the GP consisted usually of a single visit by the patient at the general practice.

Table 5. Cumulative number of deviations from the allocated therapy at follow-up.

\begin{tabular}{|c|c|c|c|}
\hline Treatment & 3 wks & $6 w \mathrm{ks}$ & 12 whs \\
\hline Manual therapy & 1 inj & 1 inj & $\begin{array}{l}1 \text { inj } \\
2 \text { physiotherapy } \\
1 \text { referral to specialist }\end{array}$ \\
\hline Physiotherapy & & & 1 manual therapy \\
\hline Placebo therapy & 7 physiotherapy & 9 physiotherapy & $\begin{array}{l}15 \text { physiotherapy } \\
2 \text { manual therapy } \\
2 \text { referral to specialist }\end{array}$ \\
\hline General practitioner & $\begin{array}{l}3 \text { physiotherapy } \\
1 \text { manual therapy }\end{array}$ & $\begin{array}{l}4 \text { physiotherapy } \\
1 \text { manwal therapy } \\
1 \text { sport massage } \\
2 \text { referral to specialist }\end{array}$ & $\begin{array}{l}7 \text { physiotherapy } \\
4 \text { manual therapy } \\
2 \text { cesar/mensendieck } \\
1 \text { HNP operation } \\
1 \text { hospitalisation } \\
1 \text { referral to specialist } \\
2 \text { alt med } \\
1 \text { sport massage }\end{array}$ \\
\hline
\end{tabular}

inj = injection by general practitioner

alt med $=$ treatment with alternative medicine 
Besides drop-outs (table 3) and patients who changed from the assigned therapy (switch overs) (table 5), all patients in the physiotherapy group, manual therapy group and placebo group received the assigned therapy, while four patients in the GP group did not visit the GP. According to the study protocol (for ethical reasons) patients could change therapy at six weeks after randomization. Table 5 presents the cumulative frequency of the deviations of the allocated therapy. It appears that contamination mainly occurred in the placebo group and in the general practitioner group. Between the 6 and 12 weeks follow-up a considerable number of patients in the placebo and GP group changed from the assigned therapy.

Table 6. Improvement on physical functioning and change in range of motion at 3,6 and 12 weeks follow-up in the intention-to-treat anallysis.

Mean (SD) improvement on physical functioning (10\%points scalle)

manual therapy $(\mathrm{n}=53)^{\mathrm{a}}$

physiotherapy $(\mathrm{n}=54)$

placebo therapy $(n=51)$

general practitioner $(n=44)$
$3.5(1.9)$

$3.1(\mathbb{1 . 8})$

$2.6(2.3)$

$2.4(2.6)$
$4.0(2.3)$

$3.4(2.3)$

$3.4(2.2)$

Cervical flexion: patients with neck complaünts

Mean (SD) change of range of motion cervical forward

flexion (degrees)

manual therapy $(n=23)$

physiotherapy $(n=22)$

placebo therapy $(n=18)$

general practitioner $(n=21)$

$$
\begin{array}{r}
-2(16) \\
0(16) \\
5(20) \\
-7(20)
\end{array}
$$

$3(14)$

2 (18)

$5(13)$

-11 (23)

$4(16)$

4 (15)

9 (15)

$-7(21)$

Mean (SD) change of range of motion cervical

lateroflexion (degrees)

manual therapy $(n=23)$

physiotherapy $(\mathrm{n}=22)$

placebo therapy $(\mathrm{n}=18)$

general practitioner $(n=21)$

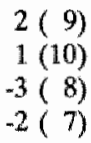

$2(10)$

0(9)

1 (11)

$3(10)$

$-1(8)$

$2(8)$

$-3(9)$

$-3(10)$

Spinal nexion: patients with back complaints

Mean (SD) change of range of motion spinal

flexion at $\mathrm{T} 1$ (degrees)

imanual therapy $(\mathbf{n}=36)$

physiotherapy $(n=31)$

placebo therapy $(\mathrm{n}=39)$

general practitioner $(\mathbf{n}=30)$

$0(10)$
$-1(12)$
$-4(11)$
$3(10)$

$-2(12)$

$.2(15)$

$4(13)$

$6(13)$

$-3(9)$

$0(10)$

0(14)

$0(18)$

a Number of patients after 6 weeks follow -up. After 3 and 12 weeks the numbers may vary slightly because of missing values.

\section{Outcome}

Table 6 lists the results of the outcome measures. All four groups showed an increasing mean improvement of physical functioning (rated by the blinded research assistant) at the three follow-up measurements. The improvement for the manual therapy group was 
larger than for the other groups at all follow-up measurements. Physiotherapy, placebo therapy, and treatment by the GP showed similar results at 3 and 12 weeks follow-up. At 6 weeks the physiotherapy scores were slighly better than the placebo therapy and the treatment by the GP.

The mean changes in spinal mobility appear to be small and show no consistent pattern. The maximal mean increase in ROM was $9^{\circ}$ (cervical anteflexion in the placebo group), and the maximal mean decrease in ROM was $11^{\circ}$ (cervical anteflexion in the GP group). In most cases, however, the mean changes in ROM varied between $0^{\circ}$ and $5^{\circ}$. The standard deviations indicate the large variation for this outcome measure between the patients in each group. Cervical retroflexion and lateroflexion to the right, and spinal forward flexion measured at $\mathrm{L} 1$ are not presented because these results were almost identical to the ones presented.

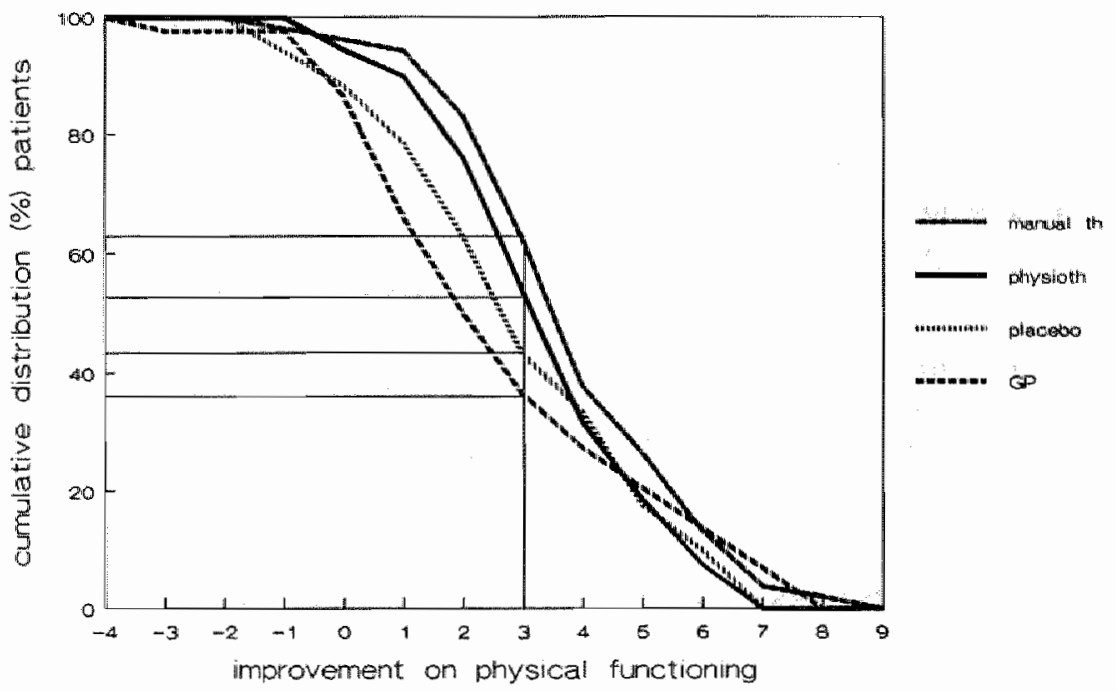

Figure 1. Improvenent on physical functioning at 6 weeks follow-up (intention-to-treat analysis).

Figure 1 is a graphical presentation of the cumulative distribution of the improvement scores of physical functioning of the four study groups at 6 weeks follow-up. On the abscissa the reader can choose the preferred cut-off point of the improvement score and read the proportion of patients of the four study treatments with at least that score, on the ordinate. For example, respectively $36 \%$ in the GP group, $43 \%$ in the placebo group, $54 \%$ in the physiotherapy group, and $62 \%$ in the manual therapy group had an improvement score of 3 points or more. In general, curves which lay more in the direction of the right upper corner of this figure indicate a more favourable outcome. In all four study groups most patients improved between zero and six points. Only a small percentage in each study group showed an improvement of 6 points or more. The manual therapy group showed the best outcome for patients with improvement scores of less than 6 points, whereas the GP group showed the lowest improvement. The cumulative distributions of physiotherapy and placebo therapy were in between. 
Table 7. Group difercnces (90 percent confidence limits) for mean improvenent of physical functioning at 6 weeks. intention-to-treat and alternative analysis.

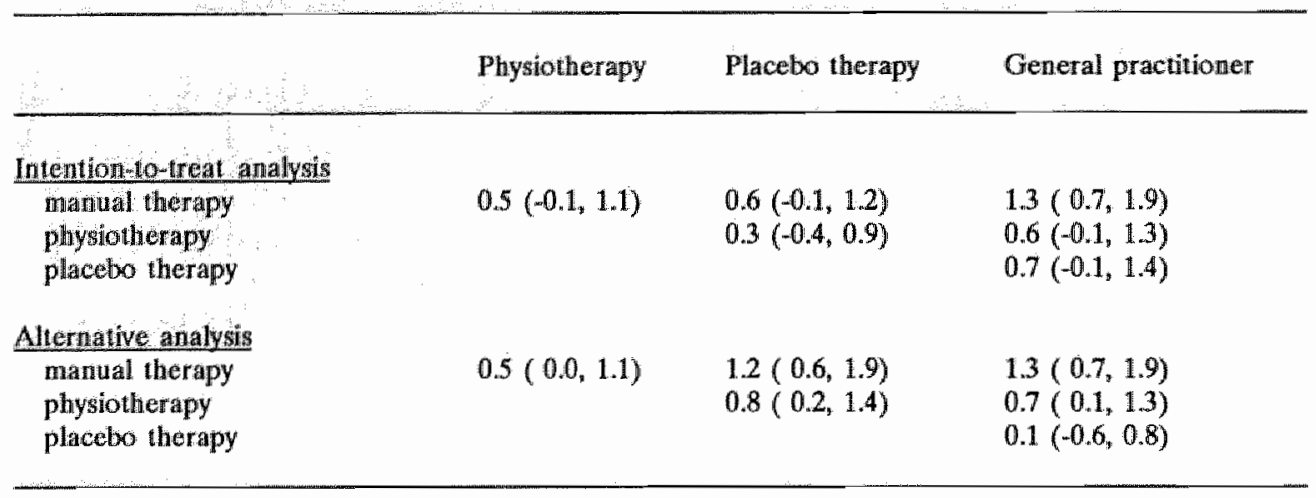

Table 7 shows the magnitude of the group differences and the 90 percent confidence intervals at six weeks follow-up. When the value 'zero' is not included in the confidence interval, the group difference is statistically significant at $5 \%$ level (one-sided test). Only the difference between manual therapy and treatment by the GP was statistically significant. Group differences were also calculated at 3 and 12 weeks. At three weeks all differences between manual therapy and the other three groups were statistically significant. The difference with physiotherapy was $0.8(0.2,1.4)$, and with placebo therapy and treatment by the GP both $0.7(0.1,1.3)$. All other contrasts were not statistically significant. At 12 weeks there appeared to be no statistically significant differences between the four groups.

\section{Alternative analysis}

In this study the results in the placebo group and GP group (especially beyond 6 weeks) of the intention-to-treat analysis may be biased due to drop-outs, missing values and contamination. Therefore, we also present an analysis in which we assume that patients who dropped out, had a missing value or changed therapy did not improve since the last follow-up measurement that is available. The main underlying assumption for this analysis is that patients probably stop or change therapy because they do not (expect to) benefit (anymore) from the assigned therapy. The results of this alternative analysis is presented in table 8 .

Table 8. Improwement on physical functioning at 3,6, and 12 weeks follow-up in the alternative analysis.

$\begin{array}{llll}\text { Oucome measure } & 3 \mathrm{wks} & 6 \mathrm{wks} & 12 \mathrm{wks}\end{array}$

Mean (SD) improvement on physical functioning (10-point scale)

manual therapy

plysiotherapy

placebo therapy

general practitioner

$\begin{array}{lll}2.1(2.1) & 3.1(2.1) & 3.6(2.4) \\ 1.3(1.8) & 2.7(2.0) & 2.9(2.2) \\ 1.0(1.9) & 1.7(2.3) & 2.1(2.4) \\ 1.3(2.0) & 1.8(2.4) & 2.3(2.5)\end{array}$


The underlying assumptions for the alternative analysis appeared to affect the placebo group and GP group the most. Manual therapy continued to show the best results at all follow-up measurements. The differences between manual therapy and physiotherapy on the one hand, and placebo therapy and treatment by the GP on the other hand turned out to be larger than in the intention-ti-treat analysis at 6 and 12 weeks. This pattern is also clearly visible in the graphical presentation (figure 2). The differences between manual therapy and physiotherapy on the one hand, and the placebo therapy on the other hand were statistically significant at six weeks (table 7). At 12 weeks these differences could still be demonstrated.

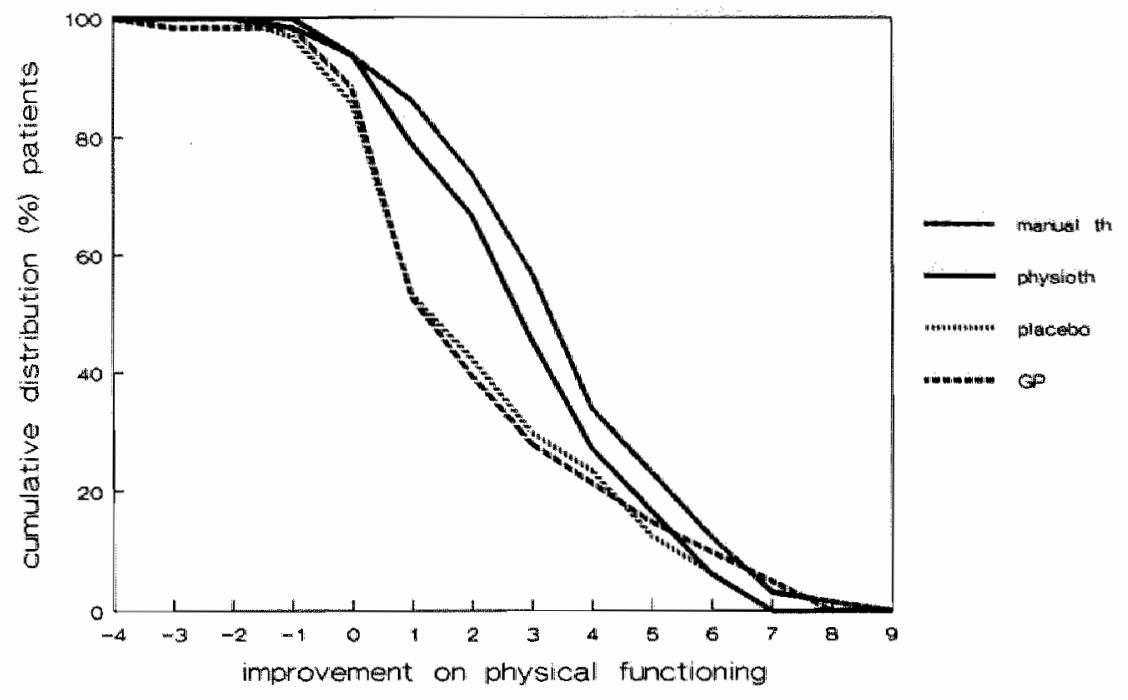

Figure 2. Improvenent on physical functioning at 6 weeks follow-up (alternative analysis).

\section{Discussion}

Manual therapy showed a faster and larger improvement in physical functioning, as measured by the blinded research assistant, than the other 3 therapies. At 3 weeks the difference between manual therapy and the other 3 therapies was statistically significant, whereas at 6 weeks this was the case only for the contrast between manual therapy and treatment by the GP. At 12 weeks there appeared to be no statistically significant differences in the intention-to-treat analysis. Although the patients in all 4 study groups showed a mean improvement in physical functioning, this pattern was not found for the change in mean spinal mobility measured with the Cybex EDI 320. Considering the total range of motion of the movements measured at baseline, the mean changes at follow-up were all relatively small in the 4 study groups. These findings indicate that the improvement in physical functioning occurred relatively independently of changes in range of motion of the spinal movements. Generally, spinal range of motion is considered to be an objective and relatively reproducible measure ${ }^{17}$ 
${ }^{18}$ However, it inight not be very suitable for measuring progress of patients with chronic back and neck complaints. 1920

The outcome of physical functioning supports to a large extent the findings of the primary outcome parameters of this clinical trial (improvement on the main complaint and global perceived effect), which indicated a favourable outcome for both manual therapy and physiotherapy compared to treatment by the general practitioner or the placebo treatment. ${ }^{13}$ The main difference is that, especially after 3 weeks follow-up, manual therapy appeared to improve physical functioning more than physiotherapy. An intention-to-treat comparison is most valid when the drop-out rate (and number of missing values) is low and there is no contamination. In this study, however, the results especially at 12 weeks follow-up might be biased substantially due to switch-overs. Especially in the placebo group and GP group a considerable number of patients changed from the assigned therapy to (mainly) physiotherapy and manual therapy. Furthermore, the number of drop-outs and missing values were the highest in the placebo group and the GP group. We dealt with these problems by substituting the results at follow-up with the last available measurement before changing therapy (to physiotherapy or manual therapy) or before having a missing outcome. Thus, we assumed no further improvement after these moments for the patients involved. This means that for these patients we ignored the general trend of improvement over time, but also ignored the possibility of a deterioration among these patients. Readers can choose the analysis they prefer for drawing conclusions. We believe that the intentionto-treat analysis overestimates the efficacy of the placebo therapy and treatment by the GP especially at 12 weeks follow-up. On the other hand the alternative analysis might lead to some underestimation of the effect of especially the placebo therapy and treatment by the GP. 


\section{References}

1. Frymoyer JW. Back pain and sciatica. N Engl J Med 1988; 318: 291-300.

2. Nachemson $A$. The lumbar spine: An orthopaedic challenge, Spine 1976; 1: 59-71.

3. Nachemson A. Towards a better understanding of low back pain. Rheum Reh 1975; 14: 129-143.

4. Nachemson A. A critical look at the treatment for low back pain. Scand J Rehab Med 1979; 11: $143-147$.

5. Deyo RA. Conservative therapy for low back pain. JAMA 1983; 250: 1057-1062.

6. Spitzer WO, Leblanc $\mathrm{FE}_{\mathrm{s}}$ Dupuis $\mathrm{M}$. Scientific approach to the assessment and managenent of activity-related spinal disorders, Spine 1987; 7 (suppl 1): 1.59.

7. Waddell G. A new clinical model for the treatment of low-back pain. Spine 1987; 12; 632-644.

8. Koes BW, Assendelft WJ, Heijden van der GJMG, Bouter LM, Knipsehild PG. Spinal manipulation and mobilization for back and neck complaints. A blinded review. Br Med J 1991; 303: 1298-1303.

9. Farrell JP, Twomey LT. Acute low back pain: comparison of two conservatiwe treatment approaches. Med J Aust 1982; 1: 160-164.

10. Bergquist-Ullman M, Larsson $M$. Acute low back pain in industry: a controlled prospective study with special reference to therapy and confounding factors. Acta Orthop Scand 1977; 170 (suppl): 111-117.

11. Postachini $F$, Facchini $M_{\text {, }}$ Palieri $P$. Efficacy of various forms of conservative treatmeut in low back pain: a comparative study. NeurouOrthopedics $1988 ; 6: 28-35$.

12. Waagen GN, Haldeman S, Cook G, Lopez D, DeBoer KF. Short term trial of chiropractic adjustments for the relief of chronic low back pain. Manual Med 1986; 2:63-67.

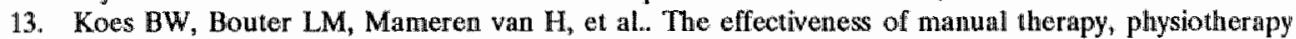
and treatment by the general practitioner for chronic non-specific back and neck complaints: a randomized clinical trial. Spine (in press).

14. Koes BW, Bouter LM, Knipschild PG, et al.. The effectiveness of manual therapy, physiotherapy and continued treatment by the general practitioner for chronic non-specific back and neck complaints: design of a randomized clinical trial. J Manipulative Physiol Ther (in press).

15. Koes BW, Mameren van $H$, Bouter $\mathbb{L M}_{*}$ et al.. Reproducibility of range of motion measurements of the spine with the CYBEX EDI 320. Proceedings of the 3rd International Physiotherapy Congress, Hong Kong, Link Printing, Sydney, 1990; 442-447.

16. Dixon WJ, Brown MB, Engelman L, Hill MA. BMDP statistical software manual. University of California Press, Berkeley, 1988.

17. Gajdosik RL, Bohannan RW. Clinical measurement of range of notion. Phys Ther 1987; 67: 1867. 1872.

18. Stratford $\mathrm{P}$, Agostino V, Brazeau C, Gowitzke BA. Reliability of joint angle measurement: a discussion of methodological issues. Physiotherapy Canada $1984 ; 36: 5-9$.

19. Mameren $\mathrm{H}$ wan, Drukker $J_{\text {, Sanches }} \mathbf{H}$, Beursgens $\mathbf{J}$. Cervical spine motion in the sagital plane $\mathrm{I}$ : range of motion of actually performed movements: an $X$-ray cinematographic study. Fur $J$ Morphology 1990; 28: 47-68.

20. Mameren $\mathrm{H}$ van. Motion patterns in the cervical spine (PhD-thesis). Maastricht, the Netherlands: University of Limburg, 1988. 150p. 


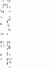

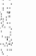


Chapter 7

\section{RANDOMISED CLINICAL TRIAL OF MANUAL THERAPY AND PHYSIOTHERAPY FOR PERSISTENT BACK AND NECK COMPLAINTS}

Results of one year follow-up*

BW Koes, LM Bouter, H van Mameren, AHM Essers, GMJR Verstegen, DM Hofhuizen, JP Houben, PG Knipschild 


\section{Abstract}

In a randomised clinical trial we compared the effectiveness of manual therapy, physiotherapy, treatment by the general practitioner, and a placebo therapy (detuned ultrasound and detuned short wave diathermy) for patients $(\mathrm{n}=256)$ with persistent non-specific back and neck complaints. A large number of the patients who had been originally assigned to treatment by their general practitioner or to placebo treatment changed from the assigned therapy to another therapy during the year follow-up. This clearly indicates the superiority for both manual therapy and physiotherapy. Results for the outcome measures after 6 and 12 months follow-up are presented for the manual therapy group and physiotherapy group. Manual therapy showed a larger improvement of the main complaint compared to physiotherapy. The difference on a 10-point scale was 0.9 and its $95 \%$ confidence interval was $0.1,1.7$ after 12 months follow-up. Manual therapy also showed a larger improvement in physical functioning. The difference on a 10-point scale was 0.6 and its $95 \%$ confidence interval was $-0.1,1.3$ after 12 months follow-up. The global perceived effect after 6 and 12 months follow-up was similar for both treatments. Overall, the findings indicate slightly better results for manual therapy compared to physiotherapy after 12 months follow-up. The original number of treatment sessions was much fewer for manual therapy (mean=5.4) than for physiotherapy $($ mean $=14.7)$. 
In most cases of back pain and neck pain no underlying pathology can be established and the causes of the complaints remain unknown. ${ }^{12}$ Fortunately, the majority of patients with acute complaints recover within a few weeks, often with the belp of (bed)rest, analgesics and advice about posture and exercises. ${ }^{3}$ Within a few months the complaints disappear in about $90 \%$ of the cases ${ }^{245}$, although the recurrences rate is high. ${ }^{1}$ When the complaints persist there are several options for treatment. General practitioners in the Netherlands frequently refer patients with persisting complaints to physiotherapy or, less frequently, manual therapy.

Physiotherapists usually give exercise therapy, alone or in combination with other treatments (for example, massage, heat, traction, ultrasound, or short wave diathermy). ${ }^{6}$ We know of 16 randomised clinical trials (RCTs) investigating the efficacy of exercises given alone or in combination with additional physical treatment modalities.

Unfortunately, most of these studies show severe methodological flaws. Long term positive effects of exercises were only reported in one of the two studies which included an effect measurement after 12 months. ${ }^{\text {D }}$ Despite its widespread use the efficacy of physiotherapy still remains questionable. ${ }^{13-6}$ We know of 35 RCTs investigating the efficacy of manipulation and mobilisation for back and neck complaints, but the majority of these studies also show severe methodological flaws and inconsistent results. ${ }^{7}$ In only 7 of the available RCTs were effects measured at least 12 months after randomisation. ${ }^{8-14}$ Long-term positive effects favouring manipulation were reported in only one of these studies. ${ }^{9}$

In this article we present the long term results of a randomised clinical trial in which we compare manual therapy, physiotherapy, treatment by the general practitioner and a placebo treatment for patients with persistent back and neck complaints. Elsewhere, the design ${ }^{15}$ and short-term results ${ }^{16} 17$ are reported in detail.

\section{Methods}

\section{Selection of the patients}

Patients with back and neck pain for at least six weeks were selected by general practitioners (GPs) and by advertisements in the local press during a two-year period (January 1988 - December 1989). Subsequently, all potential participants were seen by the same research assistant (an experienced physiotherapist and manual therapist) who performed a physical examination and did the final check with respect to the admission criteria. ${ }^{15}$ The purpose of these criteria was to select a (relatively) homogeneous group of patients suitable for treatment with physiotherapy, manual therapy and continued care by the general practitioner. Eligible patients completed the informed consent by signing a letter. Subsequently, randomisation was carried out by a second research assistant using a list of random numbers.

\section{Treatments}

The following 4 treatments were included: (1) physiotherapy, which consisted of exercises, massage and/or physical therapy modalities (heat, electrotherapy, ultrasound, shortwave diathermy); (2) manual therapy, which consisted of manipulative techniques (manipulation and mobilisation of the spine) according to the directives of the Dutch Society for Manual Therapy (NVMT); (3) continued treatment by their general 
practitioner, which consisted of prescription of medication (e.g. analgesics, NSAIDs), advice about posture, home exercises, participation in sports, (bed)rest, etc; (4) placebo treatment, which in each session consisted of a physical examination and subsequently detuned shortwave diathermy (10 minutes) and detuned ultrasound (10 minutes) carned out by the participating physiotherapists. The placebo treatment sessions were schediuled twice a week for a period of six weeks.

All therapists (except for the placebo treatment) were free to choose from their usual therapeutic domain within some explicitly formulated limits (e.g. no manipulative techniques could be performed by the physiotherapists). All treatments were given for a maximum duration of three months.

\section{Outcome measures}

Follow-up measurements were carried out at 6 and 12 months after randomisation in order to study long-term effects. Below, we focus on the 3 outcome measures which proved to have been sensitive to measure changes at the short-term follow-up $(3,6$ and 12 weeks after randomisation) 1617 : (1) severity of the main complaint, (2) global perceived effect and (3) physical functioning.

The main complaint was determined as that complaint which the patient considered to be the most important at baseline. Its severity was assessed by the research assistant on a 10 -point scale $(1=$ minimal severity, $10=$ maximal severity $)$ and was based on history taking and physical examination. During all follow-up measurements the research assistant was unaware of the treatment to which the patients were assigned. He also had no information about the previous scores. Global perceived effect was assessed by the patients themselves on a 6 -point scale $(1=$ no benefit, $6=$ maximal benefit) after 6 and 12 months follow-up. Physical functioning was operationalised as the ability of patients to perform active spinal movements. Patients with neck complaints were asked to perform a standardised set of cervical movements (anteflexion, retroflexion, lateroflexion, and rotation); those with back complaints had to perform a similar set of trunk movements. At baseline the research assistant noted for each patient the movements (max. 3) for which the patient reported the most severe pain or limitation of the range of motion (ROM). In addition, the severity of the pain (or of the limitation of the ROM) for these movements was scored on a ten-point scale $(1=$ minimall severity, $10=$ maximal severity). At follow-up the movements chosen at baseline were re-assessed by the same (blinded) research assistant, who was unaware of the previous scores. The physical functioning score was calculated by adding the severity scores of all (max. 3 ) the movements at issue divided by the number of movements. ${ }^{17}$

\section{Statistical analysis}

The cumulative number of patients in each of the 4 treatment groups who deviated from the allocated therapy at follow-up after 6 and 12 months was calculated. The effects in the group receiving placebo therapy and the group receiving treatment by the GP appeared to be seriously biased due to contamination and co-interventions (see results). Therefore, we restricted the data-analysis for the 3 outcome measures to manual therapy and physiotherapy only.

For two outcome measures (severity of main complaint and physical functioning) we calculated the differences between the follow-up scores and the baseline score for the individual patients. Subsequently, the two study groups were compared among each other for their improvement at $\mathbf{1 2}$ months after randomisation. They were also 
compared for their global perceived effect at 6 and 12 months. In addition, cumulative distributions of the improvement scores of the severity of the main complaint, globall perceived effect, and the improvement scores for physical functioning after 12 months follow-up were calculated. Group differences and $95 \%$ confidence intervals were calculated for the 3 outcome measures after 6 and 12 months follow-up using a linear regression model, with the aim of estimating between group differences adjusted for small imbalances at baseline for important prognostic indicators. In the model we entered the following co-variables: localisation and duration of the main complaint, the baseline score of the outcome measure at issue (except for global perceived effect in which case severity of the main complaint at baseline was chosen), age and recruitment status (general practitioner or advertisement). The analyses were carried out with BMDP version $1990 .^{18}$

\section{Results}

Study sample and prognostic comparability

A total of 256 patients were included and randomly assigned to the 4 study treatments. Table 1 shows the demographic and clinical characteristics of the participants.

Comparability between the 4 groups for the main prognostic variables such as duration, severity, localisation of the complaints and age, seems to be satisfactory.

Table 1. Baseline characteristics of the study population.

Characteristic

manual

physion-

placebo

general

all

therapy

therapy

therapy

practilioner

subjects

No. of subjects
Selected through advertisement (\%)
Mean age (yrs)
Gender(\% female)
Localisation of complaints (\%):
Back
Neck
Back and Neck
Median duration of present
episode of complaints (wks)
patients with back or neck
complaints ( $\mathrm{n}=208$ )
patients with back and neck
complaints ( $\mathrm{n}=48$ )
back
neck
Mean severity main complaint
(10 point scale)
Mean physical functioning
score (10-point scale)

65

75

43

54

55

20

25

52

78

91

7.0

5.9
66

64

42

48

54

32

14

52

26

26

7.0

5.8

\section{4}

60

43

52

62

22

16

52

45

52

61

43

38

53

26

21

25

25

19

256

68

43

52

56

6
5
9

(1)


Compliance with treatment

Table 2 shows the number of treatments, session time and duration of treatment for the 4 study groups. The number of treatments was much lower in cases of manual therapy compared to physiotherapy (mean 5.4 versus 14.7 ). Patients in the GP group mostly paid orily a single visit to their GP.

Table 2. Mean number of treatments, session time and duration of treatment during the intervention period. The medians are given in parentheses

\begin{tabular}{lrll}
\hline & $\begin{array}{l}\text { Number of } \\
\text { treatments }\end{array}$ & $\begin{array}{l}\text { Session } \\
\text { tîme (min) }\end{array}$ & $\begin{array}{l}\text { Duration } \\
\text { (wks) }\end{array}$ \\
\hline Manual therapy & $5.4(6)$ & $41(40)$ & $8.9(9)$ \\
Plisysiotherapy & $14.7(14)$ & $35(30)$ & $7.8(8)$ \\
Placebo therapy & $11.1(12)$ & $29(30)$ & $5.8(6)$ \\
General practitioner & & - & - \\
\hline
\end{tabular}

a (contiuued) treatment by the GP consisted usually of a single visit by the patient at the generall practice.

\section{Outcome}

Table 3 presents the cumulative frequency of the deviations of the allocated therapy according to the study protocol at follow-up after 6 and 12 months. It appears that contamination and co-interventions mainly occurred among the patients who received a placebo treatment or remained in the general practice. Among the patients who were allocated to manual therapy or physiotherapy this occurred much less frequently. In addition, there were 3 patients in the physiotherapy group, and 9 patients in the manual therapy group who continued their allocated treatment after the planned maximum of 3 months intervention period. There were 4 patients in the physiotherapy group and 3 patients in the manual therapy group who started a new period of the allocated treatment. Overall, the number of deviations from the study protocol among patients receiving manual therapy or physiotherapy seemed equally distributed.

After 6 months follow-up 11 patients (17\%) in the physiotherapy group and 7 patients $(11 \%)$ in the manual therapy group did not fill out the written questionnaire. After 12 months follow-up 17 patients (26\%) in the physiotherapy group and 10 patients (15\%) in the manual therapy group did not show up for their final effect measurement (change in main complaint and physical functioning) by the research assistant. However, after 12 months follow-up most patients filled out the questionnaire; only 6 patients $(9 \%)$ who received physiotherapy, and 5 patients $(8 \%)$ who received manual therapy could not be persuaded to do so. Table 4 lists the results up to 12 months follow-up for the manual therapy group and physiotherapy group. With regard to the change of the main complaint, manual therapy showed the largest improvement $(4.5 ; \mathrm{SD}=2.2)$ after 12 months follow-up. The difference in improvement scores between both groups was 0.9 and its $95 \%$ confidence interval was $0.1,1.7$. As for the change in physical functioning, the manual therapy group showed consistently better results than the physiotherapy group at all follow-up measurements. 
Table 3. Cumulative number of deviations from the allocated therapy according to the study protocol at follow-up.

\begin{tabular}{|c|c|c|}
\hline treatment & $6 \mathrm{mths}$ & $12 \mathrm{mihs}$ \\
\hline manual therapy & $\begin{array}{l}\text { 3. physiotherapy } \\
2 \text { specialist } \\
1 \text { HNP operation } \\
1 \text { injection } \\
1 \text { alternative medicine }\end{array}$ & $\begin{array}{l}5 \text { physiotherapy } \\
2 \text { specialist } \\
1 \text { HNP operation } \\
1 \text { injection } \\
2 \text { alternative medicine }\end{array}$ \\
\hline physiotherapy & $\begin{array}{l}2 \text { manual therapy } \\
1 \text { sport massage } \\
1 \text { specialist } \\
1 \text { alternative medicine }\end{array}$ & $\begin{array}{l}6 \text { manual therapy } \\
1 \text { sport massage } \\
7 \text { specialist } \\
2 \text { alternative medicine }\end{array}$ \\
\hline placebo therapy & $\begin{array}{l}18 \text { physiotherapy } \\
3 \text { manual therapy } \\
1 \text { cesar therapy } \\
2 \text { specialist } \\
1 \text { HNP operation }\end{array}$ & $\begin{array}{l}19 \text { physiotherapy } \\
3 \text { mantal therapy } \\
1 \text { cesar therapy } \\
5 \text { specialist } \\
1 \text { HNP" operation }\end{array}$ \\
\hline general practitioner & $\begin{array}{l}8 \text { physiotherapy } \\
6 \text { manual therapy } \\
2 \text { cesar therapy } \\
11 \text { sport massage } \\
2 \text { specialist } \\
1 \text { HNP operation } \\
1 \text { hospitalisation } \\
2 \text { alternative medicine }\end{array}$ & $\begin{aligned} 12 & \text { physiotherapy } \\
6 & \text { manual therapy } \\
2 & \text { cesar therapy } \\
1 & \text { spott massage } \\
2 & \text { speciallist } \\
1 & \text { HNP operation } \\
1 & \text { hospitalisation } \\
2 & \text { alternative medicine }\end{aligned}$ \\
\hline
\end{tabular}

Table 4. Outcome of therapy at follow-lip,

\begin{tabular}{|c|c|c|c|c|c|c|}
\hline oulcome measure & 3 whiks & 6 wha & 12 wks & 6 mithe & 12 miths & $\begin{array}{l}\text { diflerenow between mantitl } \\
\text { therapy and physotherapy }\end{array}$ \\
\hline \multicolumn{7}{|c|}{$\begin{array}{l}\text { mean (SD) improwement main } \\
\text { complaint }(10 \text {-point scale })\end{array}$} \\
\hline manual therapy & $23(21)$ & $3.4(2.1)$ & $4.0(2.6)$ & & $4.5(2.2)$ & $0.9(0.1,1.7) 12$ months \\
\hline physiotherapy & $2.0(2.3)$ & $3.4(2.4)$ & $3.8(2.3)$ & & $3.8(2.3)$ & \\
\hline \multicolumn{7}{|c|}{$\begin{array}{l}\text { mean (SD) global perceived } \\
\text { effect ( } 6 \text { point scale) }\end{array}$} \\
\hline manual therapy & $2.5(1.5)$ & $3.4(1.7)$ & $3.4(2.0)$ & $3.5(1.9)$ & $3.5(1.8)$ & $0.3(-0.4,1.0)$ b months \\
\hline physiontherapy & $2.6(1,6)$ & $3.3(1.6)$ & $3.7(1.7)$ & $3.5(1.8)$ & $3.2(1.9)$ & $0.4(-0.3,1.4) 12$ monthg \\
\hline \multicolumn{7}{|c|}{$\begin{array}{l}\text { mean (SD) improwement on physical } \\
\text { functioning (10-point scale) }\end{array}$} \\
\hline manual the rapy & $2.3(2.1)$ & $3.5(1.9)$ & $40(2.3)$ & & $4.2(2.1)$ & $0.6(-0.1,1.3) 12$ monihs \\
\hline physiothera py & $1.6(1.9)$ & $3.1(1.8)$ & $3.2(2.0)$ & & $3.7(2.0)$ & \\
\hline
\end{tabular}

- The group differences (95\% conffutence interval) are calculated with the use of a linear regression model. 
The difference between both groups after 12 months follow-up was 0.6 and its $95 \%$ confidence interval was $-0.1,1.3$. With respect to the assessment by the patient of the global perceived effect, both groups showed similar results at all follow-up measurements.

Even among the patients assigned to manual therapy and physiotherapy there was a considerable number of missing values at 12 months follow-up. Therefore, we also conducted an alternative analysis, in which we substituted the last measurement available for missing values. The results of this analysis showed slightly smaller improvement scores for both groups. The mean (SD) improvement for the main complaint after 12 months in this alternative analysis was: $4.1(2.4)$ for manual therapy and $3.4(2.7)$ for physiotherapy. The group difference with its $95 \%$ confidence interval was $0.9(0.1,1.8)$. The mean (SD) improvement for the physical functioning in this alternative analysis was: 3.8 (2.3) for manual therapy and 3.1 (2.2) for physiotherapy. The group difference with its $95 \%$ confidence interval was $0.8(0.1,1.5)$. Both differences were statistically significant at the $5 \%$ level.

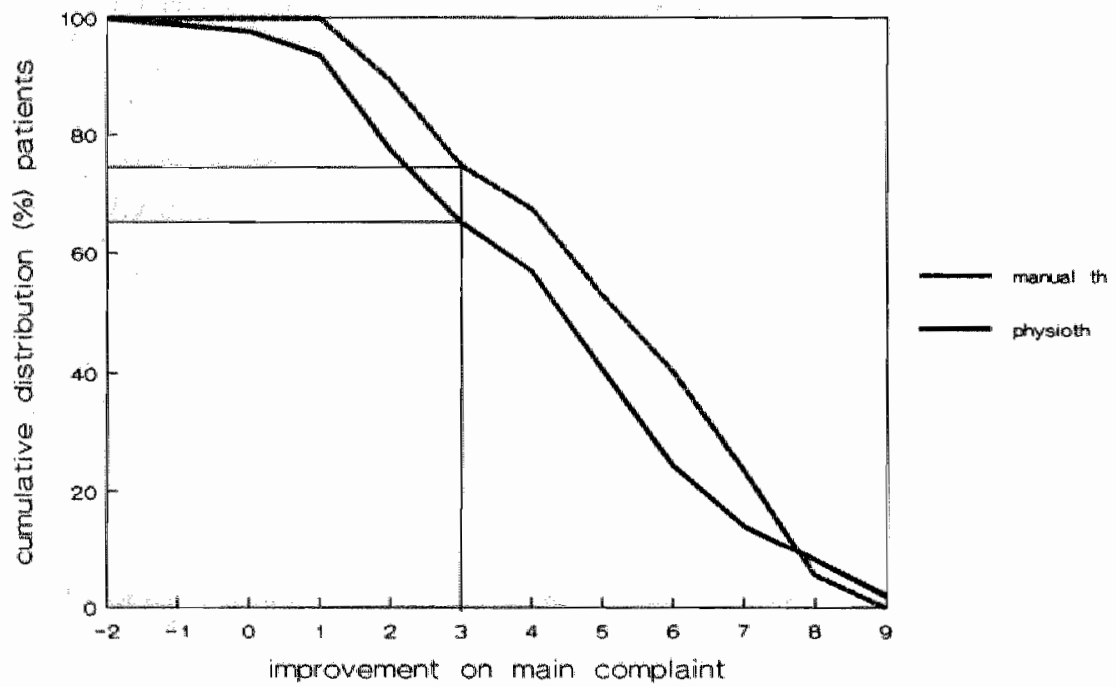

Figure 1. Improvement on main complaint after 12 months follow-up.

Figure 1 gives a graphical presentation of the cumulative distribution of the improvement score for the main complaint in the groups who received manual therapy or physiotherapy. On the abscissa the improvement scores are presented. For any cutoff point one can read the proportion of patients in both study groups with at least that score on the ordinate. For example, $75 \%$ in the manual therapy group and $65 \%$ in the physiotherapy group showed an improvement score of 3 points or more at 12 months follow-up. Manual therapy showed the best outcome for improvement scores of 7 points or less. 


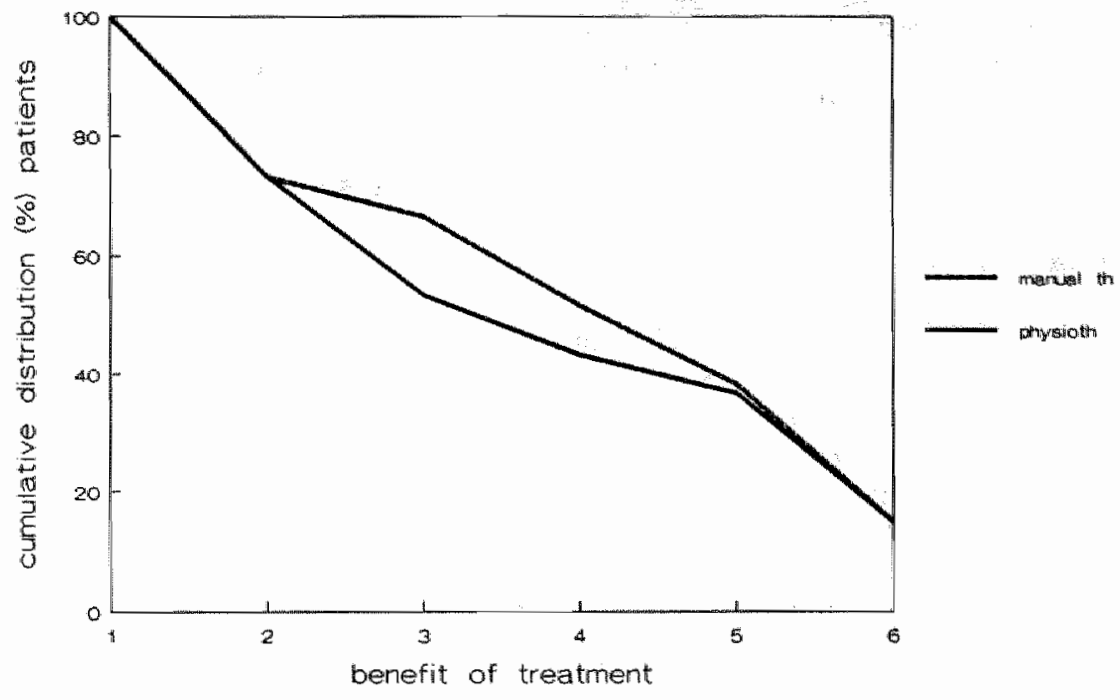

Figure 2. Global perceived effect after 12 months follow-up.

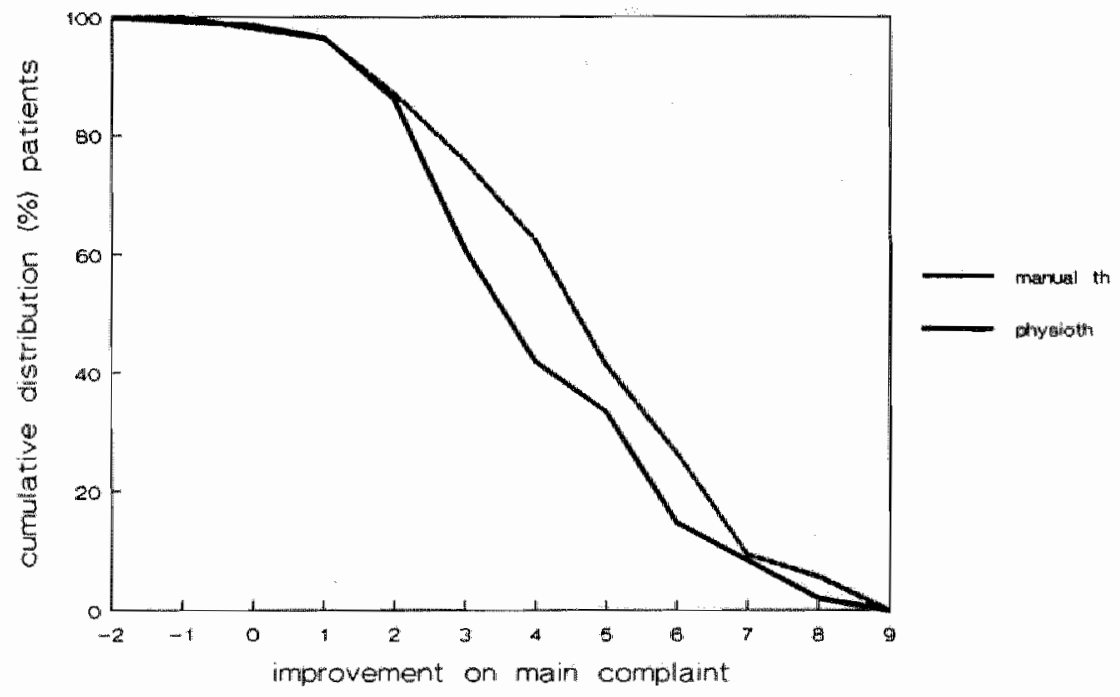

Figure 3. Improvement on physical functioning after 12 months follow-up.

Figure 2 gives the cumulative distribution of the global perceived effect at 12 months follow-up. The cumulative distributions of both groups are rather similar. Only for the 
benefit scores of 3 and 4 is the proportion of patients with at least that score somewhat higher for patients receiving manual therapy.

Figure 3 gives the cumulative distribution of the improvement scores for physical functioning after 12 months follow-up. It appears that for any improvement score the proportion of patients with at least that score is somewhat higher for patients who received manual therapy than for those who received physiotherapy.

\section{Discussion}

The number of patients who changed from the assigned therapy to another therapy during the one year follow-up was large in cases of patients originally assigned to placebo treatment or treatment by a general practitioner. A change in therapy was not chosen as an outcome measure when the trial was designed, but this outcome clearly indicates the superiority of both manual therapy and physiotherapy over the two other treatment regimens. The underlying assumption is that patients will in general turn to other therapies when the allocated therapy is not effective enough.

Because of these large numbers of deviations from the allocated therapy in the placebo group and general practitioner group after 6 and 12 months follow-up, we decided not to analyse the data on the outcome measures for these groups. In the placebo group and the group treated by a general practitioner we expected serious bias due to contamination and co-interventions. However, the comparison between manual therapy and physiotherapy at 6 and 12 months follow-up remained valid and relevant. The short-term results had revealed similar success rates in both these groups ${ }^{16} 17$, but long-term effects are also of major importance for patients with persistent back and neck complaints. The long-term effects after 12 months showed manual therapy to produce a larger mean improvement for the main complaint than physiotherapy. This pattern is also shown in figure 1 were we compare the cumulative distributions of the improvement scores for the main complaint of both groups. The difference between both groups was statistically significant. Physical functioning also appeared to improve consistently better in favour of manual therapy. However, the difference between the study groups was not statistically significant after 12 months follow-up. For the global perceived effect we could not find any substantial difference between both therapies. At 6 months follow-up both groups showed equal scores (3.5 points). At 12 months followup manual therapy scored little higher compared to physiotherapy (3.5 versus 3.2 points). The cumulative distributions only showed some difference in favour of manual therapy for benefit scores of 3 and 4 points. However, the $95 \%$ confidence interval for the group difference was $-0.3,1.4$.

It is remarkable that the patients in the manual therapy group showed better results compared with physiotherapy at 12 months follow-up. In the literature long-term benefits of manual therapy are seldom reported. ${ }^{7}$ The patients in the manual therapy group showed the highest improvement of all effect measurements, while for most patients this moment of effect measurement was about 9 months after the last. treatment session. There are some possible explanations for this finding.

Firstly, it might be that the relatively large number of missing values after 12 months represent the bad responders to therapy. The patients who did show up for their followup measurement might therefore be a selected group of patients in which the therapy was successful. However, in our alternative analysis we substituted the last available measurement for missing values and this did not change the results very much. 
Furthermore, the number of missing values was larger in the physiotherapy group (26\%) than in the manual therapy group (15\%). Therefore we think that missing values cannot explain our findings.

Secondly, many patients might have received additional manual therapy or other cointerventions during the 9 months after the intervention period. Table 3 shows that indeed a number of patients received additional treatment, but the numbers are comparable with those in the physiotherapy group.

Thirdly, it might be that the blinding of the research assistant was not fully successfful. Although we did not measure the success of blinding explicitly, we have no reason to believe that it failed.

Finally, manual therapy may indeed help to restore the function of the spine better than physiotherapy. In the case of persistent conditions a relatively long period might be needed to achieve maximal reduction of the complaints. A physiological explanation for such mechanism bas not yet been demonstrated. The few earlier studies which had included a long-term follow-up mostly did not report long-term positive results of manipulation. ${ }^{8} 10-14$ There is one other study in which the authors report long-term benefit of manipulation for chronic or severe pain, especially at longer term ( 2 years) follow-up. In this large multicentre trial chiropractic manipulation was compared with (physiotherapeutic) hospital outpatient treatment for low back pain. ${ }^{9}$

An important extra finding was that the number of treatments was much lower for manual therapy compared to physiotherapy. This might be regarded as a considerable advantage.

We suggest that after 12 months follow-up both manual therapy and physiotherapy appear to be more effective than treatment by the GP or placebo therapy in the treatment of patients with persistent back and neck pain. Furthermore, the findings indicate a slightly better result for manual therapy compared to physiotherapy after 12 months follow-up. Further trials of manipulation are needed to determine its long-term effects for patients with more specific conditions. 


\section{References}

1. Frymoyer JW. Back pain and scialica. N Engl J Med 1988; 318: 291-300.

2. Waiddell G. A now clinical model for the treatment of low-back pain. Spine 1987; 12:632-644.

3. Nachemison A A critical look at the treatment for low back pain. Scand J Rehab Med 1979; 11: 143-147.

4. Deyo RA. Conservative therapy for low back pain. JAMA 1983; 250: 1057-1062.

5. Spilzer WO, Leblanc FE, Dupuis M. Scientific approach to the assessment and management of activity frelated spinal dissorders. Spine 1987; 7 (suppl 1): 1-59.

6. Koes BW, Bouter LM Beckerman $\mathbb{H}_{f}$, Heijden van der GIMG, Knipschild PG. Physiotherapy exercises and back pain: a blinded review. Br Med I 1991; 302: 1572-1576.

7. Koes BW, Assendelft WJ, Heijden van der GJMG, Bouter LM, Knipschild PG. Spinal manipulation and mobilization for back and neck complaints. A blinded review. Br Med J 1991; 303 : 1298-1303.

8. Bergquist-Ullman M, Larsson M. Acute low back pain in industry: a controlled prospective study with special reference to therapy and confounding factors. Acta Orthop Scand 1977; 170 (suppl): 111.117.

9. Meade TW, Dyer S, Browne W, Townsend $J$, Frank AO. Jow back pain of mechanical origin: randomised comparison of chiropractic and hospital outpatient treatment. Br Med J 1990; 300: 1431-1437.

10. Sims-Willams H, Jayson MIV, Young SMS, Baddeley $\mathrm{H}$, Collins E. Controlled trial of nobilisation and manipulation for low back pain: hospital patients. Br Med J 1979; 2: 1318-1320.

11. Doran DML, Newell DJ. Manipulation in treatment of low back pain: a multicentre study. Br Med J 1975; 2: 161-164.

12. Coxhead CE, Inskip H, Meade TW, North WRS, Troup JDG. Multicentre trial of physiotherapy in the management of sciatic symptoms. Lancet 1981; 1: 1065-1068.

13. Sims-Willians H, Jayson MIV, Young SMS, Baddeley H, Collins E. Controlled trial of mobilisation and manipulation for patients with low back pain in general practice. Br Med J 1978; 2: 1338-1340.

14. Siehl D, Olson DR, Ross HE, Rockwood EE. Manipulation of the lumbar spine with the patient under general anaesthesia: evaluation by electromyography an clinicall-neurologic examination of its use for lumbar nerve root compression syndrome. J Am Osteopath Assoc 1971; 70: 433-450.

15. Koes BW, Bouter LM, Knipschild PG, Mameren van H, Essers AHM, Houben JP, Verstegen GMJR, Hofhuizen DM. The effectiveness of manual therapy, physiotherapy and contimued treatment by the general practitioner for non-specific back and neck complaints: design of a randomized clinical trial. $J$ Manipulative Physiol Ther (in press).

16. Koes BW, Bouter LM, Mameren van H, Essers AHM, Verstegen GMJR, Hofhuizen DM, Houben IP, Knipschild PO. The effectiveness of manual therapy, physiotherapy and treatment by the general practitioner for non-specific back and neck complaints: a randomized clinical trial. Spine (im press).

17. Koes BW, Bouter LM, Mameren van H, Essers AHM, Verstegen GMJR, Hothuizen DM, Houben $J P$, Knipschild $\mathrm{PG}$. A blinded randomized clinical trial of manual therapy and plysiotherapy for chronic back and neck complaints: physical outcome neasures. I Manipulative Physiol Ther (in press).

18. Dixon WJ, Brown MB, Eugelinan L, Jenrich RI. BMDP statistical software manual. University of California Press, Berkeley, 1990. 
Chapter 8

\section{A RANDOMISED CLINICAL TRIAL OF MANUAL THERAPY AND PHYSIOTHERAPY FOR PERSISTENT BACK AND NECK COMPLAINTS*}

Subgroup analysis and relationship between outcome measures

BW Koes, LM Bouter, H van Mameren, AHM Essers, GJMG Verstegen, DM Hofhuizen, JP Houben, PG Knipschild 

Abstract
In a randomised clinical trial on the efficacy of manual therapy and physiotherapy for persistent back and neck complaints we performed a limited number of subgroup analyses. Furthermore, we calculated the correlation between 3 important outcome measures of this trial: improwement for the main complaint, improvement in physical functioning, both rated on a 10-point scalle by a blinded research assistant, and global perceived effect rated on a 6 -point scale by the patients themselves. The results suggest that manual therapy showed better results compared to physiotherapy regarding improvement for the main complaint and improvement in physical functioning for (a) patients with chronic conditions (duration complaint of one year or longer) and (b) patients younger than 40 years. These differences were most evident after 12 months follow-up. Labelling of patients by the treating manual therapists as 'suitable' or "not suitable' for treatment with manual therapy did not predict differences in outcomes. Generally, there was a moderate to strong correlation between the 3 outcome measures, although a considerable number of patients gave a relatively low score for perceived benefit, while the research assistant gave a high improvement score for the main complaint and physical functioning. 
The frequent occurrence of back and neck complaints is well known. ${ }^{12}$ In western societies the incidence and prevalence of back disorders seems to have been increasing. ${ }^{3}$ Fortunately, the disease is usually self limiting. In about $90 \%$ of the cases the complaints disappear within a period of 6 weeks. ${ }^{3}$ The causes of the disease often remain unknown. In about $50-80 \%$ of the cases no underlying pathology can be established. ${ }^{245}$ There are many therapeutic interventions avallable for the treatment of back and neck complaints. However, no single treatment seems to be clearly superior to others. 16

Physiotherapy consisting of exercises, massage and plysical treatment modalities is widely used in the treatment of back disorders. ${ }^{7-9}$ Manual therapy, which can be defined as the application of passive movements to joints in order to restore the function of the spine, is also widely used in the treatment of back disorders. 1011 Recently we have completed a randomised clinical trial in which we compared the efficacy of manual therapy, physiotherapy, continued care by the general practitioner, and placebo therapy for persistent back and neck complaints. ${ }^{2} \mathrm{~A}$ complaint was considered to be persistent if the duration of the current episode was 6 weeks or longer. The results of this trial indicated that for the patients included, both manual therapy and physiotherapy had clearly better results than continued care by the general practitioner and placebo therapy (detuned ultrasound and detuned shortwave diathermy). There were no differences in effect between manual therapy and physiotherapy after 3,6 , and 12 weeks follow-up. However, the mean number of treatments during the intervention period was much fewer for manual therapy (mean 5.4) compared to physiotherapy (mean 14.7). ${ }^{1314}$ After 12 months follow-up manual therapy showed slightly better results compared to physiotherapy. ${ }^{15}$ The results of this trial in combination with previous trials ${ }^{16}$ suggest that physiotherapy and manual therapy can be considered as valuable interventions for persistent back and neck complaints. In this article we focus on two issues which are of importance for the design of future intervention studies in this field. The first issue deals with the question. which subgroup of patients, if any, will benefit particularly from manual therapy or physiotherapy. The second issue deals with the strength and direction of the relationship among the most important outcome measures which we used in our trial. The design and results of the overall analysis of this trial bave been published in detail. elsewhere. ${ }^{12-15}$ In this article we present the design of the trial briefly subsequently, we present the strategy of the subgroup analysis and the calculation of the relationship of the 3 most important outcome measures of our trial. Finally, we present the results and discuss the findings.

\section{Methods}

\section{Selection of the patients}

Patients with back and neck complaints for at least six weeks were selected by general practitioners (GPs) and by advertisements in the local press during a two-year period (January 1988 - December 1989). Patients who responded to the advertisements were firstly sent to their general practitioner who checked the admission criteria.

Subsequently, all potential participants were seen by the same research assistant (an experienced physiotherapist and manual therapist) who performed a physical 
examination and did the final check with respect to the admission criteria. Eligible patients completed the informed consent by signing a letter. Subsequently, randomisation was carried out by a second research assistant using a list of random numbers. At the first treatment session the patients who were allocated to manual therapy and pltysiotherapy were assessed by the treating therapist on suitability for the allocated treatment. The therapists rated the suitability of the patients on a 5-point scale (ranging from very suitable to not suitable).

\section{Theatments}

The following 4 treatments were included: (1) physiotherapy, which consisted of exercises, massage and/or physical therapy modalities (heat, electrotherapy, ultrasound, shortwave diathermy); (2) manual therapy, which consisted of manipulative techniques (manipulation and mobilisation of the spine) according to the directives of the Dutch Society for Manual Therapy (NVMT); (3) continued treatment by their general practitioner, which consisted of prescription of medication (e.g. analgesics, NSAIDs), advice about posture, home exercises, participation in sports, (bed)rest, etc; (4) placebo treatment, which in each session consisted of a physical examination and subsequently detuned shortwave diathermy (10 minutes) and detuned ultrasound (10 minutes) carried out by the participating physiotherapists. The placebo treatment sessions were scheduled twice a week for a period of six weeks.

All therapists (except for the placebo treatment) were free to choose from their usual therapeutic domain within some explicitly formulated limits (e.g. no manipulative techniques could be performed by the physiotherapists). All treatments were given for a maximum duration of three months.

\section{Outcome measures}

Below, we focus on 3 important outcome measures which proved to have been sensitive to measure changes in the overall analysis: (1) severity of the main complaint, (2) global perceived effect and (3) physical functioning. The first two outcome measures were considered to be the most important ones in our hierarchicall list of outcome measures which was made before the results were available. The last outcome measure was considered to be a secondary outcome measure. ${ }^{12}$

The main complaint was the complaint which the patient considered to be the most important at baselline. Its severity was assessed by the research assistant on a 10-point scale $(1=$ minimal sewerity, $10=$ maximal severity $)$ and was based on history taking and physical examination. During all follow-up measurements the research assistant was unaware of the treatment to which the patients were assigned. He also had no information about the previous scores. Global perceived effect was assessed by the patients themselves on a 6 -point scale $(1=$ no benefit, $6=$ maximal benefit). Physical functioning was operationalised as the ability of patients to perform active spinal movements. Patients with neck complaints were asked to perform a standardised set of cervical movements (anteflexion, retroflexion, lateroflexion, and rotation); those with back complaints had to perform a similar set of trunk movements. At baseline the research assistant noted for each patient the movements (maximum of 3 ) for which the patient reported the most severe pain and/or limitation of the range of motion (ROM). In addition, the severity of the pain (or of the limitation of the ROM) for these movements was scored on a ten-point scale $(1=$ minimal severity, $10=$ maximal severity). At follow-up the movements chosen at baseline were re-assessed by the same (blinded) 
research assistant, who was unaware of the previous scores. The physical functioning score was calculated by adding the severity scores of all (max. 3 ) the movements at issue divided by the number of movements. Measurements of the severity of the main complaint and physical functioning were taken at baseline and after 3,6 and 12 weeks, and after 12 months follow-up. The global perceived effect was measured after 3,6, and 12 weeks, and 6 and 12 months follow-up.

\section{Strategy for subgroup analysis}

In a trial with 4 study groups, 3 responsive outcome measures, 5 follow-up measurements, and a large number of baseline characteristics each with at least two categories, the number of subgroups which can be studied is tremendous. In order to avoid endless data-analyses which supply results which are not interpretable; we decided on the following strategy:

(1) We confined the analysis to manual therapy and physiotherapy only. Our search was focused on specific subgroups which benefit particularly from a certain therapy. We do not expect to find a subgroup of patients who were particularly successfully treated by their general practitioner, because the overall analysis showed that in this group the results were generally low. A similar reasoning holds for the placebo group. Although in the overall analysis the placebo group scored better than the general practitioner group, the results were consistently smaller than for manual therapy and physiotherapy. Consequently the placebo treatment could not be expected to have better results than manual therapy and physiotherapy in subgroups of patients.

(2) We further confined the analysis to subgroups based on 6 pre-defined baseline characteristics only: (a) duration of the present episode (lless than 1 year, longer than or equal to 1 year); (b) age (younger than 40 years, 40 years and older); (c) localisation of the complaints (back only, neck only, back and neck); (d) recruitment status (general practitioner, advertisement); (e) severity of complaint (severity score of less than 7 points, severity score of 7 points or higher); (f) appropriateness of allocated treatment according to treating therapist (suitable, not suitable).

(3) If in a subgroup the difference in effect between manual therapy and physiotherapy was less than 1 point for the outcome measure at issue, we do not report the outcomes of the analysis in this article. Although arbitrarily chosen, a difference of less than 1 point might be regarded as relatively unimportant. If the difference in a subgroup between manual therapy and physiotherapy is at least 1 point, we also estimate the subgroup difference with the use of a linear regression model. In the regression model we entered the following co-variables with the purpose to adjust for imbalances at baseline: localisation and duration of the main complaint, the baseline score of the outcome measure at issue, age and recruitment status (general practitioner or advertisement). In the subgroups which were based on one of these co-variables we excluded this variable in the regression model.

(4) We also omitted the results of subgroups which contained 10 patients or less.

Although this cut-off point is also arbitrarily chosen, the precision of estimation of the effect in subgroups with 10 patients or less, is presumably to low to allow any confidence in the result.

(5) In the cases where either manual therapy or physiotherapy had better results in a certain subgroup (for example, in the patients who are younger than 40 years), we also calculate and present the results in the complementary subgroup (in the example, the patients who are 40 years or older). 
To summarise, for each of the 6 subgroups mentioned under point 2 we analysed the data on 3 outcome measures for the 5 follow-up measurements at issue ( 90 analyses). Subsequently, the results of subgroup analyses which did not indicate important differences in effect between manual therapy and physiotherapy were omitted.

\section{Calculation relationship outcome measures}

For the calculation of the correlation between the outcome measures we the data of all four study groups. For two outcome measures (severity of main complaint and physical functioning) we calculated the differences between the follow-up scores and the baseline score for the individual patients. Subsequently, for all four treatment groups the mean improvement score is calculated. For gllobal perceived effect there was, of course, no baseline measurement. The relations among the 3 outcome measures after 6 weeks follow-up are presented in three separate tables. Pearson correlation coefficients are calculated as indicator of the strength of the correlations.

Because all analyses presented in this article are meant to be explorative only, we decided to refrain from calculating P-values or confidence intervals.

\section{Results}

Study sample and prognostic comparability

A total of 256 patients were included in the trial and randomly assigned to the 4 study treatments. Table 1 shows the demographic and clinical characteristics of all participants at baseline. There were 65 patients allocated for manual therapy and 66 patients for physiotherapy.

Table 1. Baseline characteristics of the study population

Charnacteristic

manual.

physio-

placebo

general

all

therapy

therapy

therapy

practitioner

subjects

\begin{tabular}{|c|c|c|c|c|c|}
\hline No. of subjects & 65 & 66 & 64 & 61 & 256 \\
\hline Selected through advertisenent (\%) & 75 & 64 & 60 & 62 & 68 \\
\hline Mean age (yrs) & 43 & 42 & 43 & 43 & 43 \\
\hline Gender (\% fentale) & 54 & 48 & 52 & 38 & 52 \\
\hline \multicolumn{6}{|l|}{ Localisation of complaints (\%): } \\
\hline Back & 55 & 54 & 62 & 53 & 56 \\
\hline Neck & 20 & 32 & 22 & 26 & 25 \\
\hline Back and Neck & 25 & 1.4 & 16 & 21 & 19 \\
\hline \multicolumn{6}{|l|}{$\begin{array}{l}\text { Median duration of present } \\
\text { episode of complaints (wks) }\end{array}$} \\
\hline $\begin{array}{l}\text { patients with back or neck } \\
\text { complaints ( } \mathrm{n}=208 \text { ) } \\
\text { patients with back and neck } \\
\text { complaints }(\mathrm{n}=48)\end{array}$ & 52 & 52 & 52 & 45 & 52 \\
\hline back & 78 & 26 & 92 & 78 & 79 \\
\hline neck & 91 & 26 & 65 & 52 & 52 \\
\hline Mean severity main complaint (10-point scale) & 7.0 & 7.0 & 6.8 & 6.8 & 6.9 \\
\hline \multicolumn{6}{|l|}{ Mean physical functioning score } \\
\hline$(10$-point scale) & 5.9 & 5.8 & 5.7 & 5.7 & 5.8 \\
\hline
\end{tabular}


Table 2. Outcomes of matwat therapy and physiotherapy in subgroups

mear improwe ment main conyplaint: 12 months follow-up

mean improvemeat in physical functioning: 6 weeks follow-up

mean improwement miatin complaint: 12 months follow-up

meran improwemwent main complaint: 12 months follow up

mean mprowement in physical functioning: 3 weeks follow-up

mean improwement in physical functioning: 6 weeks follow-up

mean improvement main conplaint" 12 morn the follow-up

meas inprovement in physical Itunctioning: 12 weeks follow"up

mean improwement main complaint 12 morths follow-up

mentan improwenent in physical functioning: 3 weeks lollow-up

mesan improwement in physical funtioning: 12 months follow-np mean improwement in physical functionirig: 3 weeks lollow-tip

subgroup

duration conplant $>1$ year
manual physio- diffe-
therapy therapy
$(n=27) \quad(n=24)$

4.3

1.8
1.1

1.2

severity soore at baseline less and 7 points $\begin{array}{lll}\text { mantial physio } & \text { diffe- adjusted } \\ \text { therapy therapy } & \text { rence difference } \\ (n=19) & (n=16) & \end{array}$

3.8

1.5

0.8 age younger than 40 years

$\begin{array}{lll}\text { manual physio- } & \text { diffe- } \\ \text { therapy } & \text { therapy } & \text { rence } \\ (\mathrm{n}=20) & (\mathrm{n}=18) & \end{array}$

$\begin{array}{llll}5.5 & 4.0 & 1.5 & 1.9\end{array}$

3.1

2.0

1.1

1.5

4.4

3.1

1.3

1.4

localisation complaint is the brack

\begin{tabular}{|c|c|c|}
\hline $\begin{array}{l}\text { mamual } \\
\text { therapy } \\
(\text { n }=32)\end{array}$ & $\begin{array}{l}\text { physio- } \\
\text { therajpy } \\
(t)=26)\end{array}$ & $\begin{array}{l}\text { diffex } \\
\text { rence }\end{array}$ \\
\hline
\end{tabular}

4.7

32

1.5

0.7

3.9

$$
3.0
$$

0.9

0.3

recruiled by advertise nient:

manual physio difie- adjusted
therapy therapy rence difference

adjusted diffentence $(n=32) \quad(n=26)$

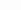

2.0

3.1

30

0.1

0.0

localisation complaint is the neck manual physio difte anjusted therapy therapy nence difference $(n=12) \quad(n=17)$

$\begin{array}{llll}4.5 & 4.1 & 0.4 & 1.1\end{array}$

4.8

3.4

1.4

19

reouited by the generit pragthorer manual physion diffe- adjusted therapy thempy rence differetice $(n=13) \quad(n=14)$
4.4
33
1.1
0.9
6.4
53
0.9
0.8

$\begin{array}{llll}2.4 & 0.9 & 1.5 & 1.0\end{array}$

previous mantial therapy or phyiotherapy

$\begin{array}{llll}\text { manual physio } & \text { diffe } & \text { adjusted } \\ \text { therapy } & \text { therapy } & \text { rence } & \text { difference } \\ (n=34) & (n=24) & & \end{array}$
$(n=34) \quad(n=24)$

$0.3 \quad 0.2$

3.7

0.2

2.5

1.2

1.3

1.1

$2.5 \quad 2.4 \quad 0.1$

0.1

0.5

no previous manual therupy or phyiguherapy manual plasio differ wjusted therapy therapy tence difference $(n=20) \quad(n=22)$

$\begin{array}{llll}5.0 & 3.8 & 1.2 & 1.0\end{array}$

$\begin{array}{llll}2.2 & 1.7 & 0.5 & 0.5\end{array}$


Table 2 shows the results of the subgroup analysis. The number of patients (in paremtheses) refer to the measurement of the severity of the main complaint after 12 months follow-up. Only for the subgroups based on whether they previously had received manual therapy or physiotherapy does the number refer to the measurement of physical functioning after 12 months follow-up. There appeared to be no major differences for global perceived effect between patients treated with physiotherapy and those treated with manual therapy in the subgroups under study. All between-subgroup differences were less than 1 point (on the 6-point scale). There are, however, some subgroups in which manual therapy showed better results compared to physiotherapy for the other 2 outcome measures. There appeared to be no subgroup in which physiotherapy had better results compared to manual therapy. Of all 90 subgroup analyses carried out, we only present the results in 6 subgroups. The number of patients in the complementary subgroups does not add up to 66 in the physiotherapy group and 65 in the manual therapy group, due to missing values. After 12 months follow-up the number of missing values was considerable especially in the physiotherapy group (27\% missing values for the measurement of the severity of the main complaint, and $16 \%$ missing values in the manual therapy group).

In the subgroup with chronic patients (duration of the present complaint of longer than 1 year) the mean improvement for the main complaint after 12 months follow-up was 4.3 in the manual therapy group, and 2.5 in the physiotherapy group (adjusted group difference 1.7). Manual therapy also had better results in improvement in physical functioning after 6 weeks follow-up (adjusted group difference 1.2). There appeared to be no differences in effect between manual therapy and physiotherapy in the complementary subgroup of patients with a duration of their complaint of 1 year or less.

In the subgroup with a severity score at baseline of less than 7 points, manual therapy showed better results compared to physiotherapy in the crude analysis. The mean improvement in the manual therapy group after 12 months follow-up was 3.8 and in the physiotherapy group 2.3. However the adjusted group difference was only 0.8 .

Manual therapy also showed better results compared to physiotherapy in the subgroup of patients who are younger than 40 years old. The mean improvement in the manual therapy group after 12 months follow-up was 5.5 and in the physiotherapy group 4.0 (adjusted group difference 1.9). Manual therapy also had better results in improvement in physical functioning after 3 and 6 weeks follow-up. In the complementary subgroup of patients aged 40 years or older there appeared to be no major differences in effect. In the subgroup of patients with back complaints manual therapy appeared to show the best results in improvement for the main complaint after 12 months follow-up (manual therapy 4.7 , physiotherapy 3.2). However, the adjusted group difference appeared to be only 0.7 , indicating that the differences between the subgroups were not distinct. In the subgroup with neck complaints the improvement in physical functioning after 12 weeks follow-up was 4.8 in the manual therapy group and 3.4 in the physiotherapy group (adjusted group difference 1.9). The number of patients who suffered from back and neck complaints was so small that we did not analysed the data.

Another subgroup in which manual therapy appeared to show somewhat better results compared to physiotherapy consisted of the patients who were initially recruited by means of advertisements as opposed to recruitment by the general practitioner. The improvement for the main complaint after 12 months follow-up was 4.4 for manual therapy, and 3.3 for physiotherapy. However, the adjusted group difference was 0.9 . 
Furthermore, the adjusted group difference in the complementary subgroup of patients who were initially recruited by the GP was 0.8 , indicating that there were no distinct differences between both subgroups.

We could not find any substantial difference in effect between manual therapy and physiotherapy in the subgroup of patients who previously (longer than 2 years ago) had received manual therapy or physiotherapy for the present complaint. There were no differences in improvement for the main complaint, while the differences in improvement in physical functioning were not consistent.

Not shown in table 2 are the results of the subgroup analysis on patients who were found to be suitable for the allocated treatment according to the treating therapist (manual therapist or physiotherapist). The manual therapists labelled 41 patients as 'suitable' (very suitable, suitable, reasonably suitable) and 17 patients as 'not suitable' (not very suitable, not suitable). The physiotherapists rated 49 patients as 'suitable' and 4 patients as 'not suitable'. Labelling of 7 patients in the manual therapy group and 13 patients in the physiotherapy group were missing. There appeared to be no substantiall differences in effect for any of the outcome measures between manual therapy and physiotherapy in the group of patients labelled as 'suitable'. Because of the small number of 'not suitable" patients in the physiotherapy group we could not compare the results in this group with the 'not suitable' patients in the manual therapy group.

Table 3. Outcome in patients labelled as suitable and not suitable in the manual therapy group

suitable not suitable

$(\mathrm{n}=41)^{\mathrm{an}} \quad(\mathrm{n}=17)^{\mathrm{a}}$

mean improvement main complaint on a 10-point scale

$\begin{array}{rll}3 \text { weeks } & 2.2 & 2.4 \\ 6 \text { weeks } & 3.6 & 2.8 \\ 12 \text { weeks } & 4.2 & 3.4 \\ 12 \text { months } & 4.3 & 4.4\end{array}$

mean improvement physical functioning on a 10-point scale

$\begin{array}{rrr}3 \text { weeks } & 2.0 & 2.8 \\ 6 \text { weeks } & 3.4 & 3.6 \\ 12 \text { weeks } & 3.7 & 4.5 \\ 12 \text { months } & 4.0 & 4.2\end{array}$

mean global perceived effect on a 6-point scale

3 weeks

$2.7 \quad 2.4$

6 weeks.

$3.7 \quad 2.8$

12 weeks

$3.6 \quad 3.1$

12 months

$3.5 \quad 3.3$

a number of patients labelled at baseline. The actual number at follow-up may vary (suitabie patients: 35 to 41 patients, not suitable patients: 12 to 17 patients) due to missing values. 
However, we did compare the results of the 41 'suitable' patients with the 17 'not suitable' patients who were freated with manual therapy. These results are presented in table 3 .

There appeared to be no substantial differences in effect between the 'suitable' and the 'not suitable" patients after all follow-up measurements.

\section{Relationship between outcome measures}

Tables 4 to 6 present the scores of the patients of which the results of both outcome measures at issue are available (about 200 patients). The results of one or both outcome measures at issue for other patients were missing (about 50 patients).

"Table 4. Kelation between the improvement scores for the severity of the main complaint and the global perceived effect after 6 weeks follow-up $(n=200)$

\begin{tabular}{|c|c|c|c|c|c|c|}
\hline \multirow{2}{*}{$\begin{array}{l}\text { benefit } \\
\text { score }\end{array}$} & \multicolumn{6}{|c|}{ improvement score severity of the main complaint } \\
\hline & $-4-1$ & 0.1 & $2-3$ & $4-5$ & $6-7$ & $8-9$ \\
\hline 1 & 9 & 22 & 17 & 8 & 1 & \\
\hline 2 & 2 & 15 & 9 & 9 & 4 & \\
\hline 3 & 1 & 7 & 12 & 6 & 5 & 1 \\
\hline 4 & & 4 & 15 & 7 & 1 & 2 \\
\hline 5 & 1 & 2 & 7 & 11 & 5 & 2 \\
\hline 6 & & 1 & 1 & 4 & 6 & 3 \\
\hline
\end{tabular}

(persison correlation coefficient $=.49)$

Table 4 shows the relation between the improvement scores of the severity of the main complaint and the global perceived effect after 6 weeks follow-up. In general, low scores for perceived benefit correspond with low improvement scores for severity of the main complaint, whereas high scores for perceived benefit correspond with high improvement scores for the severity of the main complaint. There are, however, some deviations from this general trend. It concerns patients given a high rating by the blinded research assistant for improvement for the main complaint, but the patients themselves give a low rating for the perceived benefit (the 'right upper corner' of the table). A similar trend is show in table 5 which presents the relation between the improvement scores in physical functioning and the global perceived effect after 6 weeks follow-up. The general positive relation between these two outcome measures also appear to be disturbed by patients who give a low rating for perceived benefit while the research assistant give high improvement scores for physical functioning.

Table 6 shows the relation between the improvement scores for the main complaint and the improvement scores for physical functioning. These outcome measures show a relatively strong relationship. Low improvement scores for the main complaint correspond with low improvement scores for physical functioning, while higher improvement scores for the main complaint correspond with higher improvement scores for physical functioning. We also calculated the relationship between the 3 outcome 
measures after 12 weeks follow-up (dat not shown). The results indicated a similar trend with the one presented after 6 weeks follow-up.

Table 5. Relation between the improvement scores for the physical functioning and the global perceived effect after 6 weeks follow-up $(n=198)$

benefit improvement score for physical functioning

score

\begin{tabular}{rrrrr}
$-4-1$ & $0-1$ & $2-3$ & $4-5$ & $6-7$ \\
\hline
\end{tabular}

$\begin{array}{rrrrrrr}1 & 16 & 21 & 12 & 3 & \\ 2 & 4 & 9 & 10 & 12 & 5 & 1 \\ 3 & 2 & 2 & 19 & 5 & 2 & 2 \\ 4 & 1 & 2 & 12 & 12 & 3 & \\ 5 & & 3 & 6 & 9 & 10 & 7\end{array}$

(pearson correlation coefficient $=36$ )

Table 6. Relation between the improvement scores for the severity of the main complaint and the improvement score for physical functioning after 6 weeks follow-up $(\mathrm{n}=202)$

physical functioning

severity of the main complaint

$\begin{array}{llllll}-4--1 & 0-1 & 2-3 & 4-5 & 6-7 & 8-9\end{array}$

$-4-1$

3

$0-1$

$2-3$

$\begin{array}{ll}7 & 17\end{array}$

$4-5$

2

1

4

$6-7$

$8-9$

17
22

7

1

9
31
18
2

31

18

2
16

18

11
3

6

1

(pearson correlation coefficient $=.72$ )

\section{Discussion}

The value of subgroup analyses must not be overestimated. The experience that not all patients will benefit from a particular intervention stimulates researchers to perform subgroup analyses. The purpose of our subgroup analyses was to investigate whether there are some groups of patients with certain characteristics, in which manual therapy or physiotherapy are extremely successful. Generally there are, however, some serious drawbacks with subgroup analysis. If a researcher carries out a large number of subgroups analyses he will always end up with some positive results in a subgroup of 
the study population. This situation is illustrated by the words of David Kleinbaum 'if you torture the data enough, they will always confess." 18

With our strategy we still carried out 90 subgroup analyses. Therefore, the findings of our subgroup analysis must be interpreted with caution. For instance, the mumbers of patients in the subgroups do not allow firm conclusions of the effects which were found. Although we did not intensively 'torture' the data, some results may just have been apparent in our trial, and will not show up in others. Furthermore, the considerable number of missing values, especially the measurement of the severity of the main complaint in the physiotherapy group (27\%) after 12 months follow-up, can provide biased results (the number of missing values in the manual therapy group was $16 \%$ ). However, one may assume that the patients with missing values represent bad responders to therapy. In this situation, because most missing values occurred in the physiotherapy group, the group differences compared to manual therapy tend to be to small.

Previous studies of manipulation have suggested beneficial effects of manipulation in subgroups of patients with a current episode duration of between $2-4$ weeks. ${ }^{19} 20$ Since our trial did not include such patients, we cannot therefore verify or refute these findings. A previous study on chiropractic manipulation indicated that this type of treatment was beneficial, especially in a subgroup of patients with sewere complaints with a chronic history. ${ }^{21}$ Our subgroup analysis suggests also better long term (12 months follow-up) results of manual therapy compared to physiotherapy, especially in chronic patients (duration of present complaint 1 year or longer). Furthermore, the subgroup analyses suggest better results of manual therapy compared to physiotherapy for patients younger than 40 years. The differences in results in the other subgroups were less clear. For the subgroups based on the localisation of the complaint, or the severity of the complaint, or where the patient had previously received manual therapy or physiotherapy, or recrutement status the differences in effect between manual therapy and physiotherapy were not distinct.

The information presented in table 3 shows that the labelling of patients by the treating manual therapists as 'suitable' or "not suitable" for treatment with manual therapy did not predict differences in outcomes. This finding indicates once more the problem of predicting the response of a newly presenting patient to therapy. ${ }^{17}$

With regard to the relationship anong the 3 outcome measures we can observe moderate to strong positive relationship among each other. There appear to be a number of patients who gave a relatively low score for the global perceived effect, whereas the research assistant gave a relatively high score for the improvement for the main complaint or physical functioning. This finding indicates that the outcome measures measure different features of progress in back and neck patients. It is not possible to determine who reported the (most) valid outcome. The findings suggest that if research interest lies in the opinion of the patient on the global perceived effect, as well as that in the opinion of a blinded observer on the improvement of the severity of the complaints it will not suffice to measure just one of the outcome parameters.

The relationship between the improvement in physical functioning and improvement for the main complaint appeared to be relatively strong. This can be explained, at least partly, by the fact that both outcome measures were measured during the same measurement sessions by one research assistant. This finding might, however, also be regarded as an indication that the severity of the main complaint of a patient concurs with the patients" limitation in physical functioning. 


\section{References}

1. Spitzer WO, Leblanc $\mathbb{F E}$, Dupuis M. (EDS) Scientific approach to the assessment and management of activity-related spinal disorders. Spine 1987; 7 (suppl): 1-59.

2. Frymoyer JW. Back pain and sciatica. N Engl J Med 1988; 318: 291.300.

3. Waddell $G$. A new clinical model for the treatment of low-back pain. Spine 1987, 12: 632-644.

4. Kelsey JL. Epidemiology of musculoskeletal disorders. New York, Oxlord Uniwersity Press, 1982.

5. Nachemson. A. Towards a better understanding of low back pain. Rheum Reh 1975; 14:129-143.

6. Lebouf $\mathrm{C}$. Low back pain: rewiew of the literature. J Manipulative Plysiol Their 1991; 14: 311-316.

7. Lidström A, Zachrisson M. Physical therapy on low back pain and sciatica. Scand I Rehab Med. $1970 ; 2: 37-42$.

8. Zylbergold RS, Piper MC. Lumbar disc disease:comparative analysis of physical therapy treatments. Arch Phys Med Rehab 1981; 62: 176-179.

9. Martin PR, Rose MJ, Nichols PJR, Russell PL, Hughes JG. Physiotherapy exercises for low back pain: process and clinical outcome. Int Rehabil Med 1980; 8: 34-38.

10. Haldeman S. Spinal manipulatiwe therapy in sports medicine. Clinics in Sports Medicine 1986; 5: $277-293$.

11. Ottenbacher K, Di Fabio RP. Efficacy of spinal manipulation/mobilization therapy: a meta-analyses. Spine 1985; 10: 833-837.

12. Koes BW, Bouter LM, Knipschild $\mathrm{PG}$, Mameren van H, Essers AHM, Houben JP, Verstegen GMJR, Hothuizen DM. The effectiveness of manual therapy, physiotherapy and continued treatment by the general practitioner for non-specific back and neck complaints: design of a randomized clinical trial. J Manipulative Physiol Ther (in press).

13. Koes BW, Bouter LM, Mameren van H, Essers AlHM, Verstegen GMJR, Holhuizen DM, Houben JP, Knipschild PG. The effectiveness of manual therapy, physiotherapy and treatment by the generat practitioner for mon-specific back and neck complaints: a randomized clinical trial. Spine (in press).

14. Koes BW, Bouter LM, Mameren van H, Essers AHM, Verstegen GMJR, Hofhuizen DM, Houben JP, Knipschild PG. A blinded randomized clinical trial of manual therapy and plissiotherapy for chronic back and neck complaints: physical outcome measures. J Manipulative Physiol Ther (in press).

15. Koes BW, Bouter LM, Mameren van H, Essers AHM, Verstegen GMJR, Hofhuizen DM, Houben JP, Knipschild PG. Randomised clinical trial of manual therapy and physiotherapy for persistent back and neck complaints: results of one year follow-up (subnitted for publication).

16. Koes BW, Assendelft WJJ, Heijden GJMG van der, Bouter LM, Knipschild PG. Spinal manipulation and nobilization for back and neck pain: a blinded review. Br Med J 1991; 303: 1298. 1303.

17. Yusur $S$, Wittes J, Probstfield $J$, Tyroler $H_{A}$. Analysis and interpretation of treatment effocts in subgroups of patients in randonized clinical trüals. JAMA 1991; 266:93-98.

18. KJeinbaum D. Lecture in Summer Course: Strategy of data-analysis in epidemiological research. Kerkrade, 1990.

19. MacDonald RS, Bell CMJ. An open controlled assessment of osteopathic manipulation in nonspecific low-back pain. Spine 1990; 15: 364-370.

20. Hadler NM, Curtis $P$, Gillings DB, Stinnett $S$. A benefit of spinal manipulation as adjunctive therapy for acute low-back pain: a stratified controlled trial. Spine 1987; 12: 703-705.

21. Meade TW, Dyer $\$$, Browne W, Townsend J, Frank AO. Low back pain of mechanical origin: randomised comparison of chiropractic and hospital outpatient treatment. Br Med J 1990; 300: $1431-1437$. 


\section{Chapter 9}

\section{GENERAL DISCUSSION}

The central question in this dissertation is whether manual therapy and physiotherapy are efficacious for treating back and neck complaints. To answer this question we first reviewed the available randomized clinical trials on the efficacy of manipulation and mobilization for back and neck complaints (chapter 2), and of physiotherapy exercises for back pain (chapter 3). To study the efficacy of manual therapy and physiotherapy for persistent back and neck complaints we conducted an RCT in the Netherlands (chapter 4-8).

The overall conclusion of this dissertation is that both manual therapy and physiotherapy are more efficacious than continued treatment by the general practitioner for patients with persistent non-specific back and neck complaints. This conclusion is mainly based on the results of the RCT which we conducted, although in the literature some promising results had already been reported on the efficacy of manipulation for back pain (chapter 2). In the literature there was little evidence in favor of exercise therapy over other conservative approaches, but the quality of the studies in this area was relatively low. Furthermore, physiotherapy traditionally also includes massage and the use of physical therapy modalities ${ }^{1}$ which we did not cover in our review (chapter 3 ), but did include in the physiotherapy treatment in our trial.

The comparison between manual therapy and physiotherapy indicates slightly better results for manual therapy. Although both treatments produced similar short term (until 12 weeks follow-up) results, the number of treatments during the intervention period for patients receiving manual therapy was much less than for patients receiving physiotherapy. Furthermore, the reduction in severity of the main complaint after 12 months follow-up indicated slightly better results for manual therapy compared to physiotherapy.

Below we discuss the results presented in this dissertation. Firstly, we discuss the results and interpretation of both blinded reviews. Secondly, attention is paid to the internal validity of the trial we carried out. Emphasis is given to the study population, the interventions, the effect measurement, and the data analysis. Thirdly, we address the practical problems when conducting the trial. Fourthly, we consider the external validity of our findings the subgroup analysis, and the implications for the treatment of patients with back and neck complaints. Finally, I present my personal opinion on the subject.

\section{Review of the literature}

The research questions of the reviews dealt with the efficacy of manipulation and mobilization (chapter 2), and of physiotherapy exercises (chapter 3) for back and neck complaints. Traditionally, the outcome of reviews of the literature depends heavily on knowledge and authority of the author. ${ }^{2}$ Although this kind of review may result in a valid assessment of the literature, it is often not clear which criteria were used to summarize the available evidence. In both our blinded reviews we used a standardized protocol for the selection and the assessment of the methodological quality of the available randomized trials. The major advantage of this approach is that it is made fully clear to the reader what has been done and how the data have been anallyzed. There might be, however, still some flaws in the methods that we have used. 
We only selected randomized clinical trials for the reviews. Although we consider the design of an RCT to be more valid than other study designs (e.g. uncontrolled studies or non-randomized comparisons), it can be argued that allso non-randomized comparisons can supply valuable information regarding the efficacy of treatments. However, in non-randomized studies the prognostic comparability of the study groups at baseline is problematic: In the case of back and neck complaints this is even more a problem, because little is known of the factors which have a major influence on the prognosis. Only by random allocation (of a relatively large study population) can one have some assurance that the study groups are balanced with respect to prognosis. ${ }^{3}$ Another point of criticism can be that the list of criteria for the methodological quality of the studies was not complete. For example, criteria such as whether the aims of the studies were fully stated, the documentation of side effects, and whether there were interim analyses were not included. This indicates that the criteria used for assessing the methodological quality of the trials have yet not been fully developed. For future reviews on the efficacy of treatments it might be useful to develop additional criteria in cooperation with specialists on the topic at issue. This might result in additional criteria dealing with patient characteristics or components of treatments in more detail.

However, we do not pretend that the set of methodological criteria we used is exhaustive and is able to assess the quality of the trials on an absolute scale. By using these criteria we believe we are able to distinguish the 'bad' from the 'good' studies. We believe that the studies with the highest scores indeed indicate the ones with the highest methodological quality. Conversely, we believe that the studies with a low methodological score indeed indicate those with serious methodological flaws. Additional attention must be paid to cases of a 'fatal flaw'. It is possible that, for instance, there was a large and selective drop-out rate. Allthough this issue is included in our list of criteria, a study can still score points on other criteria and end up with moderately high scores for methodological quality. This would be incorrect because of the amount of bias introduced by this flaw, which makes the results of the trial at issue totally invallid.

Another potential problem concerns reviewer bias (i.e. the bias which occurs when the results of a review depend on the (un)intended preference of the author for one of the treatments under study). We tried to minimize reviewer bias through assessment of the quality of the trials by two independent reviewers. From the original articles we omitted the sections in which the results and conclusions were described (blinding). We also omitted the names of the authors and the journal: Despite these measures reviewer bias might still occur. Blinding of articles is not always conclusive. When the reviewers have knowledge about the subject under study, which for obvious reasons will often be the case, they might very well recognize the study. A final point was that although we used a strict protocol for the assessment of the trials, there was still room left for the reviewers to interpret the trials and thus to decide whether or not to give points for a specific criterion.

\section{Internal validity of our study}

After our critical assessment of the previous randomized clinical trials with regard to their internal validity, we have to assess critically the trial which we have conducted ourselves. Below we will discuss the following four topics: study population, interventions, effect measurement, and data analysis. Subsequently, we present the 
assessment of the methodological quality of our trial by the two reviewers who reviewed the trials on manipulation (chapter 2).

(1) study population:

The patients in our study had persistent back and neck complaints. We did not chose to study patients with acute complaints, because most of them recover within 6 weeks irrespective the type of treatment given. ${ }^{4}$ We attempted to obtain a relatively homogeneous study population by using some strict inclusion and exclusion criteria (see chapter 4). However, we probably still ended up with a mixed group of patients. This may be attributed to the unknown course of most of the back and neck complaints. Our study population with 'non-specific' complaints probably comprises of several (unknown) subgroups of patients with their own etiology and prognosis. However, identifying these subgroups in advance is not possible due to the current limited knowledge on this topic.

When homogeneity cannot be guaranteed, it is even more important that the study groups are comparable for relevant baseline characteristics. We randomized the patients after the baseline measurements were completed. Thus, knowledige of the allocated treatment could not influence the baseline measurements. After assessing the comparability of the important characteristics we believed the randomization to be reasonably successful in obtaining prognostically comparable groups. To ensure comparability of the study groups at baseline, we prestratified for age and the localization of the complaints. Table 2 in chapter 5 shows that the study groups were comparable for the main prognostic variables such as duration, severity, localization of the complaints, and age. We later corrected for the (small) imbalances by using a linear regression model.

Missing values (including drop-outs) occurred mainly in the placebo group and in the group treated by the general practitioner, especially for the measurements by the research assistant. Because we feared biased results due to missing values, we carried out one analysis where missing values were left out, and a second analysis in which we substituted for missing values the last measurement available (chapter 5).

(2) Interventions:

The most important part of this trial was the comparison of three relevant alternatives for the treatment of patients with persistent back and neck complaints. In the case of persisting complaints general practitioners in the Netherlands have to decide to continue their treatment (medication, advice, home exercises, etc.), or to refer the patient to a physiotherapist or to a manual therapist. Other treatment options were not included in this trial.

We only partially succeeded in describing the treatments which were included in the trial in detail. Furthermore, for methodological reasons it would have been better if we had compared 4 strictly protocolized treatment regimens. Though desirable, no such treatment protocols for patients with persistent back and neck complaints were available for any of the therapies included. It was then decided that for each patient the manual therapists, physiotherapists, and general practitioners could use their therapeutic skills at their discretion within certain boundaries. For example, the physiotherapists and general practitioners were not allowed to use manipulative techniques. This decision makes it difficult to replicate this study because of the variety of treatments used. Furthermore, it is not possible anymore to attribute treatment 
effects to a specific component of the intervention. It is, however, possible to evaluate the effect of the treatments included in their complete form. So our study can be considered to be more a pragmatic trial than an explanatory trial. An advantage is that this approach probably has more resemblance to daily practice than when we would have evaluated a strict treatment protocol.

The fourth treatment in this study was the placebo treatment. Initially, it was our objective to design a placebo which looked exactly like a 'real' physiotherapy or manual therapy treatment but only lacked the supposed specific components of that treatment. Unfortunately, it appeared not to be possible to develop such a placebo treatment. Therefore the placebo treatment we opted for was: a physical examination followed by detuned short wave diathermy $(10 \mathrm{~min})$ and detuned ultrasound $(10 \mathrm{~min})$, to be given twice a week for a period of 6 weeks. The patients who received placebo treatment thus provided an estimation of the effect of referral to a physiotherapist including the placebo effect of a few physiotherapy modalities.

\section{(3) Effect measurement:}

When designing this trial we had chosen the Sickness Impact Profile (SIP) as an instrument for measuring functional status. This health status questionnaire has previously been used in back pain trials. ${ }^{67}$ However, in our trial the scores of the patients at baseline were only slightly higher than in a general population, thus leaving not much room for improvement in daily functioning. The use of this instrument in future clinical trials with patients comparable to those in this study seems not to be wery advisable. The same holds for the use of the West Haven Yale Multidimensional Pain Inventory (WHYMPI). ${ }^{8}$ Although we only used the sub-scale pain severity, this instrument (its present name is multi-dimensional pain inventory (MPI)) does not seem to be very responsive to changes in severity of complaints which obviously occurred in the trial and were easily detected.

We also measured spinal mobility for evaluating the progress in patients with back pain. Although the patients in all 4 study groups improved in physical functioning, this pattern was not found for the change in mean spinal mobility measured with the Cybex EDI 320 . Considering the total range of motion of the movements measured at baseline, the mean changes at follow-up were all relatively small in the 4 study groups. These findings indicate that the improvement in physical functioning occurred rather independently of changes in range of motion of the spinal movements. Generally, spinal range of motion is considered to be an objective and relatively reproducible measure. ${ }^{911}$ However, it might not be wery suitable for measuring progress in patients with chronic back and neck complaints.

Our overall conclusions of this trial are mainly based on the findings on three important outcome measures: severity of the main complaint rated on a 10-point scale by the blinded research assistant, the global perceived effect rated on a 6-point scale by the patients themselves, and severity of the limitation in physical functioning rated on a 10point scale by the blinded research assistant. Each of these three outcome measures contains important characteristics for measuring progress for back and neck patients: (a) In terms of relevance it seems very natural to focus on the complaint which the patient presents as being the most disturbing. Therefore, the rating of the severity of the complaint focussed on the complaint which the patient him or herself considered to be the most important at baseline. The blinded research assistant noted the most important complaints and rated the severity on a 10 -point scale. This severity score was 
based on history-taking and physical examination which consisted of a protocolized set of active and passive movements.

(b) With regard to the rating of the global perceived effect we believe that it is sensible to ask the patients themselves to assess their perceived benefit of the treatment.

(c) The rating of the severity of the limitation in physical functioning focussed on the movements (maximally 3 ) for which the patient reported the most severe pain or limitation in mobility. Thus, also this outcome measure focussed on the complaints of the patients individually.

(d) The rating of the severity of the complaint appeared to be responsive to change over time. Changes in severity of the complaint can easily be expressed in changes of the severity score on the 10-point scale. A similar reasoning holds for the rating of the limitation in physical functioning and the rating on the global perceived effect by the patients themselves.

There are, however, some remarks to be made. It is difficult to determine the minimal amount of improvement which can be regarded as a clinically relevant change. This concerns all three outcome measures, but below we focus on the score for the severity of the main complaint.

For within-group changes for the severity of the complaint it might be argued that a reduction from the baseline score of about $50 \%$ is important. In our study the mean baseline score for the severity of the main complaint for all patients was 6.9 on a 10 point scale. In this case a mean improvement of 3 or more points might therefore be regarded a relevant amount of change.

For between-group differences it might be argued that a difference of 1 point or more for the mean improvement scores for the severity of the complaints is a relevant difference. A between-group difference for the mean improvement score of 1 point might be regarded as a difference in improvement of about $15 \%$ of the mean baseline score of 6.9. Although some people might consider this to be a small difference, one does not expect to find large differences in effect between active treatments for patients with (persistent) back and neck complaints. Had there been a single treatment with clearly superior results over other approaches, these would probably already have been found in the existing reviews on this subject. ${ }^{612} 13$ In our opinion, the challenge is much more to find small but truly existing differences in effect.

When we developed this outcome measure we decided to use the difference score (follow-up score minus baseline score) as a measure of change in severity of the complaints. Subsequently, these difference scores were directly used to compare the progress of the patients in the study groups. It is, however, also possible to calculate ratio scores, for example the improvement in the manual therapy group divided by the improvement in the physiotherapy group. This option, however, would not change the conclusions of this dissertation. Another point which remains unanswered is whether the interpretation of an observed difference depends on the initial score at baseline. For example: does an improvement of 3 points mean the same for a patient with a baseline score of 6 compared to a patient with a baseline score of 9 ? We do not know the answer, although our data-analysis implicitly assumed that an improvement of 3 points for instance meant the same for patients with any baseline score.

Another remark on the rating of the severity of the main complaint is that we did not investigate the reproducibility of this outcome measure. However, all measurements were carried out by one and the same research assistant to avoid inter-observer 
variation. The intra-observer variation which might occur is probably difficult to estimate. If a reproducibility study were carried out with small time intervals between subsequent measurements, the observer might remember the patient, which would probably influence his or her rating. If on the other hand the time interval between the measurements is toolong, it might well be that the condition of the patient has changed which might lead to (real) different rating. In general, we encourage the use of this outcome measure (clinimetrical index) for measuring progress of back and neck patients. It certainly has face validity and appears to be responsive to small but important changes over time.

Another important issue of effect measurement is whether the follow-up period is adequate. It is, for example, important to know whether patients return to their baseline state after the intervention period is over. Following other investigators we evaluated the effect of treatment during and after the end of the intervention period ( 3 months maximally). We also included a 6 and 12 months follow-up to study the effect on a long term basis. Long term effects are not often measured in similar trials. We know of 35 trials evaluating manipulation and mobilization for back and neck pain. Of these only 7 trials included an effect measurement of at least 12 months after randomization. ${ }^{14-20}$ We know of 16 trials evaluating physiotherapy exercises for back pain. Of these only 2 studies evaluated long term effects of at least 12 months after randomization. 2122

In our study it turned out that the patients who were in the manual therapy group continued to improve, while for the majority this measurement took place 9 months after the last treatment session. Furthermore, it turned out that at 6 and 12 months after randomization a dramatic number of patients in the placebo group and in the group treated by the general practitioner had changed from the allocated therapy to other treatments. This finding indicates that the long term results of placebo therapy and treatment by the general practitioner are almost certainly worse than treatment with manual therapy or physiotherapy.

(4) data analysis:

In general we believe that an intention-to-treat analysis is the most valid approach for analyzing results of a clinical trial. ${ }^{3}$ In this particular trial, however, the results especially after 12 weeks follow-up might be biased substantially because a number of patients in the placebo group and GP group had already changed from the assigned therapy to (mainly) physiotherapy and manual therapy. Furthermore, the number of drop-outs and missing values were highest in the placebo group and GP group. This can be regarded as an outcome measure in itself because the treatments in groups with many patients who change therapy and many drop-outs are probably less effective. We dealt with this situation in our alternative analysis by substituting the results at followup with the last availlable measurement before changing therapy (to physiotherapy or manual therapy) or before having a missing outcome. Thus, we assumed no further improvement after these moments for the patients involved. This means that for these patients we ignored the general trend of improvement over time, but also ignored the possibility of deterioration among these patients. The intention-to-treat analysis in which missing values were left out, while the values of patients who changed therapy were included, probably overestimates the efficacy of the placebo therapy and treatment by the GP especially after 12 weeks follow-up. On the other hand, the alternative 
analysis might lead to an underestimation of the effect of the placebo therapy and treatment by the GP.

\section{Methodological assessment of our trial}

The assessment of our trial by two reviewers was carried out on the content of chapter 5. It revealed that our trial has one of the highest scores for methodological quality ( 55 points). Details of the assessment are shown in table 1. The two reviewers were the same ones who assessed the trials on manipulation in chapter 2 . The only difference is that for this trial they could (of course) not be blinded for the author, journal and outcome of the study, which may have introduced some reviewer bias. However, readers are invited to assess the methodological quality of our trial based on the content of chapter 5 themselves. The critical assessment indicates that also our trial can be improved, for example on the following points; prevention of loss to follow-up, the size of the study population, and the use of protocolized and explicitly described interventions.

Table 1. Methodological assessment of our randomized trial

Study population $(\max 30)$ :

$\begin{array}{ll}\text { A Homogeneity } & 1 \\ \text { B Comparability of relevant baseline characteristics } & 3 \\ \text { C Randomization procedure adequate } & 2 \\ \text { D Drop-outs described for each study group separately } & 0 \\ \text { E }<20 \% \text { loss to follow-up } & 0 \\ <10 \% \text { loss to follow-up } & 0 \\ \text { F }>50 \text { subjects in the smallest group } & 6 \\ >100 \text { subjects in the smallest group } & 0\end{array}$

Interventions ( $\max 30)$ :

$G$ Interventions included in protocol and described 0

H Pragmatic study 5

1 Co-interventions avoided 0

J Placebo controlled 5

K Mentioning good qualification of manipulative therapist 5

Effect (max 30):

L. Patients blinded 3

M Outcome measures relewant

N Blinded outcome assessments 4

O Follow-up period adequate 3

Data presentation and analysis $(\max 10)$ :

$P$ Intention-to-ltreat analysis 5

Q Frequencies of most important outcomes presented for each treatment group 5 
Articles reporting the results of randomized clinical trials seldomly describe the practical problems which (probably) occurred when the trial was carried out. For readers this lack of information might lead to the idea that the trial has been carried out without problems and completely according to the original study protocol. This is often not true, at least it was not in our case.

A major problem in our trial was the recruitment of enough patients who fulfilled the entry criteria. We estimated the available number of patients suitable for admission in the trial before the trial started in the participating physiotherapy and manual therapy practices. These estimations lead us to believe that we could expect about 400 suitable patients during a period of one year. However, soon after the selection of patients started it became clear that the numbers of patients who were sent in by their general practitioner for participation in the trial were much lower. Activities (visits at the general practice, reminders and a monthly report about the progress of the project) to encourage the participating general practitioners to send in new patients were initiated. Unfortunately, these activities resulted only in a slight increase in the number of patients. Finally, we decided to expand our recruitment activities by advertising in the local press informing patients about the possibility to participate in the study. This activity appeared to be rather successful and probably 'saved' our trial. In the end about two-thirds of the patients included in this trial were recruited by means of advertisements. The phenomenon that suitable patients seem to 'disappear' when the selection of patients for a trial starts, is known as Lasagna's law which states that the availability of suitable patients commonly is overestimated, even by a factor of $10 .{ }^{23}$ Another practical problem was the use of a single 'blinded" observer for the effect measurements. The advantage of a single observer is the exclusion of inter-observer variation. The drawback, however, is that the trial depends heavily on a single person which could become a great problem in the case of (prolonged) illness. Fortunately, this did not occur (except for a short episode of low back pain), but even holidays raised problems although these could be planned in advance. Therefore, future trial designers are advised to use two observers although this can lead to a certain loss of precision in the effect measurements.

A last remark concerns the role of the participating physiotherapists as practitioners involved in research. This became a problem in five patients who were allocated to placebo treatment. Their therapist did not consider this treatment to be in the interest of the patient and decided to give 'real' physiotherapy treatment (chapter 5). This decision was made on the (appropriate or inappropriate) assumption that it was better for the individual patients at issue, but it was certainly not in the interest of the trial. We explicitly state that this remark is not meant to blame the participating physiotherapists. They agreed to perform the placebo treatment, whereas the participating manual therapists could not be persuaded to do so.

\section{External validity of our study}

External validity deals with the generalization of the results of a trial to populations of patients with different characteristics. The trials on manipulation and mobilization discussed in chapter 2 show many differences in inclusion and exclusion criteria for the selection of patients. Included were patients with acute, subacute, and chronic pain with 
or without radiating complaints. Some study populations come from a gemeral practice while others are hospital-based. In addition, it is often unknown whether the treatments given in a particular trial are similar with the treatments in other trials or in daily practice. This is partly due to an insufficient description of the treatments included in the trials. Furthermore, in the case of manipulation and mobilization many manipulative techniques are available of which the similarities and differences are far from clear.

A similar argumentation can be held for the trials of plysiotherapy exercises discussed in chapter 3. Also these trials differed greatly in the type of patients, as well as in the type of exercise regimens. Thus for generalization of the results it is important to consider the inclusion and exclusion criteria for the selection of patients, the distribution of relevant prognostic factors, and the content of the treatments which are included.

In our trial we made a deliberate choice for patients with persistent back or neck complaints. Although one inclusion criterion was that the duration of the present complaints had to be at least 6 weeks, the majority of the patients had their complaints much longer which is illustrated by the median duration of the complaints of 52 weeks for all patients in the trial. Another characteristic of the patients included was that no underlying pathology for their complaints had been established. Hence, their complaints were labeled as non-specific.

Patients were selected by their general practitioner and through advertisements in the local press. Patients who responded to the advertisement were asked to go to their general practitioner who checked the entry criteria. All potential participants were subsequently sent to the research assistant who performed a physical examination and a final check on the entry criteria. The patients in this trial thus represent the patients with persistent non-specific back and neck complaints who are (or have been, or would have been) treated in primary care by their general practitioners.

The physiotherapy and manual therapy treatments included in this trial represent to a large extent the common treatments in the practices of physiotherapy, manual therapy in the Netherlands. The drawback of not restricting these therapies to a standard treatment as described in the paragraph on internal validity ensures more similarity between the treatments given in the trial with treatments given in daily practice. Thus the external validity was increased by this approach, at least with regard to the extrapolation of the results to the Dutch situation. The treatment by the GP also represents to a large extent the common continued treatment by GPs in the Netherlands. However, in our trial the GPs were not allowed to refer patients (allocated to treatment by the GP) to a manual therapist or physiotherapist, whereas in daily practice the GPs, of course, have the possibility to do so.

\section{Subgroup analysis}

The purpose of our subgroup analyses was to investigate whether there are some groups of patients with certain characteristics, in which manual therapy or physiotherapy are extremely successful. There are, however, some serious drawbacks with subgroup analysis. If a researcher carries out a large number of subgroups analyses he will always end up with some positive results in a subgroup of the study population. With our strategy we still carried out 90 subgroup analyses. Therefore, the findings of our subgroup analysis must be interpreted with caution. Furthermore, the numbers of 
patients in the subgroups do not allow firm conclusions of the effects which were found. Bearing this in mind our subgroup analyses suggested better long term (12 months follow-up) results of manual therapy compared to physiotherapy, especially in chronic patients (duration of present complaint 1 year or longer). Furthermore, the subgroup analyses suggested better results of manual therapy compared to physiotherapy for patients younger than 40 years. The differences in results in the other subgroups were less clear, although manual therapy also seemed to produce better results for patients who were recruited through advertisements. For the subgroups based on the localization of the complaint (back, neck, or back and neck), or the situation that the patient had previously received manual therapy or physiotherapy, the differences in effect between manual therapy and physiotherapy were not distinct.

The labeling of patients by the treating manual therapists as 'suitable' or 'not suitable" for treatment with manual therapy did not predict differences in outcomes. This finding indicates once more the problem of predicting the response of a newly presenting patient to therapy.

\section{Recommendations}

General practitioners in the Netherlands are often faced with patients with back and neck complaints. ${ }^{23} 24$ The literature reveals that in about $90 \%$ of the cases the complaints will disappear within 6 weeks irrespective the treatment given. ${ }^{4}$. When the complaints persist the general practitioner may consider continuing the treatment, or refering the patient for treatment with physiotherapy or manual therapy. The findings of our trial suggest that referral for both manual therapy and physiotherapy is clearly more efficacious than continued care by the general practitioner. Manual therapy and physiotherapy seem to be equally efficacious in reduction of the severity of the complaints, and the perceived benefit of the patients is about equal in both groups until 12 weeks follow-up. The number of treatments, however, is much lower for patients receiving mamual therapy than for patients receiving physiotherapy ( 5 versus 15 treatments). For patients with limited time available manual therapy appears to be an attractive alternative. However, our trial does not consider costs and availability of manual therapists. The long term effects (after 12 months follow-up) also appeared to be in favor of manual therapy compared to physiotherapy, which means that referral for manual therapy is at least as sensible, if not more so, than referral for physiotherapy. Not all patients will respond favorably to treatment with manual therapy or physiotherapy. Unfortunately, it is still not possible to know in advance which patients will benefit. Further research is needed to determine which subgroups of patients will benefit most from a particular therapy. To determine these subgroups it will be required to understand more of the factors which influence the prognosis of back and neck complaints. The labelling of complaints as 'non-specific' is not very helpful in the determination of subgroups with similar prognoses.

Finally, a last word on the non-specific effects of referral to a physiotherapist. It appeared that the patients responded remarkably well to placebo physiotherapy treatment. The placebo treatment appeared to have clearly better results than continued care by the GP. The rationale behind the effects of placebo treatment is not fully understood yet. However, the knowledge that these non-specific effects (e.g. new attention) truly exist should be used in a positive sense in the approach and treatment of patients with persistent back and neck complaints. These non-specific effects do not 
occur in referrals for physiotherapy alone. Although we did not directly assess the nonspecific effect of a referral for manual therapy, we may assume that also a large part of the effects of these referrals are non-specific.

\section{Personal opinion}

At one occasion after a presentation of the results of this trial at a congress, a lady in the audience asked what I would do if I suffered from back or meck complaints. I shall summarize my answer briefly for the case of acute and persisting complaints. The assumption in both cases is that there is no known underlying pathology present. In the case of an acute attack of back or neck pain I would probably take some (bed)rest for a few days depending of the severity of the attack. Hereafter, I would try to regain the activity level I had before the attack without forcing my back or neck. The use of some analgesics might be helpful to suppress the pain. While using this approach I would hope to be a member of the $90 \%$ group who recover within 6 weeks.

Only in the case of persisting complaints would I consider a referral to a physiotherapist who had had further education in manual therapy, which is the situation for manual therapists in the Netherlands. The type of treatment is at the discretion of the therapist. If manual therapy is indicated (based on history-taking and physical examination), this would be my preferred treatment. Furthermore, I would like to have intensive exercise therapy included in the treatment regimen. Although the randomized trials on this subject are not conclusive, it is my personal belief that active participation of the patient is a necessary component in the healing process. The type of exercise therapy to be given, however, is not yet clear. 


\section{References}

1. Haneveld GT. Geschiedenis va de fystotherapie De Tyjdstroom, Lochem, 1979.

2. Bouter LM, Nien G ter. Meta-analyse voor fysiotherapeuten: over het beland van standaardisetie en blindering bij literatuuronderzoek. Ned Tijdschr Fysiotherapie 1991; 101: 49-51.

3. Pocock SJ. Clindeal trials: a practical approacth. John Wilicy and Sons, Chicester, 1989.

4. Waddel $G$. A new clinieal model for the treatment of low back pain. Spine 1987; 12:632-644.

5. Frymoyer JW, Back pain and sciatica. N Engl J Med 1988; 318: 291-300.

6. Deyo RA A controlled rial of transcutaneous nerve stimulation (TENS) and exercise for chronic low back pain, N Engl J Med 1990; 322: 1627-1634.

7. Follick MJ, Snith TW, Ahern DK. The sïckness impact profile: a global measure of disability in chronic low back pain. Pain 1985: 21: 67.76.

8. Kerns RD, Turk DC, Rudy TE. The West Haven-Yale Multidimenisional Pain Inventory (WHYMPI), Pain $1985 ; 23: 345-356$.

9. Bergquist-Ulman M, Larsson U. Acute low back pain in industry: a controlled prospective study with special reference to therapy and confounding factors, Acta Orthop Scand 1977; 170 (suppl): 11117.

10. Postachini F, Facchini M, Palieri P. Efficacy of warious forms of conservative treatment in low back pain: a comparative study. Neuro-Orthopedics $1988 ; 6: 28-35$.

11. Wartgen $G N$, Haldeman $S$, Cook $G$, Lopez D, DeBoer KF. Short term trial of chiropractic adjustments for the relief of chronic low back pain. Manual Med 1986; 2: 63-67.

12. Spitzer WO, Lebllane FE, Dupuis M. (Eds) Scientific approach to the assessment and management of activity-related spinal disorders. Spine 1987; 7 (suppl): $1-59$.

13. Leboeuf C. Low back pain: review of the literature. J Manipulative Physiol Ther 1991; 14: 311 -316.

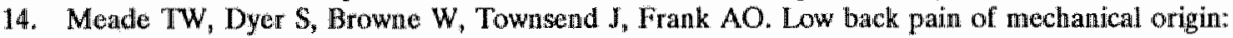
randonised comparison of chiropractic and hospitall outpatient treatment. $B$ r Med $\mathbb{N} 1990 ; 300$; $1431-1437$.

15. Sims Williams $H_{n}$ Jayson MIV, Young SMS, Baddeley $H$, Collins E. Controlled trial of nobilisation and manipulation for low back pain: hospital patients. Br Med J 1979; 2: 1318-1320.

16. Doran DML, Newell DJ. Manipulation in treatment of low back pain: a multicentre study. Br Med $1975 ; 2: 161-164$.

17. Coxhead CE, Inskip H, Meade TW, North WRS, Troup JDG. Multicentre trial of physioulherapy in the management of sciatic symptoms. Lancet 1981; 1: 1065-1068.

18. Sims-Williams H, Jayson MIV, Young SMS, Baddeley H, Collins E. Controlled trial of mobilisation and manipulation for patients with low back pain in general practice. Br Med J 1978; 2: 1338-1340.

19. Siehl D, Olson DR, Ross HE, Rockwood EE. Manipulation of the lumbar spine with the patient under general ansesthesia: evaluation by electromyography an clinical-nearologic examination of its use for lumbar narve root compression syndrome. J Am Osteopath Assoc 1971; 70: 433-450.

20. Stankovic $R_{i}$. Johnell $O$. Conservative treatment of acute low back pain: a prospective randomized triul. Spine 1990; 15: 120-123.

21. Evans $C_{x}$ Gilbert JR, Taylor DW, Hildebrand A. A randomized controlled trial of flexion exercises, education, and bed rest for patients with acute low back pain. Physiotherapy Canada 1987; 39: 96101.

22. Gore SM. Assessing clinical trials: first steps. Br Med J 1981; 282: 1505-7.

23. Hookstra OR. Patiènten met lage rugklachten in een huisartspraktijk, Staflen, Alphen aan den Rijn, 1983.

24. Grundmeijer HGLM, Brouwer HJ. De betekenis van fysiotherapie bij aandoeningen van het bewegingsapparaat. Huisarts Wet $1988 ; 31$ (suppl 12): 44-59. 
The central topic of this dissertation is the efficacy of manual therapy and physiotherapy for back and neck pain. Back and neck pain occur frequently. Epidemiological studies indicate that about $80 \%$ of the population experience back pain during their active lives. Back and neck complaints account for using a large amount of health care resources, major losses due to sick leave, and reduced work productivity. In most cases no underlying pathology can be established and thus the causes of the complaints remain unknown. These complaints are usually labelled as non-specific. Possibly as a consequence of this situation, there are many therapeutic interventions available for patients with back and neck complaints, but none seems to be clearly superior to the others. Most patients stay untreated or are treated by means of a few days of (bed)rest, analgesics, or home exercises as long as the duration of the complaints is less than 6 weeks.

In about $10 \%$ of the patients the complaints still persist after 6 weeks. The Dutch general practitioner often refers these patients for physiotherapy or, less frequently, for manual therapy. The effectiveness of these referrals has not sufficiently been investigated. Therefore we decided to conduct a randomized clinical trial in the Netherlands. It was primarily focused on the efficacy of manual therapy and physiotherapy for persistent back and neck pain. The complaints were considered to be persistent if the duration of the current episode was 6 weeks or longer.

Chapter 1 briefly introduces the subject of the dissertation as well as the contents of the various chapters.

Chapter 2 summarizes and critically assesses the available randomized clinical trials of manipulation and mobilization for back and neck pain. Manipulation involves a high velocity thrust to a joint beyond its restricted range of movement. Mobilization involves low velocity passive movements within or at the limit of joint range. We found 35 randomized trials on this topic. Unfortunately, many studies showed serious methodological flaws which makes it difficult to draw a final conclusion about the efficacy of manipulation and mobilization. However, the inefficacy of manipulation and mobilization was not demonstrated either and some studies showed promising resuits.

Physiotherapy is widely used in the treatment of back and neck pain. The treatment often includes exercises, massage, heat and other therapeutic modalities, given alone or in combination with each other. Chapter 3 discusses the available randomized clinical trials of physiotherapy exercises for back pain. We were also interested in the efficacy of physiotherapy exercises for neck pain, but we could only find 1 relevant trial. There were 16 randomized trials published on physiotherapy exercises for back pain. Most trials appeared to be of poor methodological quality. As yet, no conclusion conld be drawn whether exercise therapy was better than other conservative treatments.

Chapter 4 describes the design of our trial in detail. A total of 256 patients with back and neck complaints entered the trial and were randomly assigned to (1) manual therapy, (2) physiotherapy, (3) continued treatment by the general practitioner, and (4) placebo therapy (i.e. detuned shortwave diathermy and detuned ultrasound). These outcome measures were in order of importance: the severity of the complaints, global 
perceived effect, pain, and functional status, physical functioning and spinal range of motion. The outcome measures were placed in this hierarchical order before the results were available. Measurements were taken at baseline and after 3,6, and 12 weeks, and 6 and 12 months after randomization.

Chapter 5 discusses the prognostic comparability of the 4 study groups at baseline and the results of main outcome measures after 3,6, and 12 weeks follow-up. The main outcome measures were operationalized as follows: (1) Severity of the complaint was rated by a blinded research assistant on a 10-point scale. Patients presented at baseline their most important complaint. The rating of the severity of this complaint was based on history taking and physical examination. (2) Global perceived effect was rated on a 6-point scale. (3) Severity of the pain was rated on a 7-point scale (measured with the subscale "pain severity' of the West Haven Yale Multidimensional Pain Inventory). (4) Functional status was rated on a 100-point scale (measured with the Sickness Impact Profile): The latter three outcome measures were rated by the patients themselves. Both physiotherapy and manual therapy decreased the severity of complaints more and had a higher global perceived effect compared to (continued) treatment by the GP.

Differences in effectiveness between physiotherapy and manual therapy could not be shown during the first 3 months. A substantial part of the effect of manual therapy and physiotherapy appeared to be due to non-specific (placebo) effects. The number of treatments (visits) was considerably less for the manual therapy group (mean $=5$ ) compared to the physiotherapy group (mean $=15$ ).

Chapter 6 deals with the results of the physical outcome measures (physical functioning and spinal mobility) after 3,6 , and 12 weeks follow-up. Spinal mobility is generally considered to be an objective outcome measure for evaluating progress in patients with back pain. Physical functioning, defined as the ability to perform active and passive movements, was also measured as a relatively objective outcome parameter. Both were measured in our trial by the same research assistant who did not know about the therapy that individual patients had received. Manual therapy showed a faster and larger improvement in physical functioning compared to the other 3 therapies. The changes in spinal mobility among the 4 study groups appeared to be small and showed no consistent pattern.

In chapter 7 we present the results after 6 and 12 months follow-up in our trial. The short term results (up to 12 weeks follow-up) presented in chapter 5 and 6 are of importance in order to detect the short term recovery rates in each groups. However, we were also interested in the results after a longer follow-up period. The reviews of the literature (chapter 2 and 3 ) showed that long term effects ( 12 months follow-up) had been measured in only 7 trials of manipulation and 2 trials of physiotherapy exercises. Long term positive effects of manipulation were reported in only one of these 7 studies. Long term positive effects of physiotherapy exercises were reported in only one study. In our trial a large number of the patients who had been originally assigned to treatment by their GP or to placebo treatment changed from the assigned therapy to another therapy during the follow-up year. This clearly indicates the superiority for both manual therapy and physiotherapy. Furthermore, the findings indicated slightly better results for manual therapy compared to physiotherapy after 12 months follow-up. 
Chapter 8 presents the results of the explorative subgroup analysis. With the help of the inclusion and exclusion criteria, we tried to select a relatively homogeneous study population. However, within this study population the effects in centain subgroups could be studied separately. The purpose of this analysis was to formulate hypotheses of treatment effects in certain subgroups to be further investigated in future trials. In this chapter we also present the strengths of the associations between the outcone measures severity of the main complaint, global perceived effect, and physical functioning. The results suggest that manual therapy showed better results compared to physiotherapy regarding improvement for the main complaint and improvement in physical functioning especially for (a) patients with chronic conditions (duration complaint of one year or longer) and (b) patients younger than 40 years. These differences were most evident at 12 months follow-up. Labelling of patients by the treating manual therapists as 'suitable' or 'not suitable' for treatment with manual therapy did not predict differences in outcomes.

Generally, there was a moderate to strong correlation between the 3 outcome measures, although a considerable number of patients gave a relatively low score for perceived benefit, while the research assistant gave a high improvement score for the main complaint and physical functioning.

Chapter 9 consists of a general discussion of the research described in this dissertation. This chapter starts by drawing attention to the interpretation of the results of the reviews. Thereafter, certain issues of the design and results of our trial are discussed. Special attention is paid to the study population, the interventions, the effect measurement, and data analysis. We also present some practical problems that arose when conducting the trial. Finally, the possibilities for generalization of our findings and implications for the treatment of patients with back and neck complaints are considered. 



\section{SAMENVATTING}

De centrale vraag in dit proefschrift betreft de effectiviteit van manuele therapie en fysiotherapie bij rug- en nekklachten. Epidemiologische studies geven aan dat ongeveer $80 \%$ van alle mensen ooit last heeft van rugklachten gedurende hun actieve leven. Rugen nekklachten leggen een groot beslag op gezondheidszorgvoorzieningen, en zijn een belangrijke oorzaak van ziekteverzuim en verminderde arbeidsproductiviteit. In de meeste gevallen kan geen duidelijke onderliggende pathologie worden vastgesteld en blijft de oorzaak van de klachten onbekend. Deze klachten worden veelal met de term 'niet-specifiek' aangeduid. Mogelijk als gevolg hiervan zijn er vele therapeutische interventies voor patiënten met rug- en nekklachten beschikbaar; geen enkele behandeling lijkt echter beduidend betere resultaten te hebben. De meeste patiënten blijven aanvankelijk onbehandeld of worden behandeld met enkele dagen (bed)rust, analgetica, of eenvoudige oefeningen.

Bij ongeveer $10 \%$ van de patiënten zijn de klachten na 6 weken nog steeds aanwezig. Huisartsen in Nederland verwijzen deze patiënten vaak naar de fysiotherapeut of, minder vaak, naar de manueel therapeut. De effectiviteit van deze verwijzingen is nog onvoldoende onderzocht. Fysiotherapie bestaat doorgaans uit bewegingstherapie, massage en fysiotechnische applicaties (bijvoorbeeld electrotherapie, ultrakortegolf en ultrageluid), afzonderlijk gegeven of in combinatie met elkaar. Manuele therapie bestaat uit de toepassing van passieve bewegingen van gewrichten met als doel de functie van de wervelkolom te herstellen. In Nederland wordt manuele therapie doorgaans toegepast door fysiotherapeuten die zich gedurende een 3- of 4-jarige opleiding verder hebben geschoold in de manuele therapie.

In hoofdstuk 1 wordt het onderwerp van deze dissertatie geïntroduceerd en worden de verschillende hoofdstukken ingeleid.

In hoofdstuk 2 worden de resultaten van een literatuurstudie vermeld naar de effectiviteit van manipulatieve technieken. Binnen de manuele therapie zijn vele technieken voorhanden die kunnen worden toegepast voor behandeling van patiënten met rug. en nekklachten. De overeenkonsten en verschillen tussen deze beschikbare technieken zijn nog niet duidelijk. In dit hoofdstuk worden de beschikbare therapeutische experimenten naar de effectiviteit van manipulatieve technieken voor rug- en nekklachten samengevat en kritisch beoordeeld. Op dit moment zijn er 35 van dergelijke therapeutische experimenten bekend. Helaas vertonen vele studies ernstige methodologische tekortkomingen zodat het moeilijk is om een definitieve conclusie over het effect van manipulatieve technieken te trekken. Echter, de ineffectiviteit is evenmin aangetoond, terwijl sommige studies veelbelovende resultaten laten zien.

In hoofdstuk 3 worden de resultaten van een tweede literatuurstudie beschreven naar de effectiviteit van oefentherapie. Fysiotherapie is een veel toegepaste vorm van behandelen bij rug-en nekklachten. De behandeling bestaat veelal uit oefeningen, massage, warmte en andere fysiotechnische applicaties, afzonderlijk gegeven of in combinatie met elkaar. In dit hoofdstuk worden de beschikbare therapeutische experimenten naar de effectiviteit van oefentherapie voor rugklachten samengevat en kritisch beoordeeld. Hoewel we ook geïnteresseerd waren in de effectiviteit van oefentherapie bij nekklachten, konden we slechts 1 studie vinden die aan onze criteria 
voldeed. Op dif moment zijn er 16 therapeutische experimenten naar oefentherapie bij rugklachten beschikbaar. De meeste studies zijn echter wan geringe methodologische kwaliteit. Hierdoor kumnen geen conclusies getrokken worden of oefentherapie beter is dan andere benaderingen.

In hoofdstuk 4 wordt de opzet van het Nederlandse effectonderzoek in detail beschreven. In totaal deden 256 patiënten met rug- en/of nekklachten aan het onderzoek mee. Zij werden door loting toegewezen aan (1) manuele therapie, (2) fysiotherapie, (3) voortgezette behandeling door de huisarts, of (4) placebotherapie (ultrakortegolf en ultrageluid, beide zonder energie afgifte). De uitkomstmaten, gerangschikt naar belangrijkheid, zijn: de ernst van de klacht, de ondervonden baat, pijn, functionele status, fysiek functioneren, en mobiliteit van de wervelkolom. De uitkomstmaten zijn in deze hiërarchische volgorde geplaatst voordat de gegevens beschikbaar waren. De effectmetingen zijn vooraf verricht, en 3, 6 en 12 weken, alsmede 6 en 12 maanden na de randomisatie.

Hoofdstuk 5 beschrijft de prognostische vergelijkbaarheid van de 4 onderzoeksgroepen bij de voormeting en de resultaten van de belangrijkste uitkomstmaten na 3, 6, en 12 weken follow-up. De belangrijkste uitkomstmaten zijn als volgt geoperationaliseerd. (1) De ernst van de klacht werd gescoord door een onderzoeksassistent op een 10puntsschaal. Deze onderzoeksassistent was gedurende het gehele onderzoek onkundig in welke groep de patiënten waren ingedeeld. De patiënten presenteerden bij de voormeting hun belangrijkste klacht. De score van de ernst van deze klacht kwam tot stand op basis van een anamnese en een gestandaardiseerd bewegingsonderzoek. (2) De ondervonden baat van de behandeling werd gescoord op een 6-puntsschaal. (3) De ernst van de pijn werd gescoord op een 7-puntsschaal (gemeten met de subschaal 'ernst van de pijn' van de West Haven Yale Multidimensional Pain Inventory). (4) De functionele status werd gescoord op een 100-puntsschaal (gemeten met de Sickness Impact Profile). De laatste 3 uitkomstmaten werden gescoord door de patiënten zelf. Bij manuele therapie en fysiotherapie nam de ernst van de klachten meer af en gaven de patiënten een hogere score voor de ondervonden baat aan, dan patiënten die gecontinueerde behandeling door de huisarts ontvingen. Verschillen in effectiviteit tussen fysiotherapie en manuele therapie waren in de eerste 3 maanden niet duidelijk atanwezig. Een aanzienlijk deel van het effect van manuele therapie en fysiotherapie kan worden toegeschreven aan niet-specifieke (placebo) effecten. Het aantal behandelingen was veel lager in de manuele therapiegroep (gemiddeld 5) dan in de fysiotherapiegroep (gemiddeld 15).

In hoofdstuk 6 worden de resultaten van de fysieke uitkomstmaten (fysiek functioneren en mobiliteit van de wervelkolom) na 3,6 en 12 weken follow-up gepresenteerd. Mobiliteit van de wervelkolom wordt in brede kring beschouwd als een objectieve uitkomstmaat om verbetering van patiënten met rugklachten te meten. Fysiek functioneren, gedefinieerd als het vermogen om actieve en passieve bewegingen te verricliten, is ook gemeten als een relatief objectieve uitkomstmaat. Beide zijn in het onderzoek gemeten door steeds dezelfde onderzoeksassistent die niet wist welke therapie een individuele patiënt gehad had. Manuele therapie toonde een snellere en grotere verbetering in het fysiek functioneren vergeleken met de 3 andere therapieën. 
De veranderingen van de mobiliteit van de wervelkolom was in alle 4 groepen klein en toonden geen consistent patroon.

In hoofdstuk 7 presenteren we de resultaten na 6 en 12 maanden follow-up in onze studie. De resultaten tot 12 weken follow-up, die in hoofdstuk 5 en 6 zijn gepresenteerd, zijn belangrijk voor het opsporen van de korte termijneffecten in de vier groepen. We waren echter ook geïnteresseerd in de resultaten tna een langere follow-up. De literatuurstudies (hoofdstukken 2 en 3 ) lieten zien dat lange termijneffecten (tenminste 12 maanden follow-up) slechts gemeten waren in 7 eerdere studies over manipulatieve technieken en 2 studies over oefentherapie.. Positieve lange termijn resultaten van manipulatieve technieken werden slechts in 1 van deze 7 studies gerapporteerd.. Positieve lange termijn resultaten van oefentherapie werden in 1 studie gemeld.

In onze studie bleek een groot aantal van de patiënten die oorspronkelijk waren toegewezen aan placebo therapie of behandeling door de huisarts, te zijn veranderd van therapie gedurende de follow-up van 12 maanden. Dit resultaat is een duidelijke indicatie voor de superioriteit van manuele therapie en fysiotherapie. De onderlinge vergelijking tussen manuele therapie en fysiotherapie laat zien dat manuele therapie liets betere resultaten geeft na 12 maanden follow-up.

Hoofdstuk 8 geeft de resultaten van de exploratieve subgroepanalyses. Door middel van de in- en uitsluitciteria voor patiënten om aan het onderzoek deel te nemen, hebben we getracht om een relatief homogene onderzoekspopulatie te selecteren. Echter, binnen deze onderzoekspopulatie hebben we de effecten binnen bepaalde subgroepen van patiënten afzonderlijk bestudeerd. Het doel van deze analyse is om hypothesen te formuleren over effecten van therapie binnen bepaalde subgroepen, die nader bestudeerd dienen te worden in vervolgonderzoek. In dit hoofdstuk presenteren we tevens de onderlinge samenhang tussen de 3 uitkomstmaten: ernst van de klacht, ondervonden baat, en fysiek functioneren.

Manuele therapie lijkt vergeleken met fysiotherapie, betere resultaten te hebben bij chronische patiënten (duur van de klacht is 1 jaar of langer) en bij jongere patiënten (jonger dan 40 jaar). De verschillen waren het grootste na 12 maanden follow up. Het oordeel van de behandelende manueel therapeuten over het 'geschikt' of 'niet geschikt" zijn van de patiënt voor behandeling met manuele therapie, bleek geen voorspeller woor de resultaten te zijn.

In het algemeen bleek er een matige tot sterke correlatie aanwezig tussen de 3 uitkomstmaten. Echter, een aanzienlijk aantal patiënten gaf een relatief lage score voor de ondervonden baat van de behandeling, terwijl de onderzoeksassistent een hoge score aangaf voor de verbetering van de hoofdklacht en het fysiek functioneren.

Hoofdstuk 9 bestaat uit een algemene discussie over het onderzoek dat in dit rapport is gepresenteerd. Allereerst wordt stilgestaan bij de interpretatie van de resultaten van de literatuurstudies. Hierna wordt aandacht besteed aan de opzet en resultaten van bet eigen effectonderzoek. Speciale aandacht is er voor de onderzoekspopulatie, de interventies, de effectmetingen, en de data-analyse. We presenteren ook enkele praktische problemen die zich voordeden bij de uitvoering van het onderzoek. Tenslotte bespreken we de mogelijkheden voor generalisatie van de resultaten en de implicaties voor de behandeling van patiënten met rug- en nekklachten. 


\section{DANKWOORD}

Aan de totstandkoming van dit proefschrift hebben vele mensen meegewerkt. Allereerst wil ik alle patienten die aan het effectonderzoek, inclusief de tijdrovende effectmetingen, hebben deelgenomen, hartelijk bedanken. De deelmemende manueel therapeuten (James Gerlag, Ton Hooimeijer, Theo Krekels, John Cleven, Jo Stessen, Harry Wald, en Pieter Moust) en fysiotherapeuten (Ger Geurts, Jacques Joosten, Koen Mens, Albert Dujardin, Henk Willemsen, Harrie Hermans, Frans Thomissen, Tjeu Dols, en Guus Smeets) dank ik voor hun enthousiaste betrokkenheid bij de opzet en uitvoering van het onderzoek. Zeer erkentelijk ben ik het grote aantal huisartsen in midden- en zuid limburg, in het bijzonder de heren G. Sampers en A. de Vries, voor hun geinteresseerde houding en actieve bijdrage gedurende het gehele onderzoeksproject.

Alle belangrijke beslissingen in het kader van het onderzoek werden genomen in de projectgroep. Gemiddeld éénmal per maand werden de lopende zaken onder de loep genomen. Wanneer we om 22.00 uit het gebouw werden gezet, zetten de discussies zich veelal in het café voort. Als lid van de projectgroep leerde ik dat samenwerken veel tijd kost, maar veel op kan leveren. Jo Houben, Gard Verstegen, Domien Hofhuizen, Frolinde Kunst, hartelijk bedankt voor jullie inzet, inzichten en ruggesteun.

De leden van de begeleidingscommissie kwamen enige malen per jaar bij elkaar om de voortgang van het onderzoek te bespreken. De bijeenkomsten waren immer constructief maar ook erg gezellig. Franklin Boon, Pop Romijn, Peter Boelens, Rob Oostendorp, Jan van Binsbergen, Jaco den Dekker, en Louwe Louwes, dank voor jullie vertrouwen en de prettige samenwerking.

Mark Houben, Luc Crousen, en Michel Koken schreven in het kader van hun informatica opleiding de programma"s voor de invoer van de gegevens in de computer. Dit resulteerde in indrukwekkend lange programma's die bovendien uitstekend bleken te werken.

Met veel genoegen dank ik mijn collega's van de vakgroep Epidemiologie en Biostatistiek voor hun stimulerende ideeën, en de zeer prettige sfeer waarin wordt gewerkt. Met Geert van der Heijden had ik altijd boeiende en verhelderende discussies over onderzoek op het terrein van de fysiotherapie. Onmisbaar voor het onderzoek was Alex Essers die op deskundige wijze de selectie van de patiënten en een belangrijk deel van de effectmetingen verzorgde. Monique Latour verzorgde naast vele andere werkzaamheden op efficiënte wijze de contacten met patiënten, de randomisatie en de effectmetingen. Monique, het was zeer prettig om met je samen te werken en ik ben blij dat je één van mijn paranimfen wilt zijn. Tot twee keer toe had ik het voorrecht om wan dichtbij mee te maken hoe een zwangerschap verloopt. Tijdens de verlofperiodes heb ik je node gemist, maar Monique Koekkelkoren en Veron Schrijnemaekers waren in deze periodes prima opvolgsters waarvoor ik hun bedank. Pim Assendelft, mijn andere paranimf, was met name het bij het schrijven van het proefschrift een belangrijke sparringpartner. Pim, ik hoop dat na de publicaties van mijn onderzoek je scherpe pen in je etui blijft zitten en wacht jou promotie (want die komt er) met 
genoegen af. Riny Bodifee, Lia Gray, en Thum Aarts van het secretariaat van de vakgroep stonden immer klaar voor assistentie bij het invoeren van de vele gegevens in de computer, en typewerk in alle soorten en maten. Thum Aarts verzorgde bovendien met smaak de lay-out van dit proefschrift. Bij Fons Kessels en Hubert Schouten kon ik altijd terecht met vragen over statistische analyses van de verzamelde gegevens.

Mijn promotor Paul Knipschild bedank ik voor zijn vele inspanningen die hij als lid van de projectgroep en voorzitter van de begeleidingscommissie voor dit onderzoek heeft verricht. Zijn creativiteit en vermogen om ingewilkkelde concepten eenvoudig uit te leggen zijn uniek. Henk van Mameren, co-promotor, en tevens lid van de projectgroep, dank ik voor zijn enorme inzet om het onderzoek tot een goed einde te helpen. Henk wij wonden elkaar vaak eigenwijs. Dit proefschrift laat echter zien dat door samenwerking, mensen uit verschillende disciplines een goed product kunnen afleveren.

Lex Bouter, initiator van het project, co-promotor en voorzitter van de projectgroep was van het begin tot het eind de ideale begeleider. Ik leerde van hem ondermeer dat je als onderzoeker met name ook pragmaticus moet zijn. Tijdens alle fasen van het onderzoek stond hij klaar om adequate en afdoende adviezen te geven. Ook was hij altijd bereid om de fijne kneepjes van de epidemiologie uit te leggen. Lex, mijn oprechte dank voor je coaching. Ik wens alle jonge onderzoekers een begeleider zoals jij toe.

René Kocken en Nicole Geraerts van het coördinatiebureau eerste lijn waren zeer behulpzaam bij de benadering van huisartsen met het verzoek om aan het effectonderzoek deel te nemen. André Knottnerus maakte het als programmaleider verscheidene keren financieel mogelijk dat ik mijn onderzoek op buitenlandse congressen kon presenteren. Voor bemiddeling in deze, maar meer nog voor de prettige samenwerking in het algemeen, dank ik Ad Vissers, beheerder van de vakgroep Epidemiologie.

Mijn ouders en familie hebben met welgemeende interesse mijn verrichtingen in het zuiden des lands gevolgd. De discussies over fysiotheräpie tijdens huiselijke feestjes hebben aan de basis gestaan van mijn interesse voor onderzoek op dit terrein. Ik dank hun voor alle support door de jaren heen. Tenslotte dank ik mijn lieve vriendin Renata voor haar stimulerende enthousiasme voor mijn onderzoek. Mede door haar was het schrijven wan dit proefschrift een fluitje van een cent 
Bart Koes werd op 3 juni 1962 in Den Haag geboren. Hij behaalde in 1981 het VwO diplona aan het Huygens Lyceum te Voorburg. Van 1981 tot 1987 studeerde hij Gezondheidswetenschappen, met als afstudeerrichting Beleid en Beheer van Gezondheidszorgvoorzieningen, aan de Rijksuniversiteit Limburg te Maastricht. Van 1987 tot 1992 was hij als assistent in opleiding werkzaam bij de vakgroep Epidemiologie en Biostatistiek, waar hij deze dissertatie voorbereidde. Naast zijn opleiding tot epidemioloog binnen de valkgroep volgde hij cursussen van onder anderen Kenneth Rothman, Dawid Kleinbaum, Stuart Pocock en Olli Miettimen. 